\title{
Optimization of a roll over protective structure (ROPS) using nonlinear finite element analysis
}

Adam Michael Gillispie

West Virginia University

Follow this and additional works at: https://researchrepository.wvu.edu/etd

\section{Recommended Citation}

Gillispie, Adam Michael, "Optimization of a roll over protective structure (ROPS) using nonlinear finite element analysis" (2000). Graduate Theses, Dissertations, and Problem Reports. 1073.

https://researchrepository.wvu.edu/etd/1073

This Thesis is protected by copyright and/or related rights. It has been brought to you by the The Research Repository @ WVU with permission from the rights-holder(s). You are free to use this Thesis in any way that is permitted by the copyright and related rights legislation that applies to your use. For other uses you must obtain permission from the rights-holder(s) directly, unless additional rights are indicated by a Creative Commons license in the record and/ or on the work itself. This Thesis has been accepted for inclusion in WVU Graduate Theses, Dissertations, and Problem Reports collection by an authorized administrator of The Research Repository @ WVU. For more information, please contact researchrepository@mail.wvu.edu. 
Optimization of a Roll Over Protective Structure (ROPS) Using Nonlinear Finite Element Analysis

\title{
Adam Gillispie
}

\author{
A Thesis Submitted to the \\ College of Engineering and Mineral Resources \\ at West Virginia University \\ in partial fulfillment of the requirements \\ for the degree of \\ Master of Science \\ in \\ Mechanical Engineering
}

Kenneth H. Means, Ph.D., Chair

Victor H. Mucino, Ph.D.

John R. Etherton, Ph.D.

\section{Morgantown, West Virginia \\ 2000}

Keywords: Roll Over Protective Structures, Finite Element Modeling

Copyright 2000 Adam M. Gillispie 


\section{ABSTRACT \\ Optimization of a Roll Over Protective Structure (ROPS) Using Nonlinear Finite Element Analysis}

\section{Adam M. Gillispie}

Safety has become one of the major thrusts of our society. It is important in every facet of our lives. It is especially important in the agricultural industry. The use of a conventional Roll Over Protective Structure (ROPS) on farm tractors over the years has saved numerous lives and prevented countless injuries.

Despite the added safety of using a ROPS, it has been found a percentage of tractor owners remove the conventional ROPS. One reason for removal is lack of a storage area to house the tractor with a conventional ROPS on it. The main reason deals with the ROPS becoming entangled with crops and limbs as it is being driven, sometimes even causing this debris to strike the tractor operator. By removing the ROPS, the tractor operators place themselves in unwarranted danger.

This led the National Institute for Occupational Safety and Health (NIOSH) and West Virginia University Mechanical and Aerospace Engineering to the development of a deployable ROPS, which could remain down to aid in required housing space for the tractor and prevent debris from striking the tractor operator while being driven. This ROPS was tested for rapid deployment and also against the SAE J2194 Static Load Standard. The results of the SAE J2194 Static Load Standard tests revealed the ROPS was structurally over-designed.

This research effort focuses on the application of computer-aided design and analysis to structurally optimize the deployable ROPS and make it lighter. The first objective deals with the development of a finite element model (FEM) of the original deployable ROPS giving analytical results that matched the experimental results. This justified the use of a FEM to optimize the ROPS. Once this was accomplished, a FEM of an optimized deployable ROPS was created and verified as safe by checking energy and deflection results against the SAE J2194 Static Load Standard. 


\section{ACKNOWLEDGEMENTS}

I would like to bare my feelings here and thank some people who had a lot to do with the completion of the research this thesis is about. I would most like to thank my advisor, Dr. Means. He was more than patient with me and gave me advice and strategies on how to get through the tough and troubling times of this research. $\mathrm{He}$ definitely went beyond the call of duty with me, and he is the one person who has taught me more about being an engineer than any class I have ever taken.

I would also like to thank Eric Saunders. He was very giving of his knowledge and time to show me how to use many finite element software packages. He is another person who again went outside the lines of his job description to help me when it would have made his own work load so much easier to not be so giving. Simply stated he is a great person, and I can honestly say without his help, I would have never been able to do it.

I would like to give thanks to Dr. Victor Mucino as well for teaching me some of the basics of I-DEAS ${ }^{\mathrm{TM}}$. He was also there to assist me on the more difficult problems of I-DEAS $^{\mathrm{TM}}$. I can only say thanks a lot.

John Etherton, Richard Current, and Jim Harris are other people who were very helpful to me with their knowledge about ROPS. Their thoughtfulness to provide explanation of the SAE J2194 ROPS Standard aided me immensely. I also appreciated their unending patience concerning the completion of this research.

I would also like to thank some other people who have given me more than I have been able to give back to them on the road of life. First and foremost I would like to 
thank my grandparents who have given me unconditional support and treated me like their own son since birth. Along with my deceased Great Uncle Delano and Great Grandmother Cleo, they instilled my character, beliefs in hard work, and the desire for a college education, something that only 2 other members of entire family have ever achieved.

I would also like to thank some friends I have made while in college. In no particular order, I would like to thank Kieth Aragona, Maria Lupis, and Jerry Scheff who were all former classmates and were very helpful to my undergraduate education. They all pushed me to strive for the highest standard of myself. They also continued to give me words of encouragement once they left Morgantown. I would also like to thank Jason Skeens, Jarrod Hatfield, and Dan Carder for the same reasons.

Last, but certainly not least of all, I would like to think Chris Ilardi who gave me a job when I needed one and a discounted rent rate when financial times were tough.

I can only say God Bless everyone I have mentioned here and Amen to this document being finished. 


\section{TABLE OF CONTENTS}

$\begin{array}{ll}\text { ABSTRACT } & \text { ii }\end{array}$

ACKNOWLEDGEMENTS

TABLE OF CONTENTS $\quad$ V

LIST OF FIGURES viii

LIST OF TABLES $\quad$ X

NOMENCLATURE $\quad$ xi

CHAPTER 1 INTRODUCTION 1

1.1 Introductory Remarks 1

1.2 Review of Relevant Literature 3

$\begin{array}{ll}1.3 \text { Thesis Objective } & 8\end{array}$

CHAPTER 2 SAE J2194 ROPS STANDARD 9

$\begin{array}{lr}2.1 \text { Introduction } & 9\end{array}$

$\begin{array}{ll}2.2 \text { Energy Criteria } & 9\end{array}$

$\begin{array}{ll}2.3 \text { Accuracies and Tolerances } & 15\end{array}$

CHAPTER 3 EXPERIMENTAL APPARATUS 17

$\begin{array}{ll}3.1 \text { Test Rig and Equipment } & 17\end{array}$

3.2 Data Acquisition 25

3.3 Data Acquisition Program 29

CHAPTER 4 SOLID AND FINITE ELEMENT MODEL DESCRIPTIONS 39

4.1.1 Mechanical CAD Software $\quad 39$

4.1.2 Modeling the Two Post Deployable ROPS 39 
4.1.3 Generation of The Operator Clearance Zone Model

4.2.1 Finite Element Model Introduction 44

4.2.2 Nonlinear Statics Solution 45

$\begin{array}{ll}\text { 4.2.3 Yield Criteria } & 47\end{array}$

4.2.4 Hardening Rules $\quad 48$

4.2.5 Uniaxial Stress-Strain Data 49

4.2.6 Boundary Conditions $\quad 49$

4.2.7 Finite Element Meshes $\quad 53$

4.2.8 Solution Set and Control 55

CHAPTER 5 COMPARISON OF I-DEAS ${ }^{\text {TM }}$ TO EXPERIMENTAL 58 RESULTS CONCERNING ORIGINAL PROTOTYPE DEPLOYABLE ROPS

$\begin{array}{ll}5.1 \text { Introduction } & 58\end{array}$

$\begin{array}{ll}5.2 \text { FEM of Original ROPS } & 58\end{array}$

5.3 Comparison of Experimental and Analytical Strains for Original 61 ROPS

5.4 Comparison of Experimental and Analytical Strains for Original 62 ROPS

$\begin{array}{ll}5.5 \text { Summary } & 64\end{array}$

CHAPTER 6 THE OPTIMIZED DEPLOYABLE ROPS FEM 65

$\begin{array}{ll}6.1 \text { Introduction } & 65\end{array}$

6.2 Selecting Tube Sizes for the Optimized Deployable ROPS 65

6.3 Results of FEM of Acceptable Optimized ROPS 72

6.3.1 First Longitudinal Loading Results $\quad 73$

6.3.2 Side Transverse Loading Results 75

6.3.3 Vertical Crush Load Results 77 
6.3.5 Acceptable Optimized ROPS Conclusions 


\section{LIST OF FIGURES}

Figure 1.1. Deployable ROPS (a) before deployment and (b) after deployment 2

Figure 2.1. Structural Testing Requirements (Ref. SAE J2194) 10

Figure 2.2. Rear and Front Load Application Points for the 1st and 4th Loads (Ref. SAE J2194) 11

Figure 2.3. Application Point for Side Transverse Load (Ref. SAE J2194) 12

Figure 2.4. Vertical Crush Application Scenario (Ref. SAE J2194) 12

Figure 2.5. Occupancy Clearance Zone (Ref. SAE J2194). 14

Figure 3.1. Experimental Apparatus Overview 20

Figure 3.2. Side View of Front and Rear Longitudinal Loading Fixture 21

Figure 3.3. Back View of Front and Rear Longitudinal Loading Fixture 22

Figure 3.4. CAD of Front and Rear Longitudinal Loading Fixture 22

Figure 3.5. Transverse Loading Fixture 23

Figure 3.6. CAD of Transverse Loading Fixture 23

Figure 3.7. Vertical Crush Test Fixture $\quad 24$

Figure 3.8. ROPS/Tractor Axle Attachment Blocks 25

Figure 3.9. Typical Closed Loop System (Ref. MTS Product Information) 27

Figure 3.10. Strain Gage Locations at Base of Lower Post 28

Figure 3.11. (a) Top View of ROPS Showing the Three Energy Loadings and Strain 29

Gages and (b) Enlarged View of Strain Gages Located Near Bottom of Lower Left Post

Figure 3.12. Strain Data For First Longitudinal Loading (a) Gage A \& (b) Gage B 30

Figure 3.12. Strain Data For First Longitudinal Loading (c) Gage C \& (d) Gage D 31

Figure 3.13. Strain Data For Side Transverse Loading (a) Gage A \& (b) Gage B 32

Figure 3.13. Strain Data For Side Transverse Loading (c) Gage C \& (d) Gage D 33

Figure 3.14. Strain Data For Second Longitudinal Loading (a) Gage A \& (b) Gage B 34

Figure 3.14. Strain Data For Second Longitudinal Loading (c) Gage C \& (d) Gage D 35

Figure 3.15. Force-Deflection Data for First Longitudinal Loading 37

Figure 3.16. Force-Deflection Data for Transverse Loading 37 
Figure 3.17. Force-Deflection Data for Second Longitudinal Loading 38

Figure 4.1 Front and Side Views of Original ROPS 41

Figure 4.2. Front and Side Views of Optimized ROPS 42

Figure 4.3. Operator Clearance Zone (Side View) 43

Figure 4.4. Von Mises Yield Surface 48

Figure 4.5. Load and Restraint Conditions for Original ROPS 51

Figure 4.6. Load and Restraint Conditions for Optimized ROPS 52

Figure 4.7. HR 1018 Steel Stress-Strain Plot 54

Figure 4.8. Filler Material Stress Strain Plot 55

Figure 5.1. Mesh of Original Deployable ROPS in (a) Isometric View (b) an X-Y View 60

Figure 6.1. (a) Load - Deflection and (b) Energy - Deflection Curves for the First 69

Longitudinal Loading for Different Wall Thicknesses

Figure 6.2. (a) Load - Deflection and (b) Energy - Deflection Curves for the Side 70

Transverse Loading for Different Wall Thicknesses

Figure 6.3. (a) Load - Deflection and (b) Energy - Deflection Curves for the Second Longitudinal Loading for Different Wall Thicknesses

Figure 6.4. Time History of Loading in FEM of Optimized ROPS 73

Figure 6.5. (a) Load - Deflection Curve and (b) Energy - Deflection Curve for the First 74 Longitudinal Loading

Figure 6.6. (a) Side View and (b) Top View of the Deformation of the Optimized ROPS 75 with the Operator Clearance Zone during the First Longitudinal Loading

Figure 6.7. (a) Load - Deflection Curve and (b) Energy - Deflection Curve for the Side 76 Transverse Loading

Figure 6.8. (a) Front View and (b) Top View of the Deformation of the Optimized ROPS 77 with the Operator Clearance Zone during the Side Transverse Loading

Figure 6.9. (a) Front View and (b) Top View of the Deformation of the Optimized ROPS 78 with the Operator Clearance Zone during the Vertical Crush Load

Figure 6.10. (a) Load - Defection Curve and (b) Energy - Defection Curve for Second Longitudinal Load

Figure 6.11. (a) Side View and (b) Top View of the Deformation of the Optimized ROPS with the Operator Clearance Zone during the Second Longitudinal Loading 


\section{LIST OF TABLES}

$\begin{array}{ll}\text { Table 3.1. Test Rig Components } & 18\end{array}$

Table 3.2. Vertical Crush Test Set-up Components $\quad 18$

Table 3.3. Equipment List and Instrumentation 26

Table 4.1. Identity and Geometry of Original ROPS 41

Table 4.2. Identity and Geometry of Optimized ROPS 42

Table 4.3. Identity and Geometry of Operator Clearance Zone 43

Table 4.4. Simulated Load Sets for Original ROPS 50

Table 4.5. Simulated Load Sets for Optimized ROPS $\quad 50$

Table 5.1. Experimental and Analytical Strain Comparison for Original Deployable ROPS 61

Table 5.2. Experimental and Analytical Deflection Comparison for Original Deployable ROPS 62

Table 6.1. Standard Sizes of Tubing 66

Table 6.2. Availability of Tubing by Outer Diameter 66 


\section{NOMENCLATURE}

[ $B$ ] interpolation function derivative matrix, see equations 4.5 and 4.6

CPU computer processing unit

$\{d\} \quad$ virtual displacements

$\mathrm{E}$

energy required for loading in the SAE J2194 Static Load Standard

FEA

finite element analysis

FEM finite element model(s)

$\left\{f_{\mathrm{B}}\right\} \quad$ body loads, see equations $4.4,4.5$, and 4.6

$\left\{f_{\text {Surface }}\right\} \quad$ surface loads, see equations $4.4,4.5$, and 4.6

$\left\{F_{i}\right\} \quad$ point load, see equations $4.4,4.5$, and 4.6

$\mathrm{m}_{\mathrm{t}} \quad$ tractor mass

NIOSH National Institute for Occupational Safety and Health

$[N]$ interpolation function matrix (also called the shape of displacement function matrix), see equations 4.5 and 4.6

$\{R\} \quad$ Residual Force, see equation 4.6

ROPS Roll Over Protective Structure

SAE Society of Automotive Engineers

$U$

strain energy of the elements, see equation 4.3

$W_{e} \quad$ work done by the external forces acting on the elements

$\delta U \quad$ total virtual work of the real internal stresses, see equations 4.1 and 4.2

$\delta W \quad$ total virtual work, see equation 4.1

$\delta W_{e} \quad$ total virtual work of the external forces and moments, see equations 4.1 and 4.2

$\{\varepsilon\} \quad$ strain due to virtual displacement, see equation 4.4

$\{\sigma\} \quad$ actual stress due to applied loads, see equations 4.4 and 4.5 


\section{Chapter 1}

\section{INTRODUCTION}

\subsection{Introductory Remarks and Background}

There is much focus on safety in vehicles in today's society. In automobiles there are safety belts and airbags to help prevent injuries to passengers in the event of an accident. Despite these innovations, there are numerous deaths each year. However the focus on safety is not limited just to automobiles. There are many deaths each year due to farm tractor rollovers. These deaths have continued to occur despite the implementation of Rollover Protective Structures (ROPS) on most new tractors sold today.

Even with the implementation of the ROPS, there are still deaths caused by tractor overturns. Some of these deaths are due to the ROPS being removed from the tractor. This begs the question: "Why would someone remove a safety device that can ultimately help to save their life?" There are few explanations to this question, none of which are justified. One explanation commonly expressed is the aesthetic look and size of the ROPS. Some farmers do not have storage facilities with door heights capable of driving the tractor in and out conveniently. Other farmers remove them because the ROPS entangle limbs of close trees and damage crops as well as bring the limbs in that strike the tractor operator. Whatever the reason, the ROPS are being removed despite the safety risks.

West Virginia University and the National Institute for Occupational Safety and Health (NIOSH) have been researching and testing ROPS for the last 6 years. The early 
tests dealt with a simple two post, non-dispersible, ROPS like most of the ROPS used on farm tractors today. This particular ROPS was one of the ones typically used for the Ford-New Holland 4600 Tractor series. These tests were conducted according to the SAE J2194 ROPS Standard.

In the second phase, the idea for a deployable ROPS came to be the focus (see Figure 1.1). This deployable ROPS was designed and built for the Ford-New Holland 4600 Tractor series as was for the previous phase. The tests at this point were aimed to see if the internal mechanisms such as the springs, pistons, and elastomeric materials could withstand deployment and if the rate of deployment was sufficient for actual use. It was estimated that full deployment took 0.133 seconds. Upon passing deployment requirements, this deployable ROPS was later tested to see if it could structurally ensure safety to an operator. As in phase 1, the SAE J2194 ROPS Standard was used to determine success or failure.
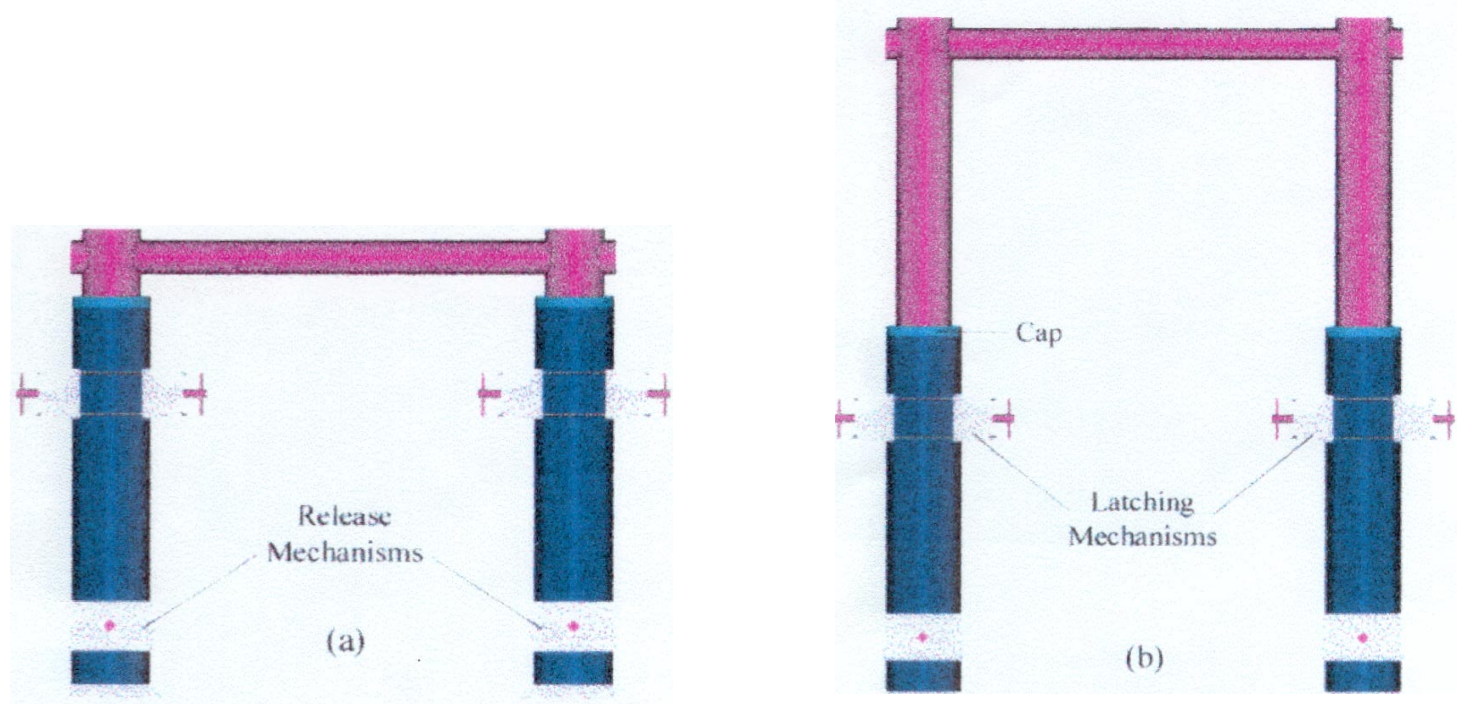

Figure 1.1. Deployable ROPS (a) before deployment and (b) after deployment. 
The results of the tests were quite clear. The deployable ROPS was more than sufficient to withstand the loads called for by the SAE J2194 ROPS Standard. This was due to the method of deployment chosen. The size of the springs used to deploy the ROPS in 0.1-0.2 seconds was the primary design parameter in the dispersible ROPS. The results of this design were a structurally over-designed ROPS.

This led to the idea of structurally optimizing the current deployable ROPS using experimental data from the tests conducted and using a Nonlinear Statics Finite Element Analysis of the Two Post Deployable ROPS. The computer model's accuracy will be directly correlated to West Virginia University and NIOSH's experimental findings of the deployable ROPS tested to SAE J2194 static load standard. Once an acceptable model using Structural Dynamic Research Corporation Package, I-DEAS ${ }^{\mathrm{TM}}$ Master Release 7 was produced, the dimensions of the ROPS was minimized to the limit of safety and passing the standard while the restraints and boundary conditions of the ROPS were kept in check.

\subsection{Review of Relevant Literature}

The use of tractors in farming has revolutionized the ease at which crops are planted, plowed, and harvested. This vast widespread use of tractors has aided in economic growth and prosperity for many farmers over the years. With all of the success the use of tractors has brought, it has also brought many safety hazards to the operators. Due to uneven and awkward terrain, tractors may be pushed to the limit of safe operation. This has caused numerous tractor overturns, which have resulted in many injuries, if not fatalities, to tractor operators. Due to the disturbing safety hazards, researchers and engineers have developed procedures and criteria for testing ROPS for tractors in the 
event of tractor overturns. The following is a review of relevant literature regarding ROPS testing and the use of finite element modeling.

The early research in tractor safety began at the National Swedish Testing Institute for Agricultural Machinery in 1954 and 1955. This research was very important because no procedures existed at that time for farm tractors. These first tests dealt with anti-crush protection structures on farm tractors, and all tests were live roll tests. It was quickly realized that this type of test was not feasible due to the tractor being damaged severely on most roll-overs, thus tests were expensive. Also, these tests were not reproducible due to the impacts varying over wide limits depending on how the vehicle happened to strike the ground.

As a consequence of both these reasons, Sweden then started to develop a new test method that would incorporate four considerations. First, a safety cab is fitted on exactly the type of tractor it was designed for. Second, the tractor should be secured to a bedplate in its normal position. Third, the safety cab's strength should be determined by blows delivered by a swinging weight, and, also by the application of a static load; and fourth, the test should be repeatable (Staab, 1971).

While Sweden was developing their testing procedures, researchers in the United States were also investigating tractor overturn accidents. This was a major concern to persons associated with safety in the rural United States in the 1960's. The two most often asked questions by safety experts were "How can tractor overturn accidents be prevented?" and "What can be done to improve tractor safety?"

Until 1972 little had been done to answer these questions. In order to determine the factors associated with tractor overturns and to suggest ways of preventing accidents, 
data was collected and analyzed from tractor overturns in Nebraska from January 1, 1966 to January 1, 1972. There were 175 accidents investigated during this time, and 78 of the accidents resulted in a fatality. It should be noted that of the 175 tractors involved in the accidents, only 8 were equipped with either a protective tractor cab or a roll bar and seat belt. Of these 8 tractors, no fatalities occurred in these accidents, and 4 of these 8 accidents resulted in no injuries (Schnieder, Rollin D. and Baker, L. Dale, 1972). This data gave credible evidence that implementing protecting structures on tractors would help save lives.

By the late 1970's ROPS were becoming fairly common to farm tractors as well as being implemented in mining, construction, earthmoving, and forestry equipment. The status of ROPS field performances in these areas was reported by Jack L. Woodward and Stephen Swan (1980). They found that ROPS generally exceed structural performance requirements and do reduce the number of injuries and deaths due to rollovers. Some other conclusions determined were the severity of rollovers varied widely between different types of machines, and the quality control during ROPS fabrication was very important.

This study also showed that fatalities occur about 3.3 times as frequently on nonROPS machines as on ROPS-equipped machines. The study was quick to point out that this number may understate the safety contribution of ROPS since more accidents with ROPS go unreported than accident without ROPS due to the operator being more likely to be injured in a machine roll-over without ROPS. In addition, the chances of surviving a roll-over and minimizing injury were enhanced substantially by wearing a seat belt. In 
fact, statistics in this study showed almost 88 percent of fatalities occurring on ROPSequipped machines were not using their seat belts.

The literature evidence at this point is quite clear in showing that implementing ROPS will save lives. One important aspect of ROPS design is the occupant clearance zone. The occupant clearance zone is the major parameter in determining whether the ROPS is acceptable, and this zone has evolved and changed over the years. As of 1987, it recognized the SAE J2194 (ASAE S519) was one of the better standards for tractors because there is no suspension system for the seats (Fritz, 1991). This evidence was supported by Teaford (1993), who went on to add that protection from sharp surfaces and corners around the occupant clearance zone is important for any ROPS standard.

Due to the cost and damage of overturning tractors to experimentally test protective structures, this led some researchers to seek other possibilities to improve ROPS design. One such possibility for improving ROPS design was proposed by Rudolph E. Yeh, Yuan Huang, and Edward L. Johnson (1976). They developed an analytical procedure for the support of ROPS design. This analytical procedure was based on an incremental process in force and/or displacement, which operates on the plastic hinge principle. This analytical procedure was comprised of eight major steps.

1. A given set of loads (forces or displacements) is applied to the framed structure.

2. Each of the elements is examined to determine its state of yielding.

3. The incremental load set that causes the formation of the first plastic hinge is calculated, and a scale factor is determined.

4. Every element force and joint displacement are interpreted by the scale factor, and then added to the respective cumulative values. 
5. The amount of work done on the structure is calculated, and is added to its cumulative value.

6. The plastic hinges are inserted, and the structural geometry may be updated.

7. The given set of loads is applied on the modified structure, and a new analysis cycle is initiated.

8. The incremental process is terminated when the requirement is satisfied. The requirement is based on one of two variables, load or energy. The process will also terminate when a collapsed mechanism has developed.

It was concluded that SAPROPS was one possible computer code that followed the 8 major steps. SAPROPS stands for Structural Analysis Program for Roll-Over Protective Structures and was used in the 1970's. It was concluded after many ROPS and protective cabs were analyzed and verified by test, the SAPROPS code is effective and economically beneficial for the support of ROPS design. It should be noted however; the program did not take into account strain hardening effects, so the results were conservative.

It should be pointed out that SAPROPS was developed after and expanding on other computer codes. One of these codes was STRESS (1964). STRESS was capable of performing only linear elastic frame analysis, and a piece-wise linearized process with an incremental loading was employed. This was very a tedious process; nevertheless for that time, the results were very helpful in evaluating the behavior of the structure and identifying the necessary design changes.

In the 1990's more recent developments using FEM on ROPS have taken place at West Virginia University. Some of these include using ANSYS ${ }^{\mathrm{TM}}$ Nonlinear FEM 
techniques to simulate both static and dynamic loading scenarios (Harris, 1995), as well as using I-DEAS ${ }^{\mathrm{TM}}$ Master Series Release 2 to conduct nonlinear finite element analysis of a two post factory ROPS (Brewer, 1996). One other exhibition of FEM used LSDYNA 3D to analyze impacts on elastormeric materials that were used in a two post deployable ROPS (Howard, 1998).

\subsection{Thesis Objective}

Due to the high costs of construction and testing of prototypes, the trend of using Finite Element Modeling has been developing over the years. This would also be the case for the objective of this thesis. The objective here is to develop a Nonlinear Statics Finite Element Analysis of an Optimized Two Post Deployable ROPS using the Structural Dynamics Research Corporation Package, I-DEAS ${ }^{\mathrm{TM}}$ Master Series Release 7. One of the key descriptive words in the previous statement is "optimized". What will be shown is finite element modeling to minimize the tube cross-sections of an already constructed deployable ROPS that was structurally over designed.

However, in order to have confidence in any finite element model, there must be some proof of accuracy of the model. In this case, the strategy was to construct a finite element model to accurately match the already built and experimentally tested deployable ROPS test results. Then, examine the finite element model and decide the amount to which the particular cross-section(s) can be reduced. It should once again be noted the SAE J2194 Static Load Standard is the judge as to whether the new optimized ROPS is acceptable. 


\section{Chapter 2}

\section{SAE J2194 ROPS STANDARD}

\section{$\underline{2.1 \text { Introduction }}$}

The SAE J2194 ROPS Standard is comprised of two parts, Static Testing and Dynamic Testing. The whole purpose of the Static Test is to simulate the loads encountered in the event of an overturn. The standard is structured to set up strict guidelines in testing and performance of ROPS designed for wheeled agricultural tractors. This thesis is concerned with only the static testing of ROPS at ambient temperature, and this chapter will concentrate on how the standard applies to the research conducted.

\subsection{Energy Criteria}

A significant portion of the SAE J2194 Standard is based upon energy criteria. Energy criteria is directly proportional to the mass of the tractor. More specifically, Section 2.3.4 of the SAE J2194 ROPS Standard states a mass, not less than the tractor mass shall be used for calculation of the force and energy inputs during the tests. It is also imperative to understand that if a number of tractor models form a family and use the same type of ROPS, the tractor having the heaviest mass shall be used as the reference $\operatorname{mass}\left(\mathrm{m}_{\mathrm{t}}\right)$.

The whole purpose of the Static Test is to simulate the loads encountered in the unfortunate event of an overturn. In order for a ROPS to successfully pass the static part of SAE J2194, it must be able to withstand a series of 4 loadings. It should be pointed out there is a specific order to which the separate loadings must be applied. It should also 
be stated no adjustments or repairs can be made while testing, and if any fixture used for restraint purposes breaks or shifts, then the loading must be repeated.

As previously stated, there is a specific order to which the ROPS must be loaded. It must also be determined whether the majority of the tractor mass rests on the rear wheels or the front wheels because the loading orders are different for each. For the tests conducted for this thesis, it was determined that less than $50 \%$ of the tractor mass was on the rear wheels. A schematic of the loading sequences can be seen in Figure 2.1 below.

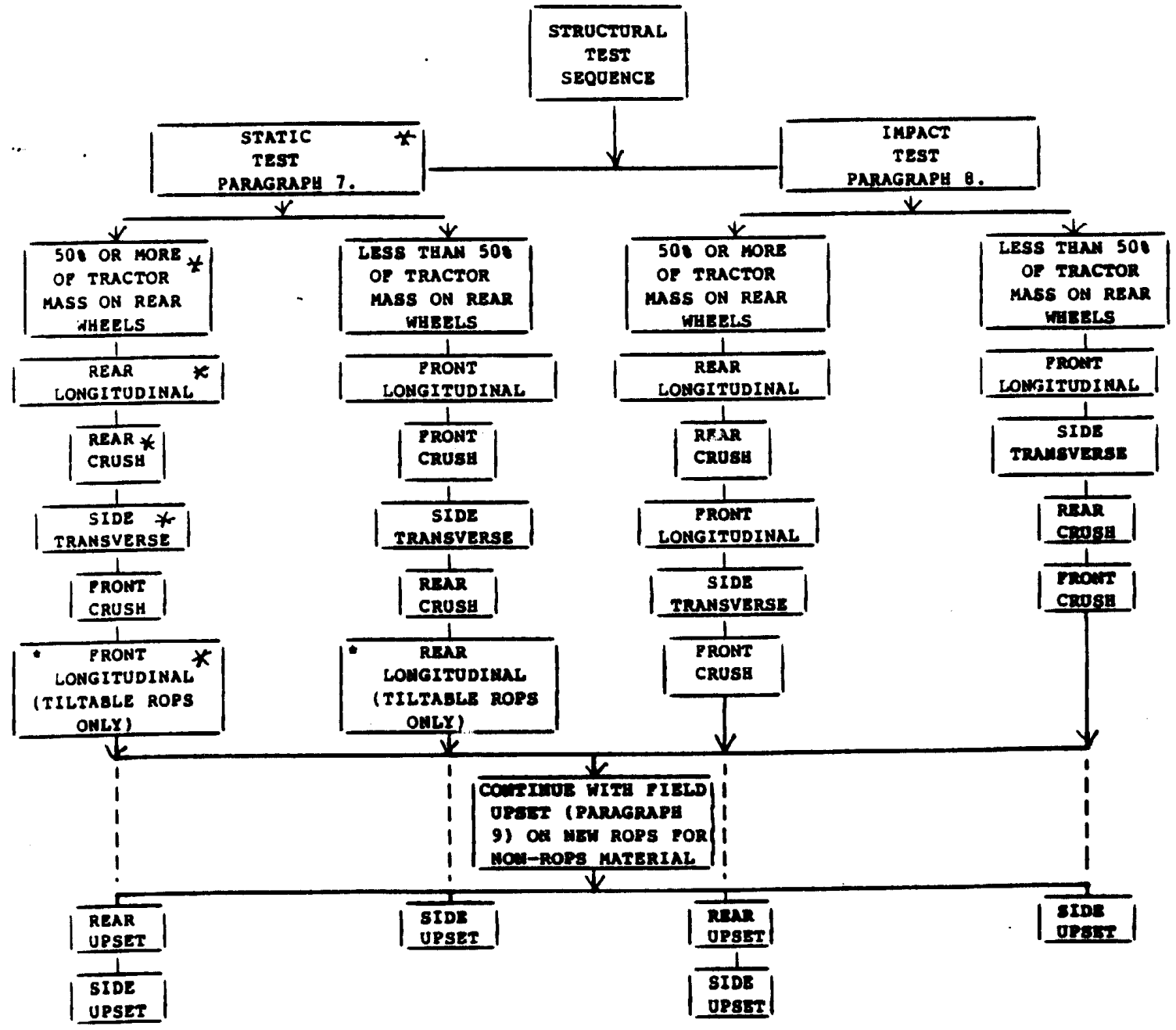

Figure 2.1. Structural Testing Requirements (Ref. SAE J2194). 
Therefore, the first load to be applied to the ROPS was the front longitudinal. The loading in the front longitudinal direction was applied until the energy requirement was met. The energy requirement was calculated to be $\mathrm{E}=1.4 * \mathrm{~m}_{\mathrm{t}}$ (Joules), which for our case resulted in E being 4,589.2 Joules (or 40,617 inch-lbs). This was due to the reference tractor mass being 3,278 kg according to the Nebraska Tractor Test 1223.

It is also important to state the first longitudinal loading was applied to the uppermost transverse structural member of the ROPS. This is the part of the ROPS, which would likely strike the ground first in the event of a front or rear overturn. It should also be stated the point of application of the loading was located at one-sixth of the width of the top of the ROPS inward from the outside corner (see Figure 2.2).

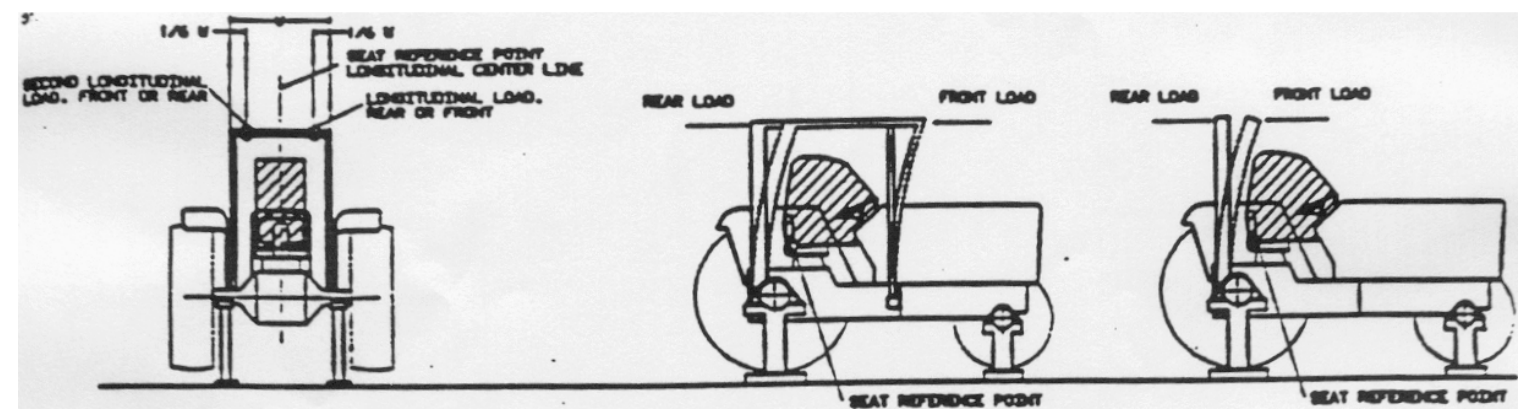

Figure 2.2. Rear and Front Load Application Points for the 1st and 4th Loads (Ref. SAE J2194).

The second load to be applied to the ROPS was the side transverse load. Like the first loading, the load was applied until the specified energy requirement was met. For the transverse load, the energy requirement was calculated to be $\mathrm{E}=1.75 * \mathrm{~m}_{\mathrm{t}}$ (Joules), which for the case of interest resulted in E being 5,736.5 Joules (or 50,772 inch-lbs). The side transverse loading point of application was the part of the ROPS side, which will touch the ground first in the event of a sideways overturn (see Figure 2.3). 


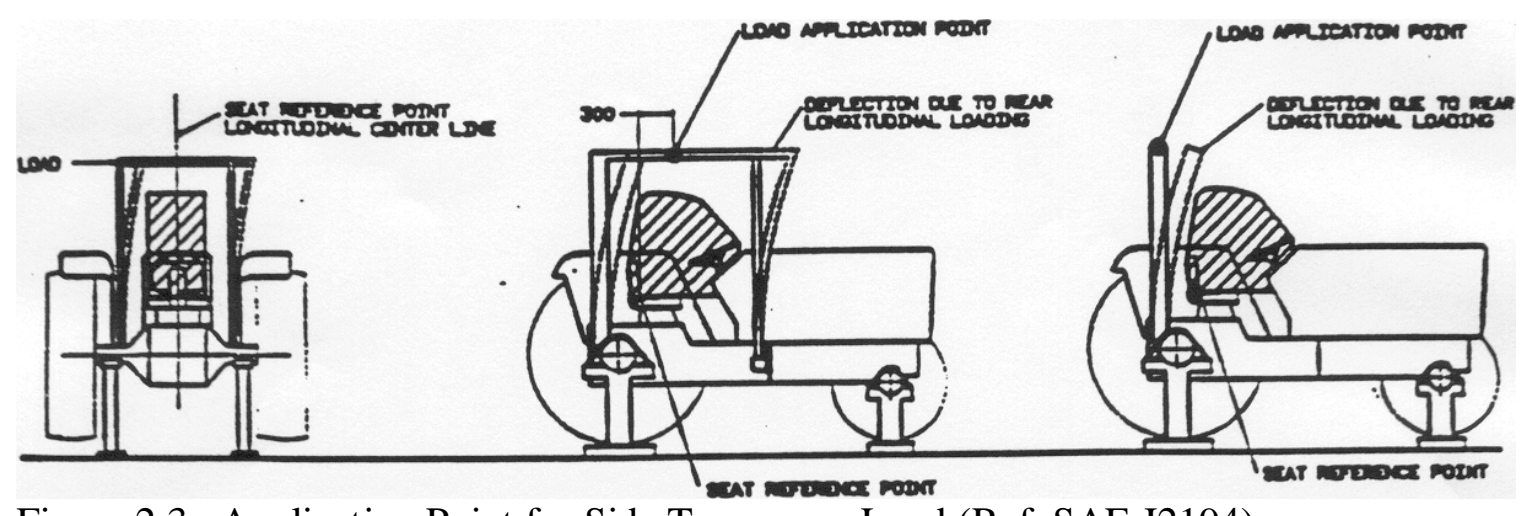

Figure 2.3. Application Point for Side Transverse Load (Ref. SAE J2194).

The third load to be applied to the ROPS was the vertical rear crush load. Unlike the first two load applications, the third load is not based upon an energy requirement. To the contrary, this load is applied to ensure the ROPS does not buckle and have a catastrophic failure. The ROPS must be able to withstand a force of $\mathrm{F}_{\mathrm{F}}=20 * \mathrm{~m}_{\mathrm{t}}(\mathrm{N})$. For a ROPS on the tractor being designed for, $\mathrm{F}_{\mathrm{F}}$ was calculated to be $65,560 \mathrm{~N}$ (or $14,738 \mathrm{lbs})$. It is important to state this load must be applied to the rear uppermost structural member(s) of the ROPS (see Figure 2.4). Using a rigid beam positioned on top of the ROPS typically does the load application, and the loading is applied through the beam. Of course, the rigid beam must be secured to the ROPS and not allowed to slip.

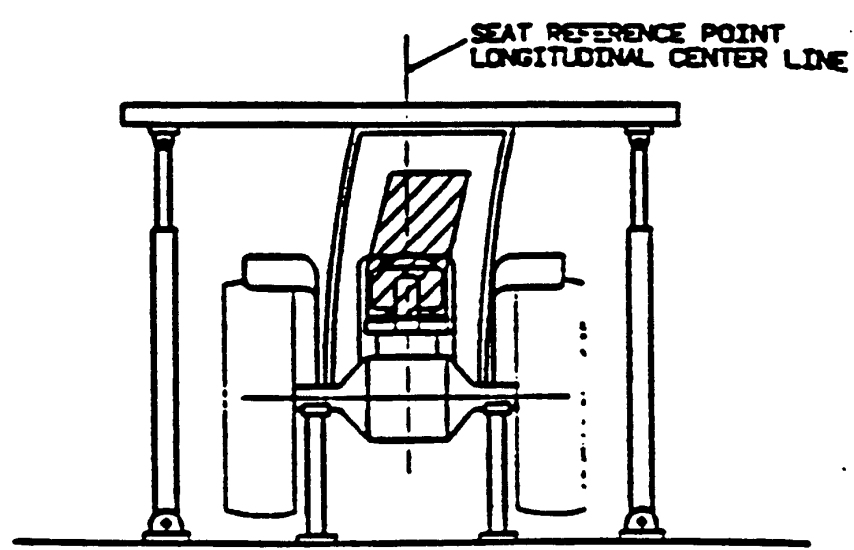

Figure 2.4. Vertical Crush Application Scenario (Ref. SAE J2194). 
The fourth and final load to be applied to the ROPS was the second longitudinal load. The load must be applied in the opposite direction to and at the corner furthest from the point of application of the first longitudinal load. Again, the point of application of the load was located at one-sixth of the width of the top of the ROPS inward from the outside corner (see Figure 2.2). The energy requirement for the fourth load was found by $\mathrm{E}=0.35 * \mathrm{~m}_{\mathrm{t}}$ (Joules), which resulted in E being 1,147 Joules (or 10,154 inch-lbs).

After each of the four loads are applied, failure is determined by whether the Occupant Clearance Zone has been intruded upon by the deformed ROPS, or if the three point ground plane intrudes upon the zone. Success means the ROPS was able to absorb the prescribed amount of energy or force without intrusion upon the zone. This means the determination of the Occupant Clearance Zone an important process. Each class of tractor uniquely determines every zone. The first step in creating the zone depends upon the seat reference point, and the seat reference point can be determined by ISO 3462 standard with the seat to its uppermost and rearmost position (1987). Once the seat reference point is known, the zone can be successfully represented and modeled (see Figure 2.5). 

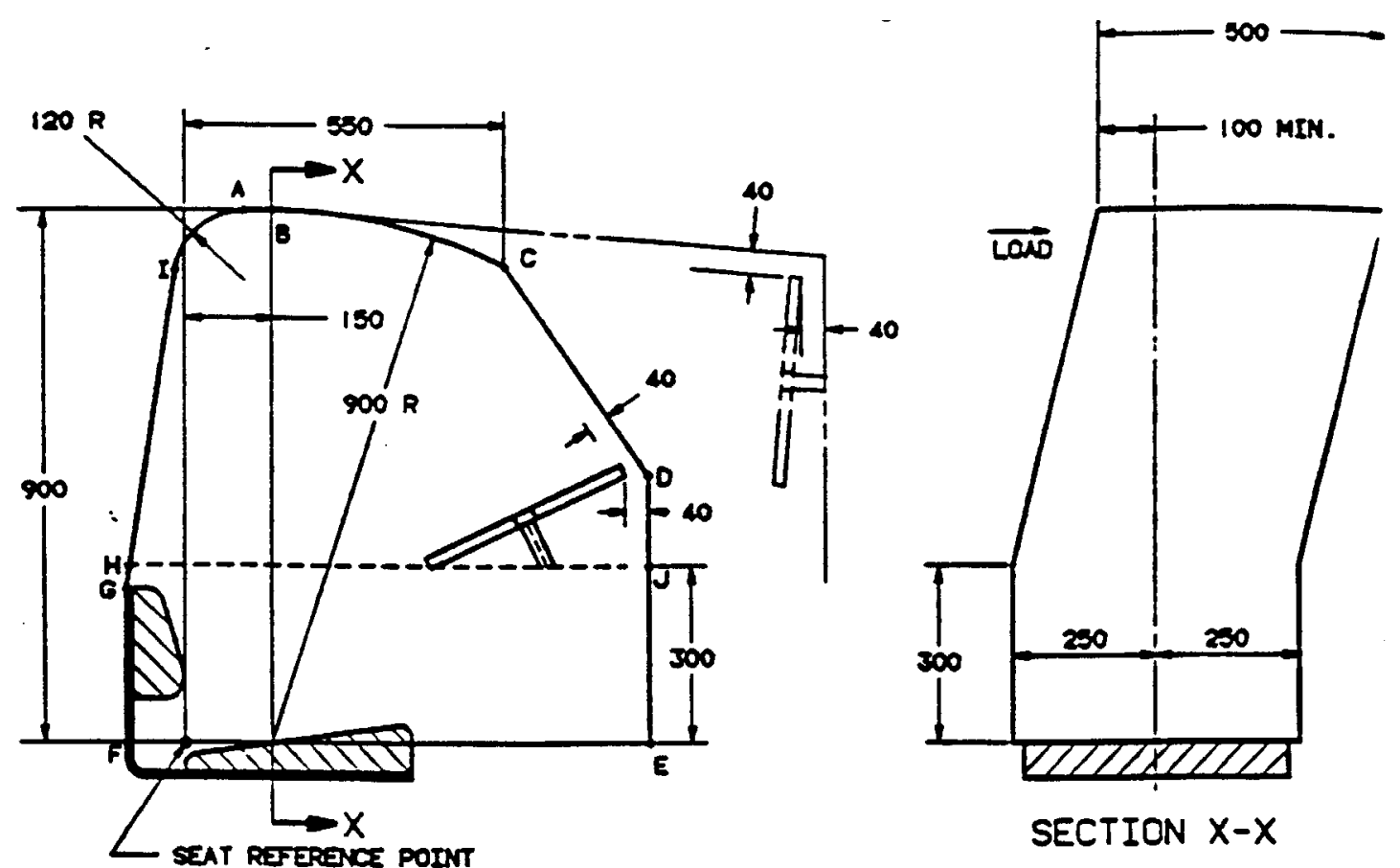

ODMESTONS ARE MILLDETERS.

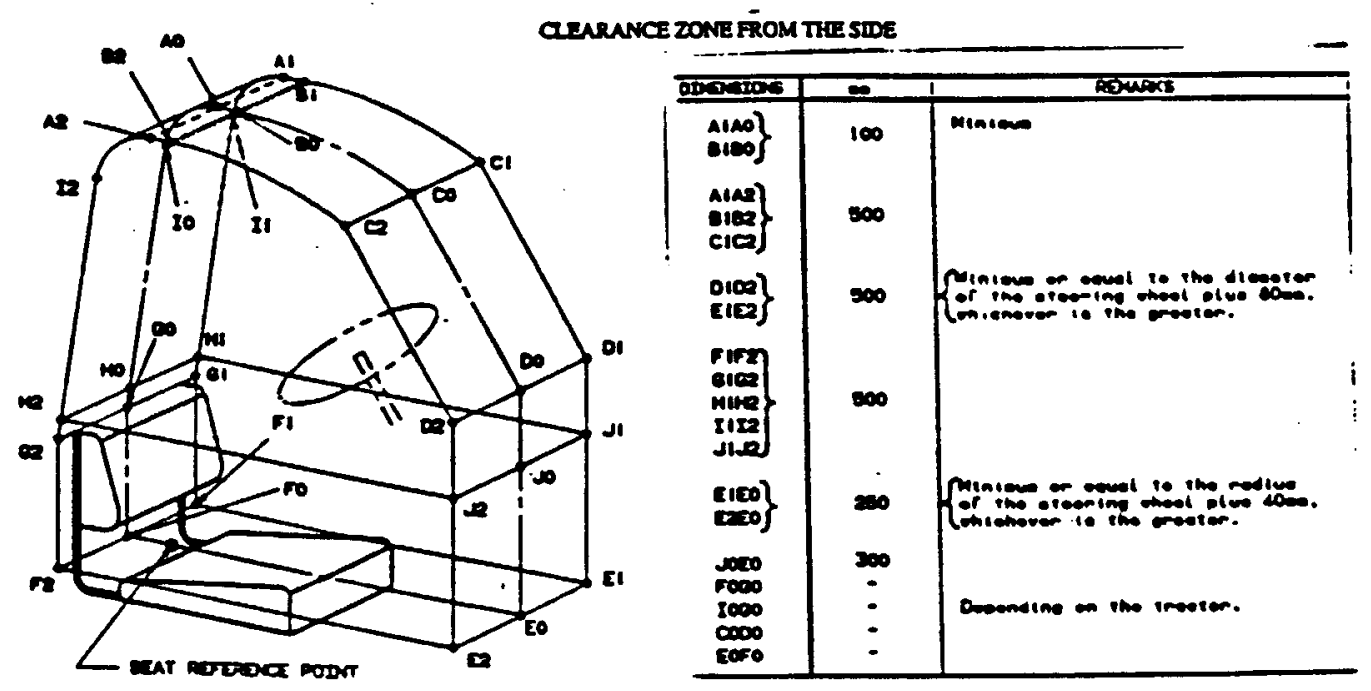

Figure 2.5. Occupancy Clearance Zone (Ref. SAE J2194). 


\section{$\underline{2.3 \text { Accuracies and Tolerances }}$}

The static portion of the SAE J2194 Standard mandates continuous monitoring of the energy requirement and force requirement. This is accomplished with a high resolution data acquisition system. The type of instrumentation used must be able to satisfy the tolerances of the standard. The following measurement accuracies are required:

Dimensions $\quad \pm 3 \mathrm{~mm}$

Deflections $\quad \pm 3 \mathrm{~mm}$

Tractor mass $\quad \pm 20 \mathrm{~kg}$

Loads and Forces $\quad \pm 2 \%$

Direction of Loading

At start of test: \pm 2 degree for all loading

During test: 10 degrees above to 20 degree below horizontal,

for horizontal loads

One of the other key requirements of the standard is the ROPS must be tested on the tractor frame or an equivalent apparatus without support of the tractor tires. In addition, the supporting bedplate the tractor is mounted on must not deflect significantly under load. Also, there can be no additional support under the axle other than its initial configuration.

Finally, the way in which the loads are applied is very important. The loads applied horizontally must be applied normal to the direction of the loading and distributed over a projected area less than $0.1 \mathrm{~m}^{2}$. In addition, the means of loading the ROPS must allow the ROPS to deflect freely in any given matter. This can be 
accomplished by using a loading apparatus that has universal joints or any two dimensional swiveling head.

The vertical loading on the other hand must be carried entirely through the ROPS. This means the tractor must have some type of direct support where the ROPS is attached to the axle. Also, the distribution requirement of the application beam for this loading must be at least $250 \mathrm{~mm}$ wide. 
Chapter 3

\section{EXPERIMENTAL APPARATUS}

\section{$\underline{\text { 3.1 Test Rig and Equipment }}$}

The basis of any ROPS testing facility is a test bed, test rig, tractor restraints, loading interfaces, and ROPS/tractor axle securing blocks. Also, there must be adequate instrumentation for continuous data recording.

The test bed plate, designed and manufactured by Lake Shores Inc., was made in four sections that required assembly on site. It was designed so to react up to 100 tons in either the $\mathrm{X}, \mathrm{Y}$, or $\mathrm{Z}$ directions or any combination of the aforementioned. The plate has a $10 \mathrm{ft}$. by $15 \mathrm{ft}$. work area and is at least 7 inches thick of high strength ductile iron with each section weighing approximately 6,000 pounds.

The test rig, designed and constructed by Dr. Ken Means and Clay Brewer, was built primarily for testing required by the SAE J2194 ROPS Standard. The estimated maximum force values the rig would be subjected to during the static testing were obtained from Colorado State University's ROPS testing in their transverse and longitudinal loadings. The initial design of the test rig was done using classical deflection equations to select proper I-beams. An ANSYS ${ }^{\mathrm{TM}}$ finite element model was later done to verify stress and deflection calculations as well as optimize the selection of I-beams. The safety factor used in the analysis was at least two, but in most instances, it was quite higher. The test rig material components are summarized in Table 3.1. 
Table 3.1. Test Rig Components.

\begin{tabular}{|c|c|c|}
\hline Quantity & Description & Size \\
\hline 2 & Upright I-beams & $9 \mathrm{ft}$ W10 X 77 \\
\hline 1 & Horizontal I-beam & $7 \mathrm{ft.}$ W8 X 48 \\
\hline 2 & Angled Legs (Box Tubing) & 7 " X 7" \\
\hline 4 & Base Plates & 14 " X 16" -1 " thick \\
\hline 2 & Brace Mounting Plate & 18 " X 9" -0.5 ” thick \\
\hline
\end{tabular}

All loadings except the vertical crush test could be performed on the test rig frame. Two actuators aligned vertically on each side of the ROPS were required for the vertical crush test. The actuators were connected to a stiff beam on the top of the ROPS and mounting plates on the bottoms of the actuators were connected to the test bed. The vertical crush test material components are found in Table 3.2.

Table 3.2. Vertical Crush Test Set-up Components.

\begin{tabular}{|c|c|c|}
\hline Quantity & Description & Size \\
\hline 1 & Horizontal Crush I-beam & $9 \mathrm{ft}$. W8 X 45 \\
\hline 2 & Actuator Mount Plates & 16 " X 10" - 1" thick \\
\hline
\end{tabular}

In order to restrain the tractor rigidly to the test bed, tractor stands were used to secure both the rear wheel hubs of the tractor to the test bed. The tractor stands mounts the tractor without tires rigidly to the test bed. The tractor stands consists of two parts; vertical mount plates that are bolted to the wheel hubs and to the rear tractor stands, 
which are bolted to the test bed. The vertical mount plates are 14 " X 16 " X 0.5 " steel plates, and the mount plates are firmly bolted to each side of the tractors wheel hub bolt pattern. The front of the tractor is also secured to the test bed by using a tractor stand that is bolted to both the under carriage on the front of the tractor and the test bed. The aforementioned experimental apparatus can be seen in Figure 3.1. 


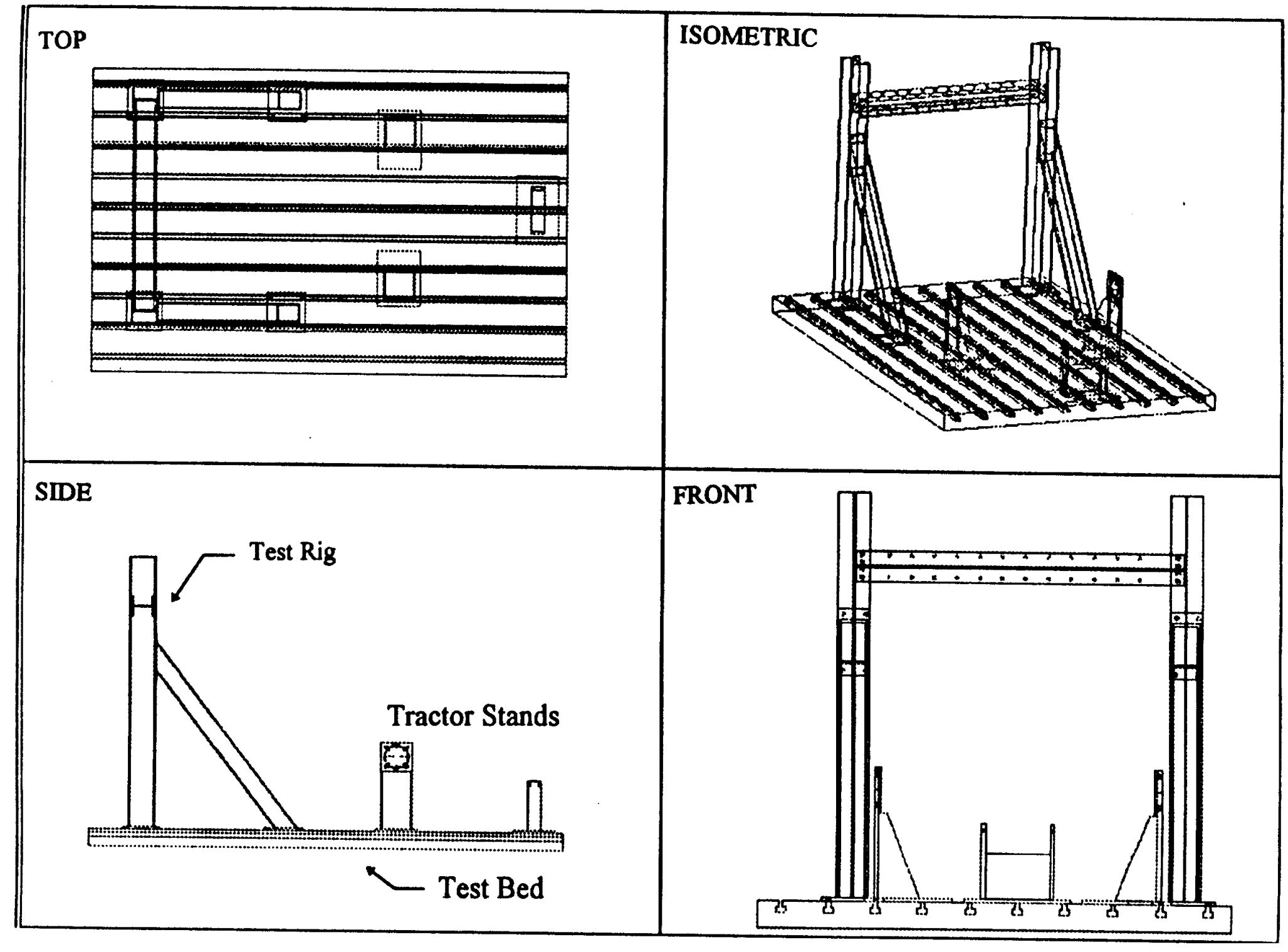

Figure 3.1 Experimental Apparatus Overview 
The loading interfaces requirements varied due to the ROPS being completely comprised of tubular members. Also, the SAE J2194 Standard is for ROPS of different geometric sections, so there was some interpretation required. The statement from the standard used for the design of all loading interfaces was the fixtures could not constrain the ROPS in rotation or translation in any direction other than the direction of the loading.

Due to both tubular posts and a tubular crossbar, the loading interface used for the forward and rear longitudinal loadings consisted of a steel plate with steel blocks welded on. In the blocks, the outer radii of the upper posts and crossbar of the ROPS were machined out so as to give a snug fit against the ROPS. A U-bolt was also used to prevent slippage. This loading fixture can be seen in Figures 3.2, 3.3, and 3.4.

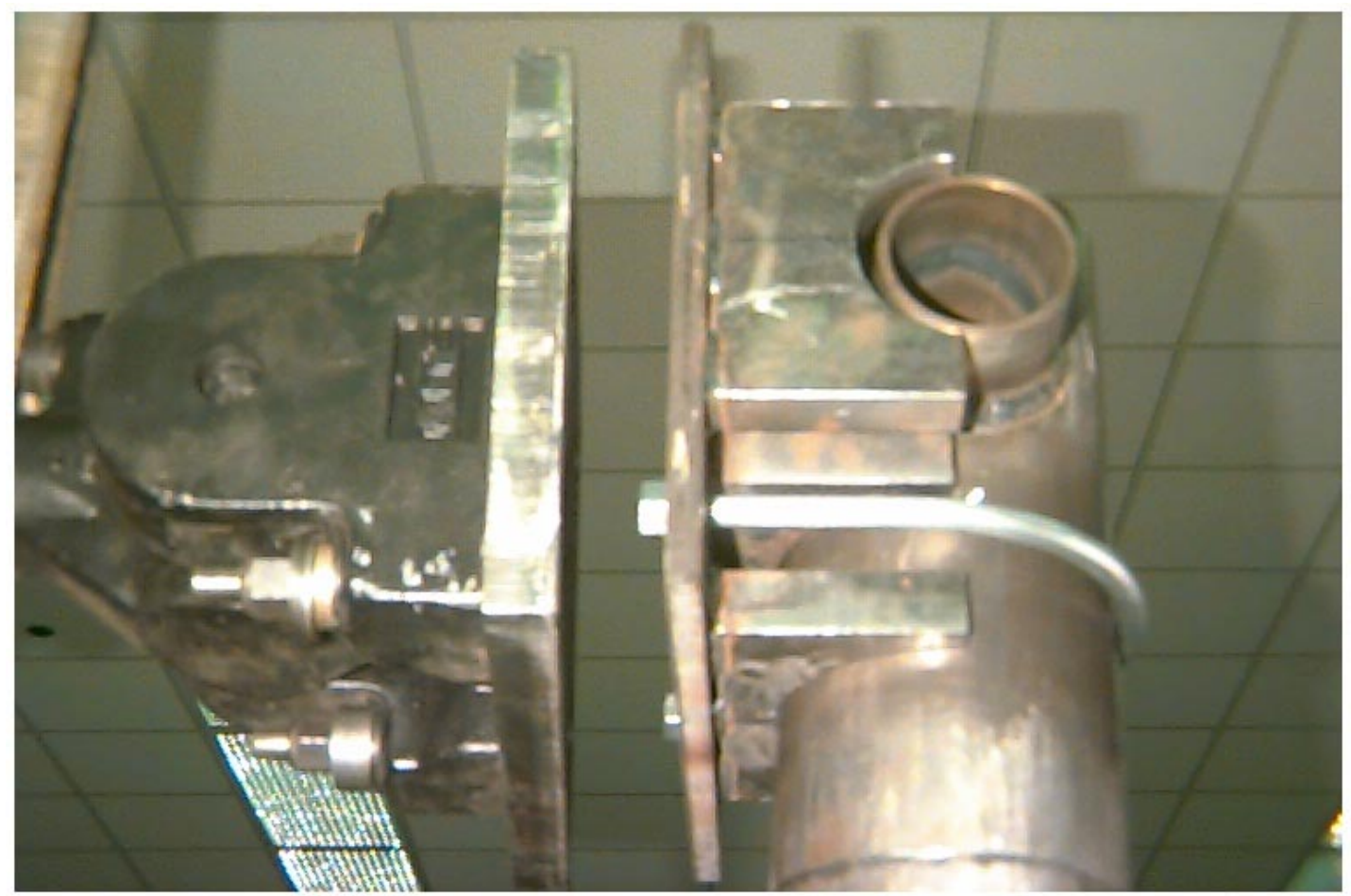

Figure 3.2. Side View of Front and Rear Longitudinal Loading Fixture. 


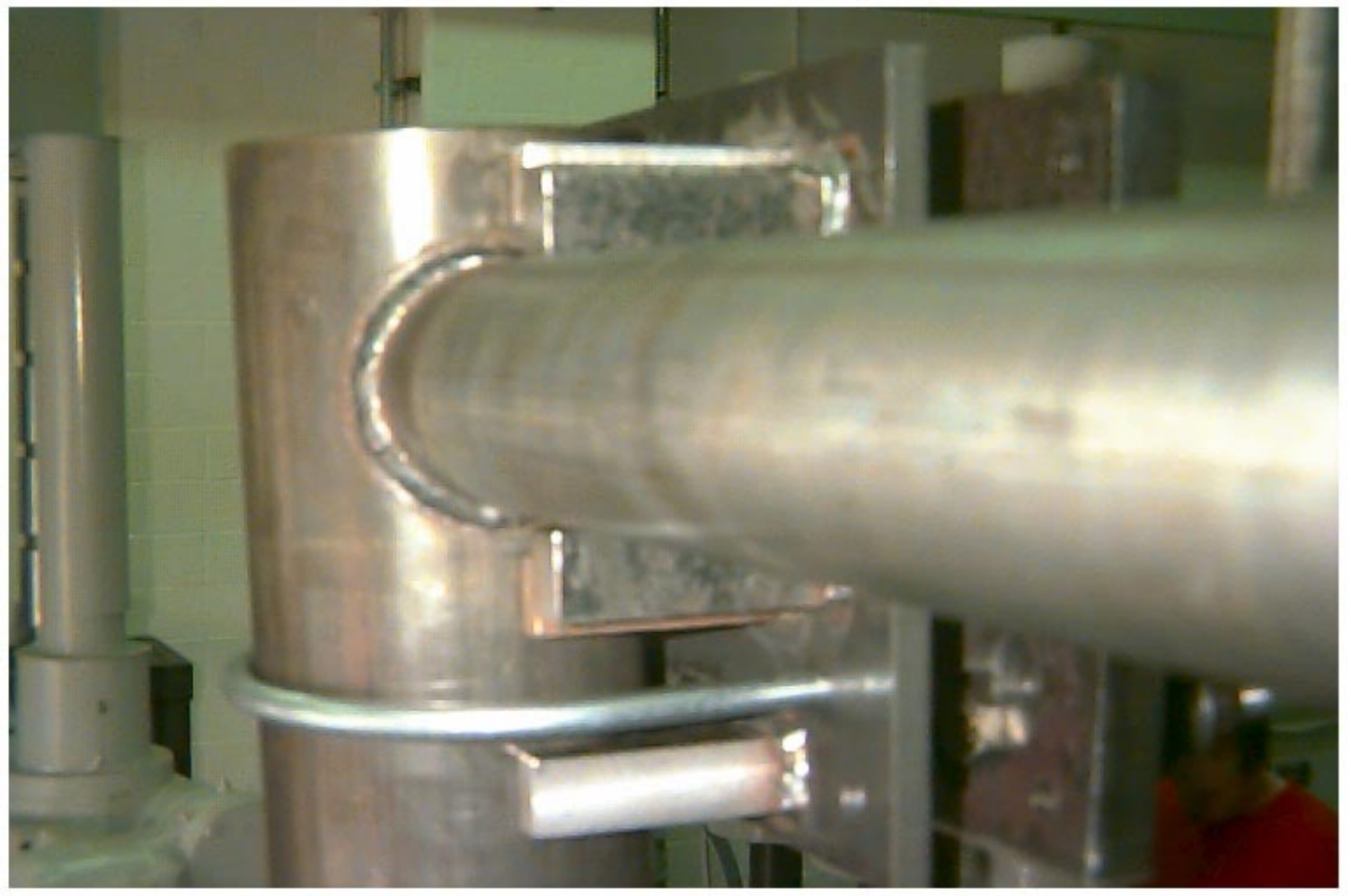

Figure 3.3. Back View of Front and Rear Longitudinal Loading Fixture.

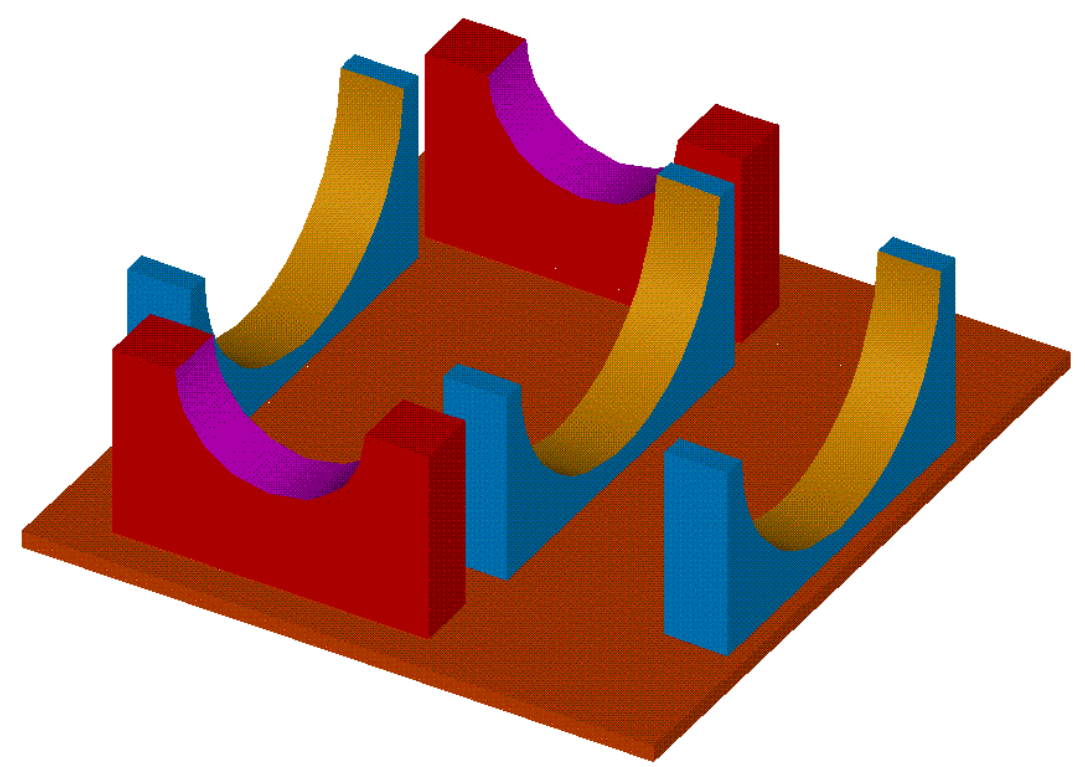

Figure 3.4. CAD of Front and Rear Longitudinal Loading Fixture. 
The transverse loading fixture was mounted on the end cap of the crossbar because it was the uppermost member on the side of the ROPS. An all-thread bolt was used on the inside perimeter of the ROPS to prevent slipping during the test. This loading fixture can be seen in Figures 3.5 and 3.6.

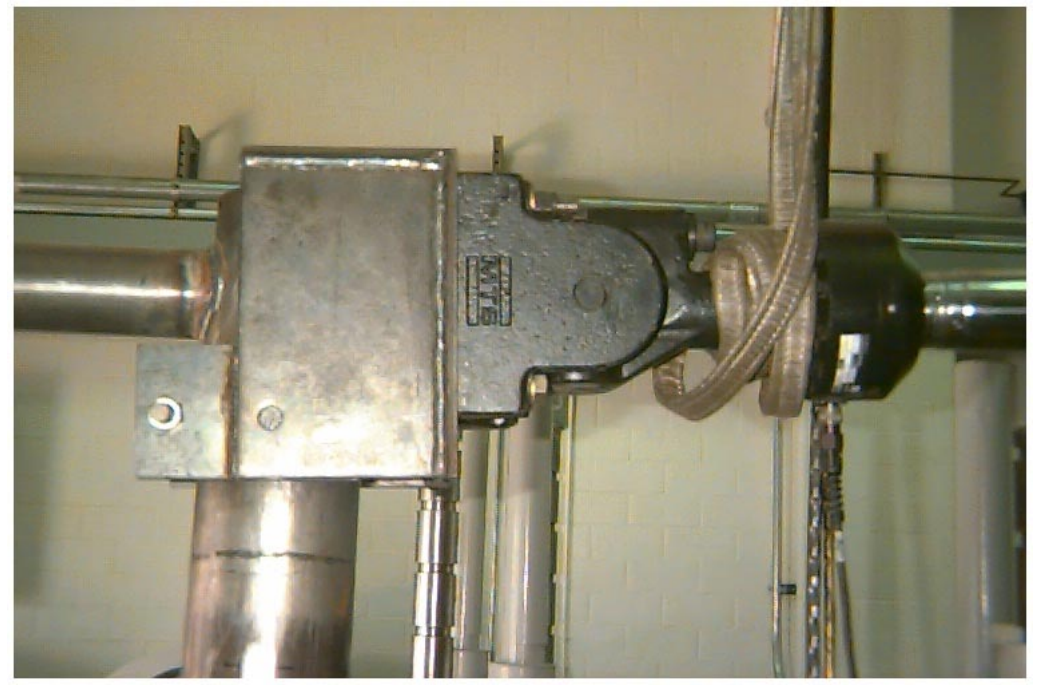

Figure 3.5. Transverse Loading Fixture.

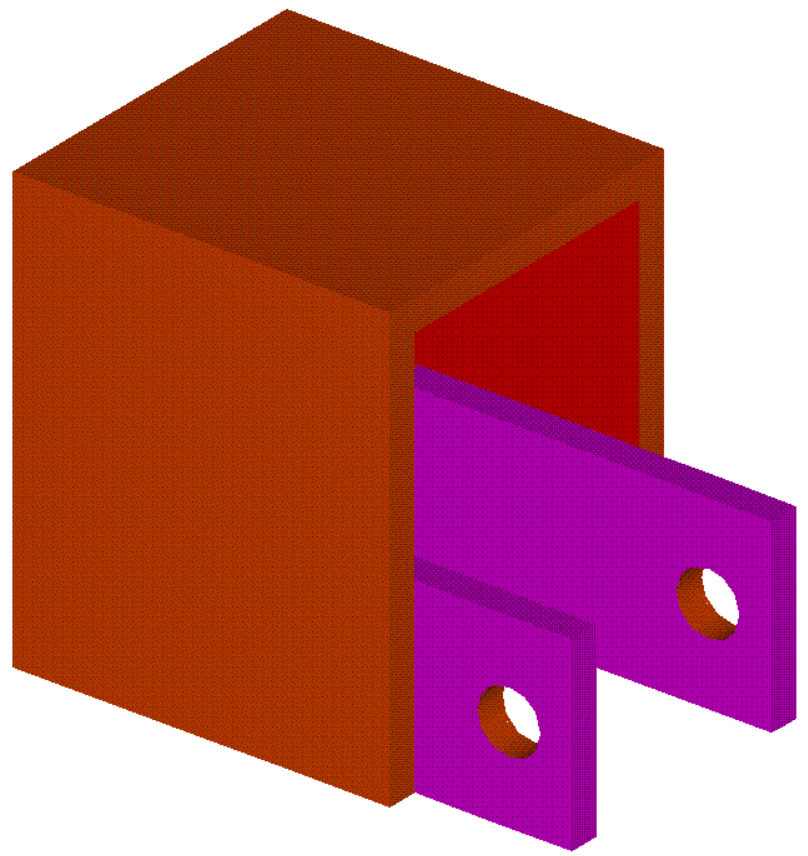

Figure 3.6. CAD of Transverse Loading Fixture. 
The vertical crush interface was made by using a section of C-channel that was bolted to and underneath the I-beam. To prevent slipping, the section of C-channel had to have angle brackets welded to it to prevent the I-beam from slipping off. The vertical crush test and fixture can be seen in Figure 3.7.

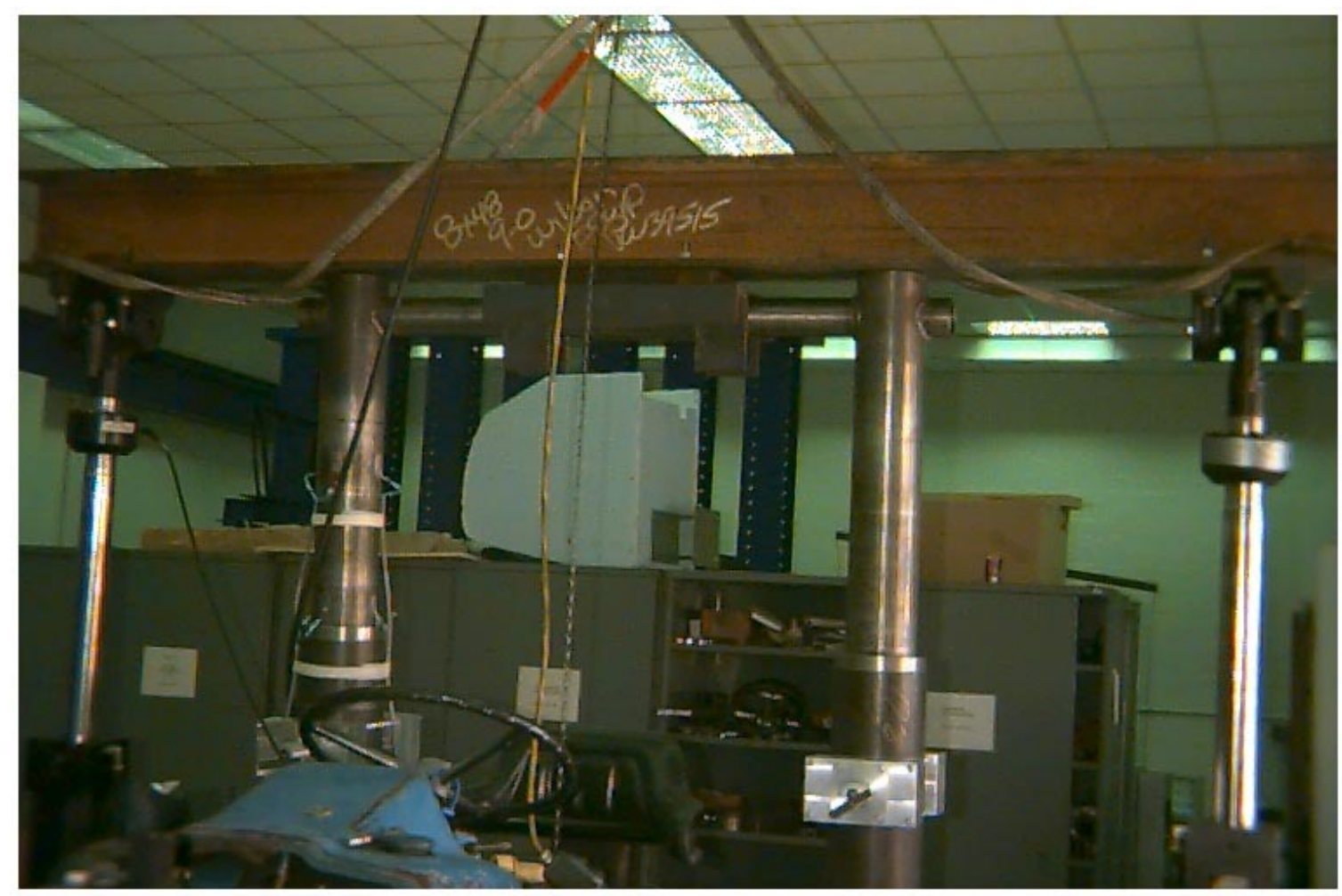

Figure 3.7. Vertical Crush Test Fixture.

One of the challenges of testing the prototype dispersible ROPS was to design a way of securing the base of the ROPS to the axle of the tractor to prevent rotation and translation. This was due to the large lower posts of the ROPS, which used compressed springs to deploy and hydraulics to retract the ROPS once deployed. Therefore, to try to prevent rotation and translation, rigid blocks that fitted the grooves in the axle were 
constructed and implemented (see Figure 3.8). High strength all-threads and nuts were used to clamp the rigid blocks to the axle.

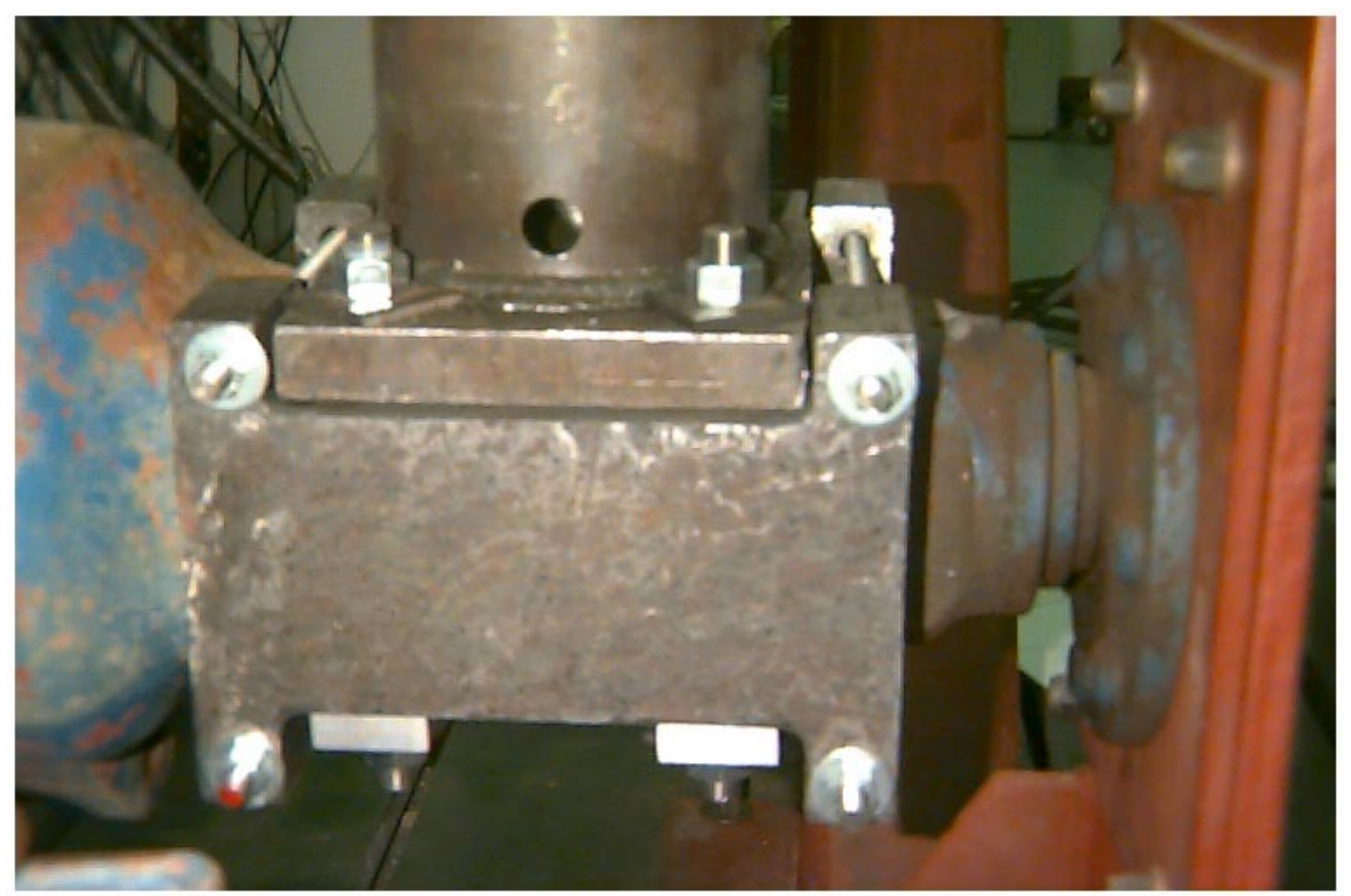

Figure 3.8. ROPS/Tractor Axle Attachment Blocks.

\subsection{Data Acquisition}

Since continuous data monitoring was needed to verify the energy cut off requirements for 3 of the 4 loadings, NIIOSH was able to supply dependable and accurate testing equipment. The equipment was purchased from the MTS Systems Corporation. The instrumentation used allowed the user to control the actuators by either force (load) or displacement (stroke length of actuator). The actuators could be controlled by 
inputting the desired load into TestLink Interface ${ }^{\mathrm{TM}}$, a user friendly data acquisition program supplied by MTS, or a program could be custom designed and written by the user. This was beneficial because the front and rear longitudinal loadings as well as the transverse loading were under displacement control which had a custom designed program written by Clay Brewer and Jim Harris of NIOSH. The vertical crush test was load dependent and monitored using the TestLink Interface ${ }^{\mathrm{TM}}$.

Both actuators used in the experiment contained a swivel rod end and base, closed housing LVDT, load cell, and servovalve (see Table 3.3). The actuators were capable of producing $\pm 22,000$ pounds of force and had a stroke length of 30 inches. Control of the test system involved a closed loop system (see Figure 3.9).

Table 3.3. Equipment List and Instrumentation.

\begin{tabular}{|c|l|}
\hline Quantity & \multicolumn{1}{|c|}{ Description } \\
\hline 1 & MTS Model 458.20 MicroConsole \\
\hline 2 & MTS Model 458.11 DC Controller \\
\hline 2 & MTS Model 458.13 AC Controller \\
\hline 1 & MTS Model 458.91 MicroProfiler \\
\hline 2 & MTS Model 661.20E-03 Axial Load Cell \\
\hline 2 & Model 252.54 Servovalve \\
\hline 2 & Model 249.23 Swivel Rod End \\
\hline 2 & Model 249.23 Swivel Base \\
\hline 2 & Model 244.22 Linear Actuator \\
\hline 1 & MTS Model 510.10-460 Hydraulic Power Supply \\
\hline 1 & Slotted Base Plate (four sections) \\
\hline
\end{tabular}




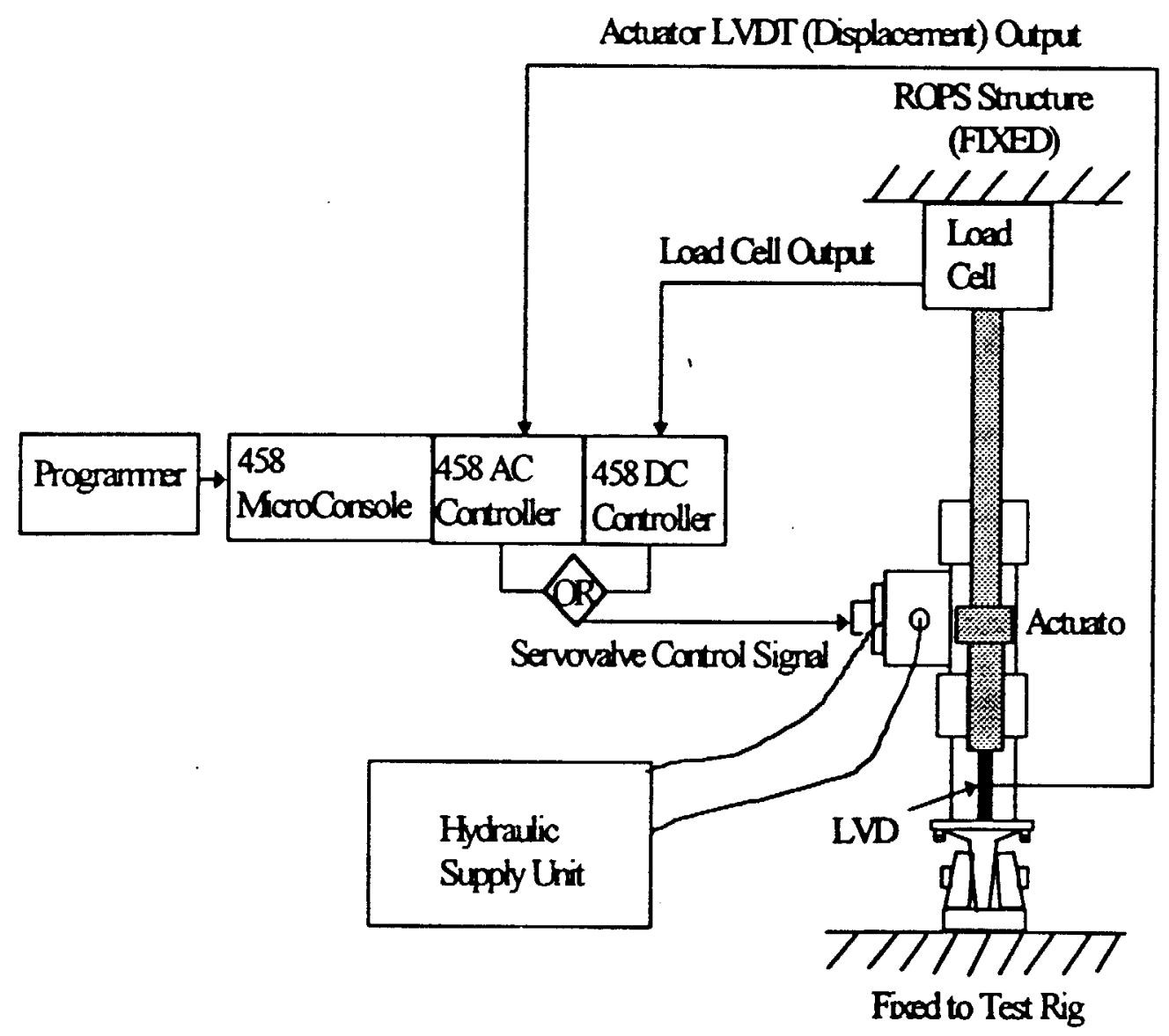

Figure 3.9. Typical Closed Loop System (Ref. MTS Product Information)

Strain and deformation was also measured and recorded during each of the load applications by applying 16 strain gages in a quarter-bridge gage configuration. The 16 strain gages (Micro-Measurements CEA-06-25OUT-120) were attached to the base and upper post to assess the level of elastic and plastic deformation of the higher-stressed side of the deployable ROPS. At four different levels, rings of four strain gages were placed; approximately 2 inches above the base plate on the lower post, approximately 17 inches above the base plate in the mid portion of the lower post, on the upper post in the intersection between the lower and upper posts, and approximately midway up the upper 
post. For each ring of gages, the four gage locations were on the planes of maximum tension and compression and on the neutral axis. The data was acquired by using the LabView Software. The resolution of the data acquisition card was 12 bit, and the sampling rate used in the tests was $250 \mathrm{~Hz}$. The strains measured for gages LR1-A, LR1B, LR1-C, and LR1-D for the complete application and load let-off of the first longitudinal loading, transverse loading, and second longitudinal loading can be seen in Figures 3.12, 3.13, and 3.14. It should be noted the LR1 gages were the gages approximately 2 inches above the base plate on the lower post (see Figures 3.10 and 3.11). This is where the highest deformation and strain occurred.

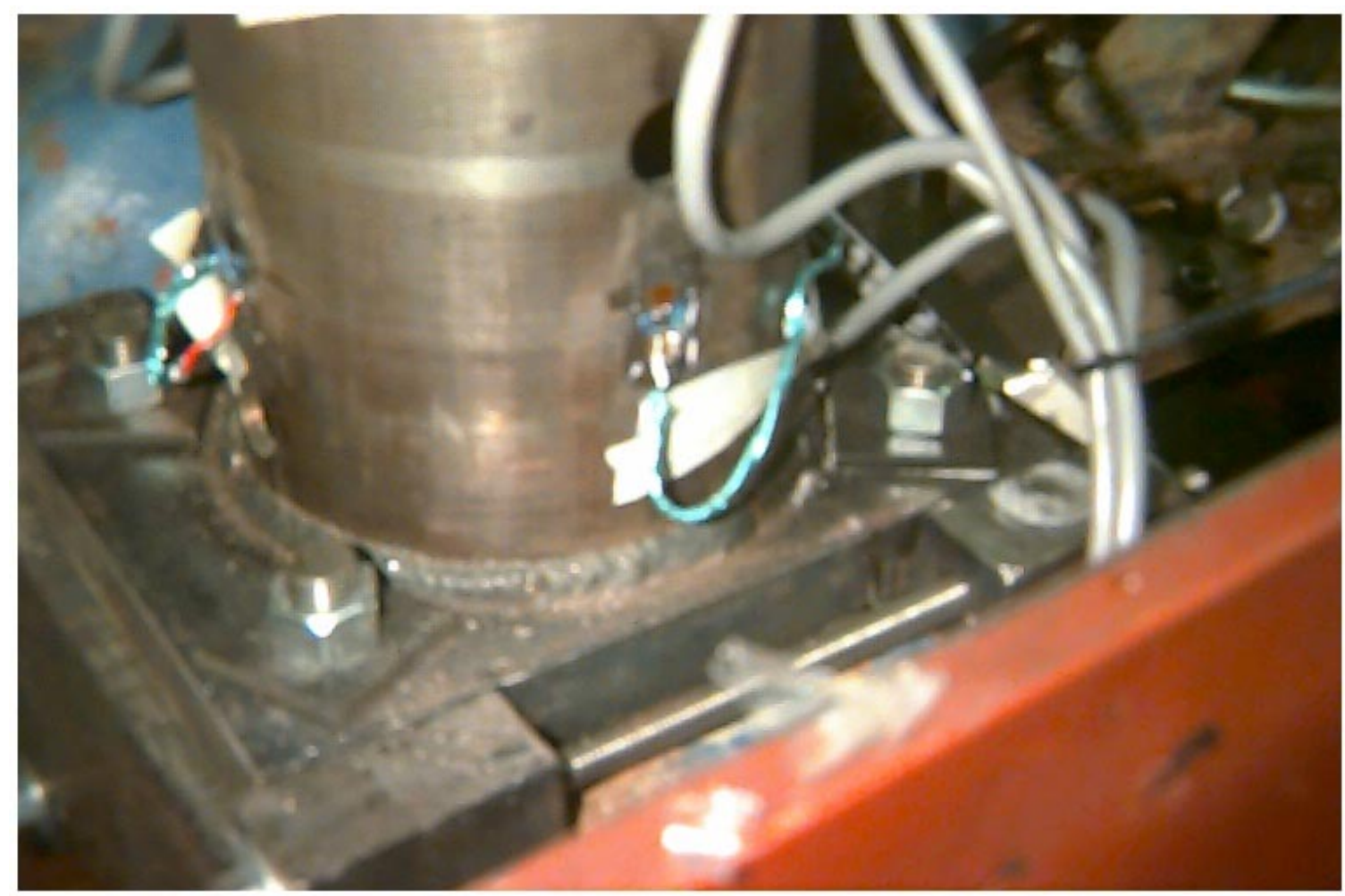

Figure 3.10. Strain Gage Locations at Base of Lower Post. 


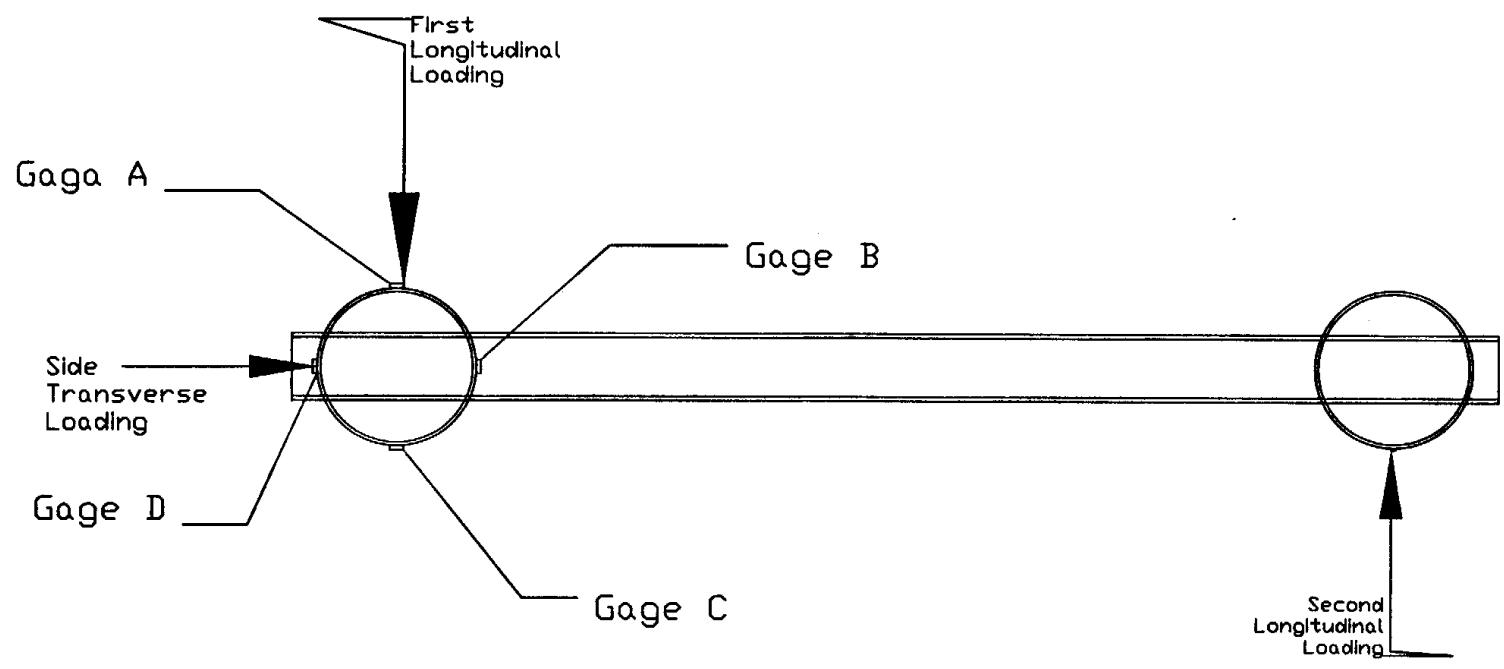

(a)

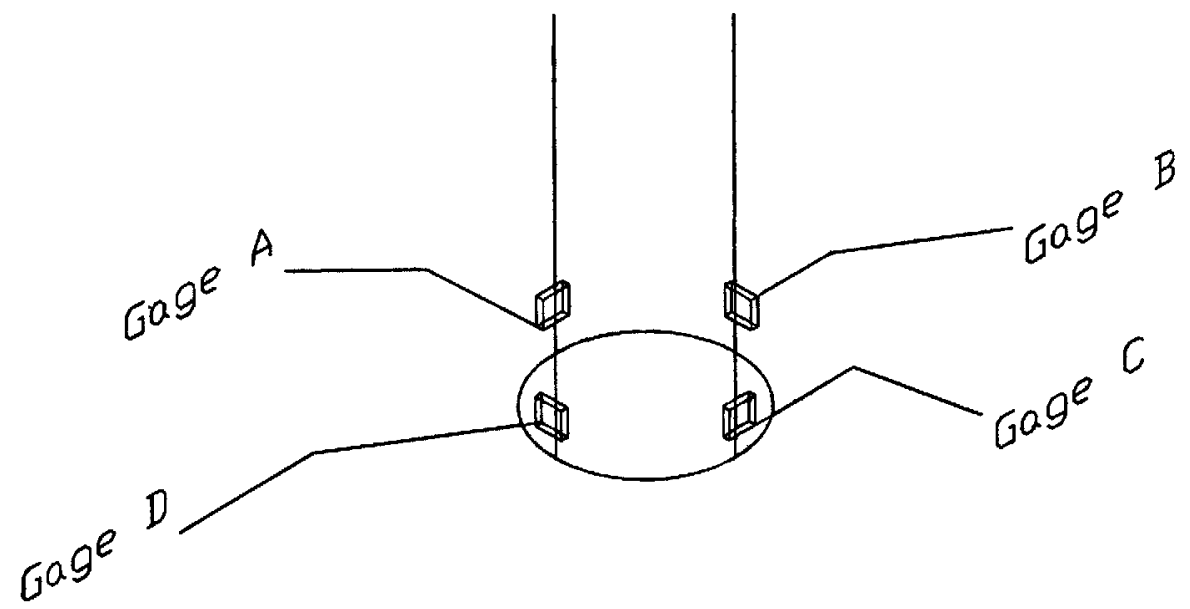

(b)

Figure 3.11. (a) Top View of ROPS Showing the Three Energy Loadings and Strain Gages and (b) Enlarged View of Strain Gages Located Near Bottom of Lower Left Post.

\subsection{Data Acquisition Program}

The data acquisition program was written in Microsoft QuickBasic Version 4.5 in order to establish a controlling method to pause the loading of the ROPS when the energy criteria has been met or was exceeded. This program monitored four channels because each actuator has two channels, which correspond to their individual load cell and LVDT, but only one actuator was actually used in the energy testing sequences. The program 
was able to access and control the waveform generator device, Model 458.91 MicroProfiler $^{\mathrm{TM}}$, through a RS232 serial interface connection between the personal computer and the MicroProfiler. The MicroProfiler creates unique waveforms by linking a series of programmed segments together, which include ramps, haversine and hold time segments (MTS Manual 1995). A way of outlining the test loading was established with the programming features available through the MicroProfiler.

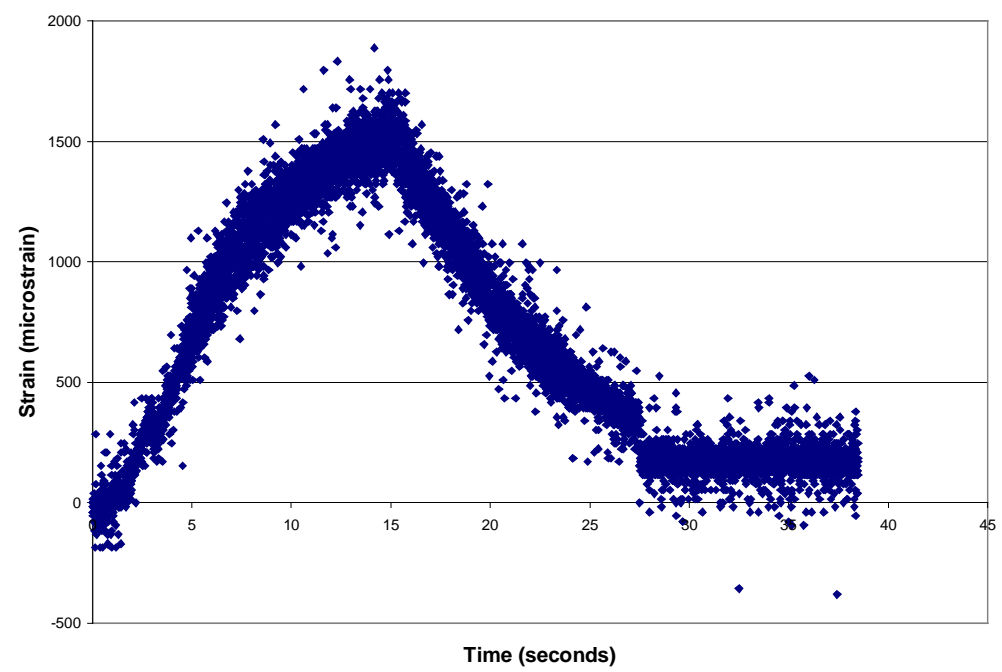

(a)

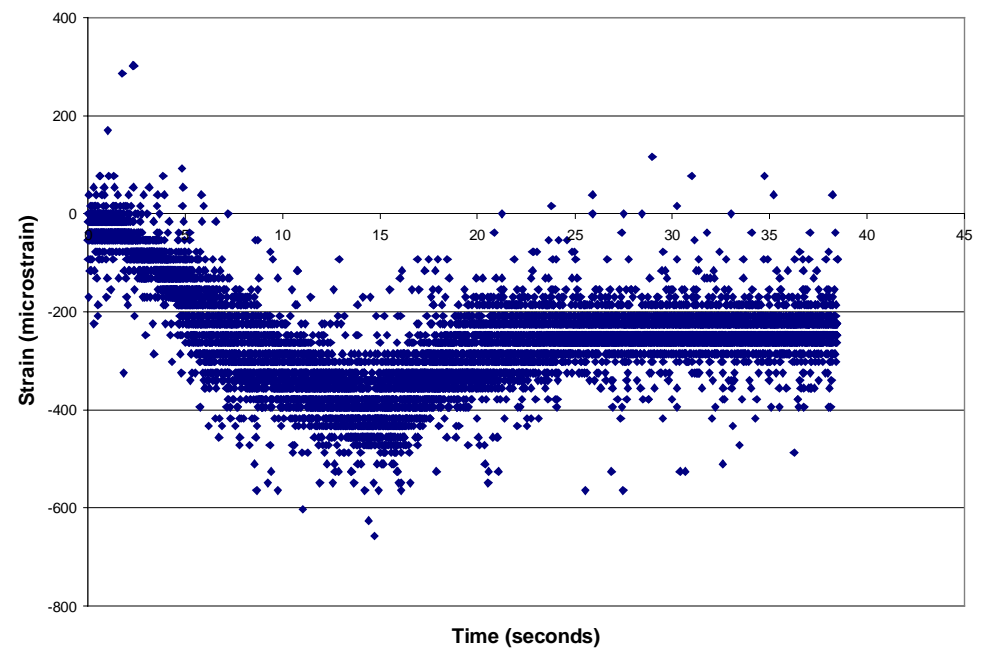

(b)

Figure 3.12. Strain Data For First Longitudinal Loading (a) Gage A \& (b) Gage B. 


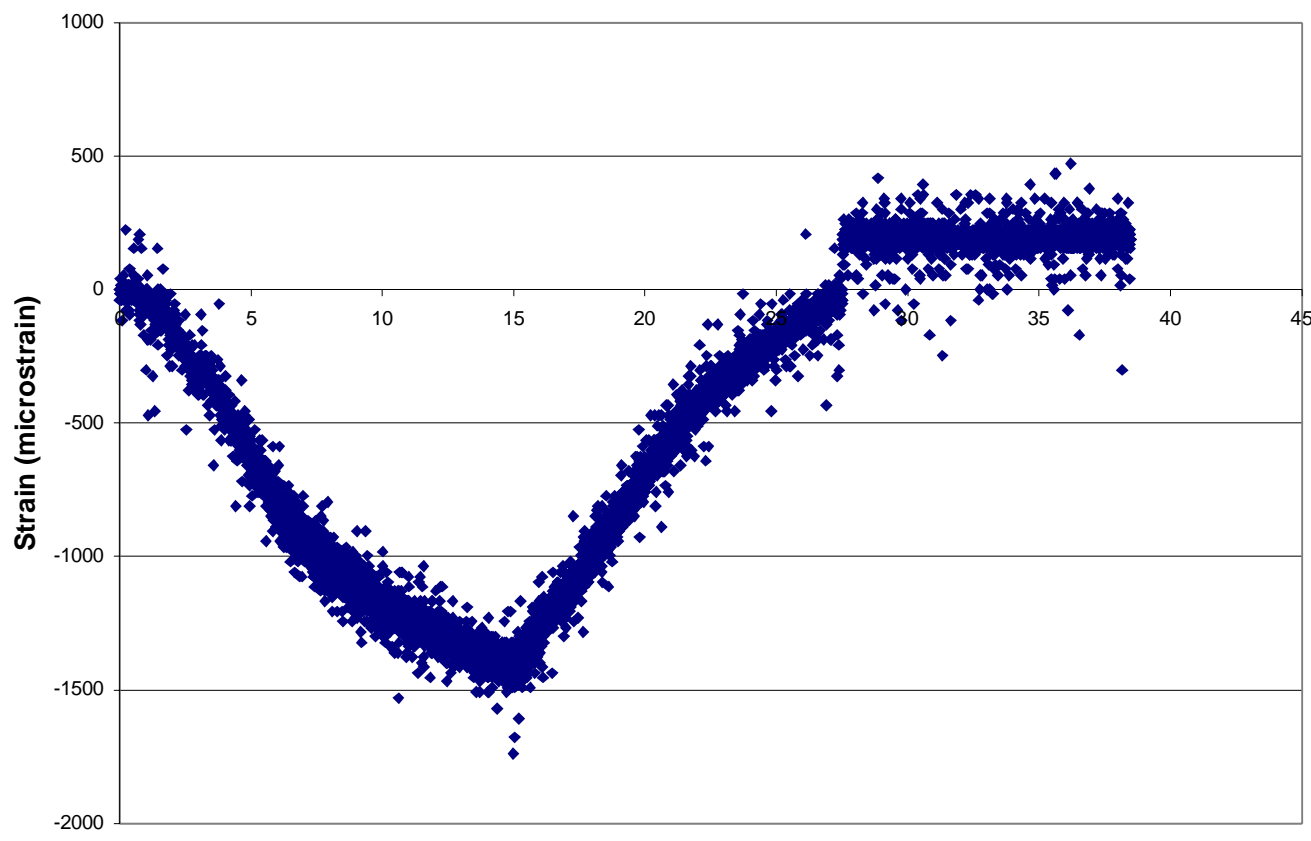

Time (seconds)

(c)

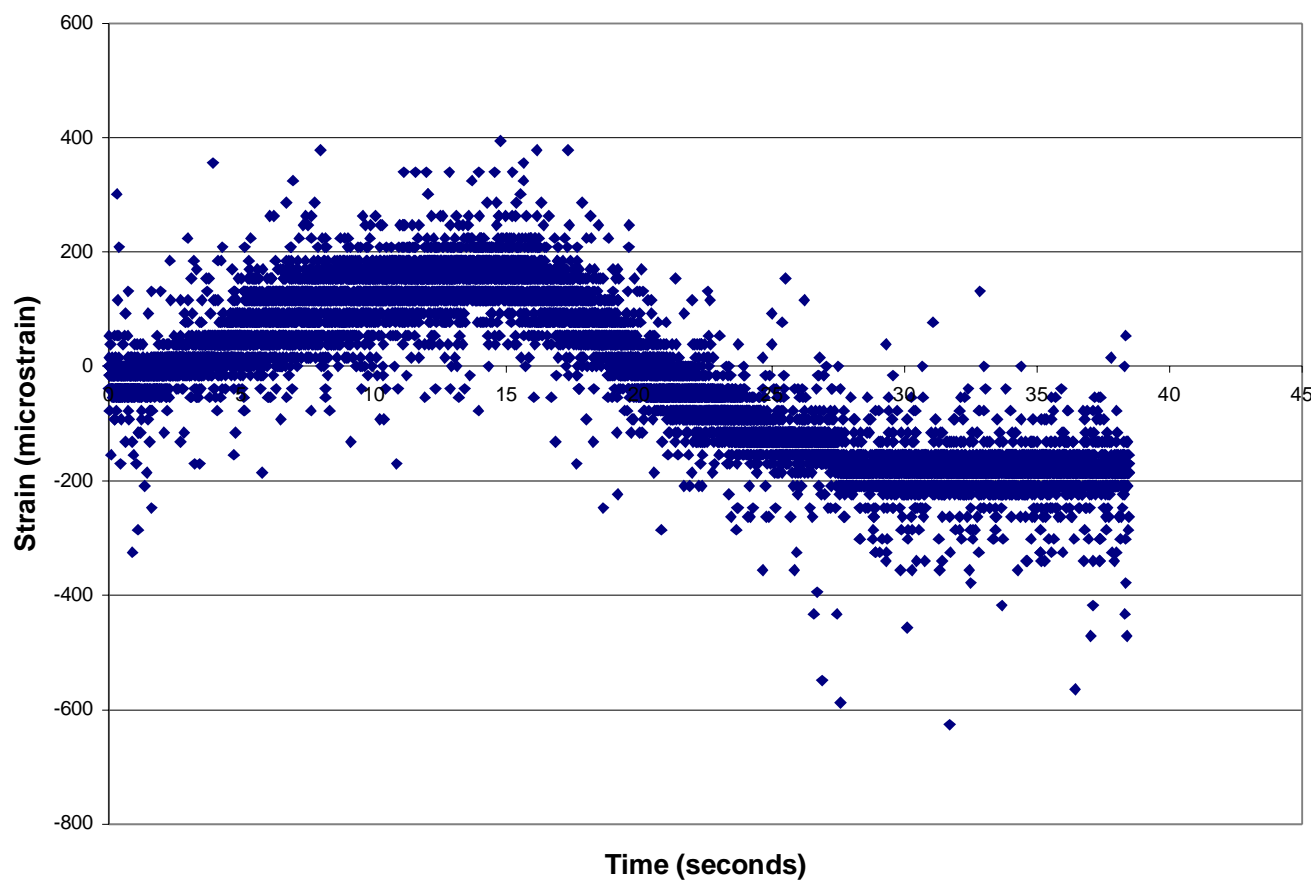

(d)

Figure 3.12. Strain Data For First Longitudinal Loading (c) Gage C \& (d) Gage D. 


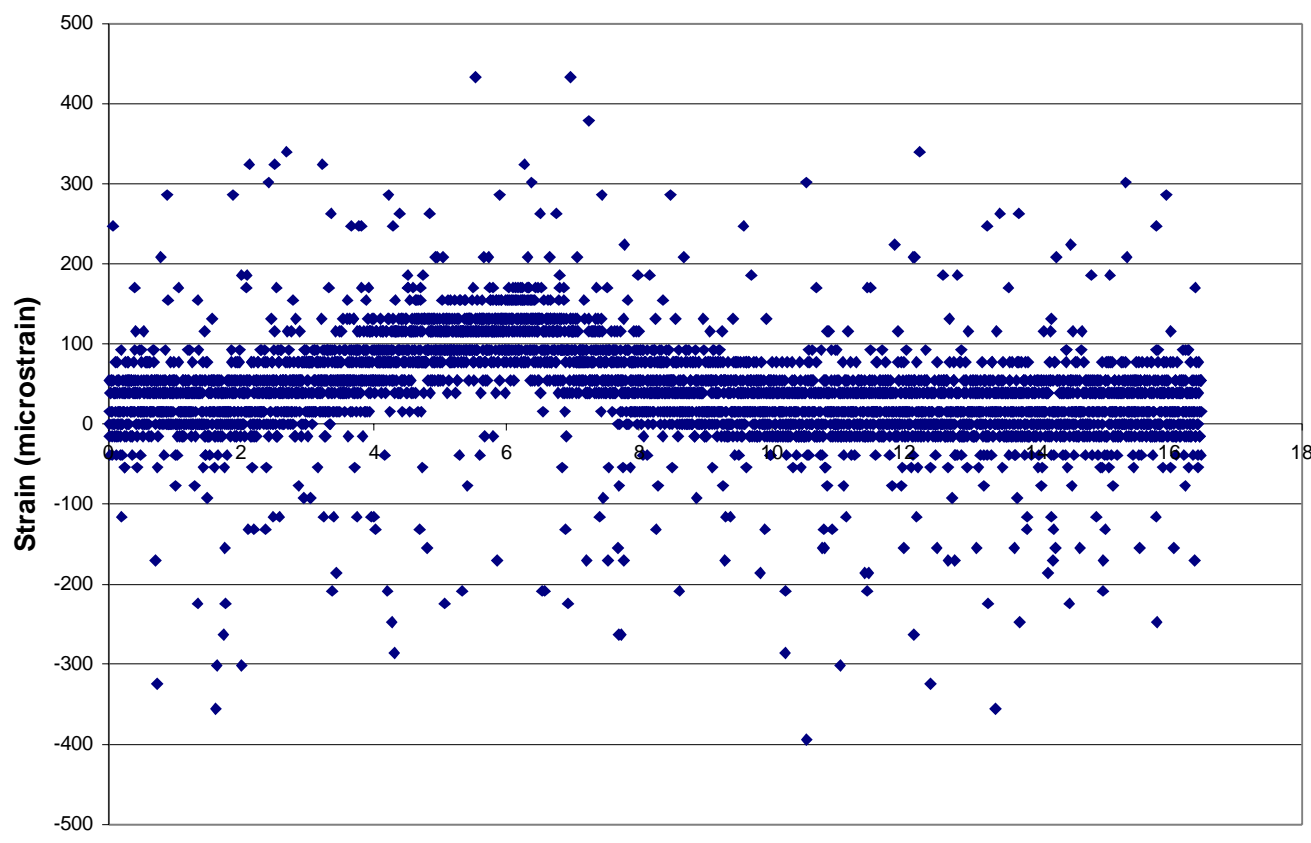

Time (seconds)

(a)

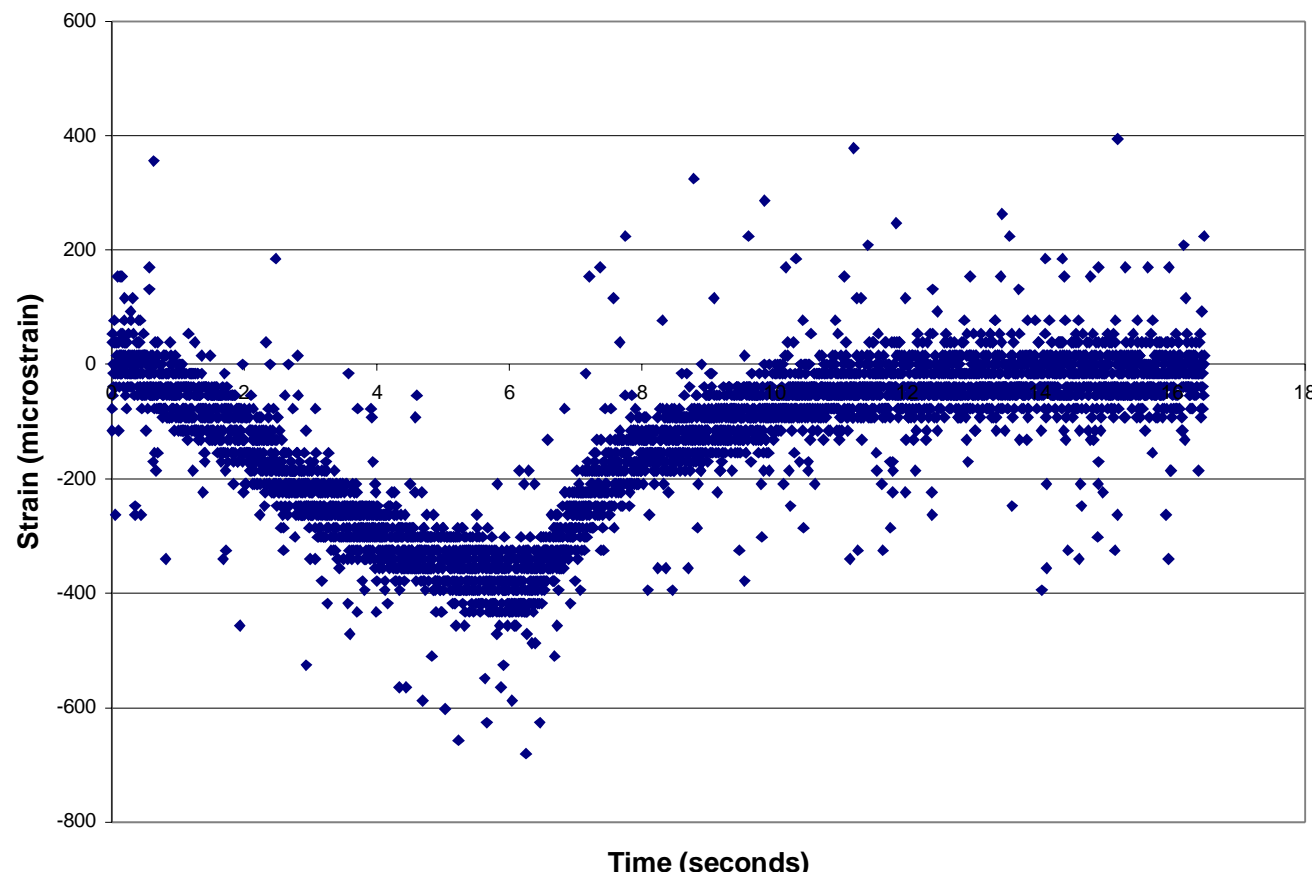

(b)

Figure 3.13. Strain Data For Side Transverse Loading (a) Gage A \& (b) Gage B. 


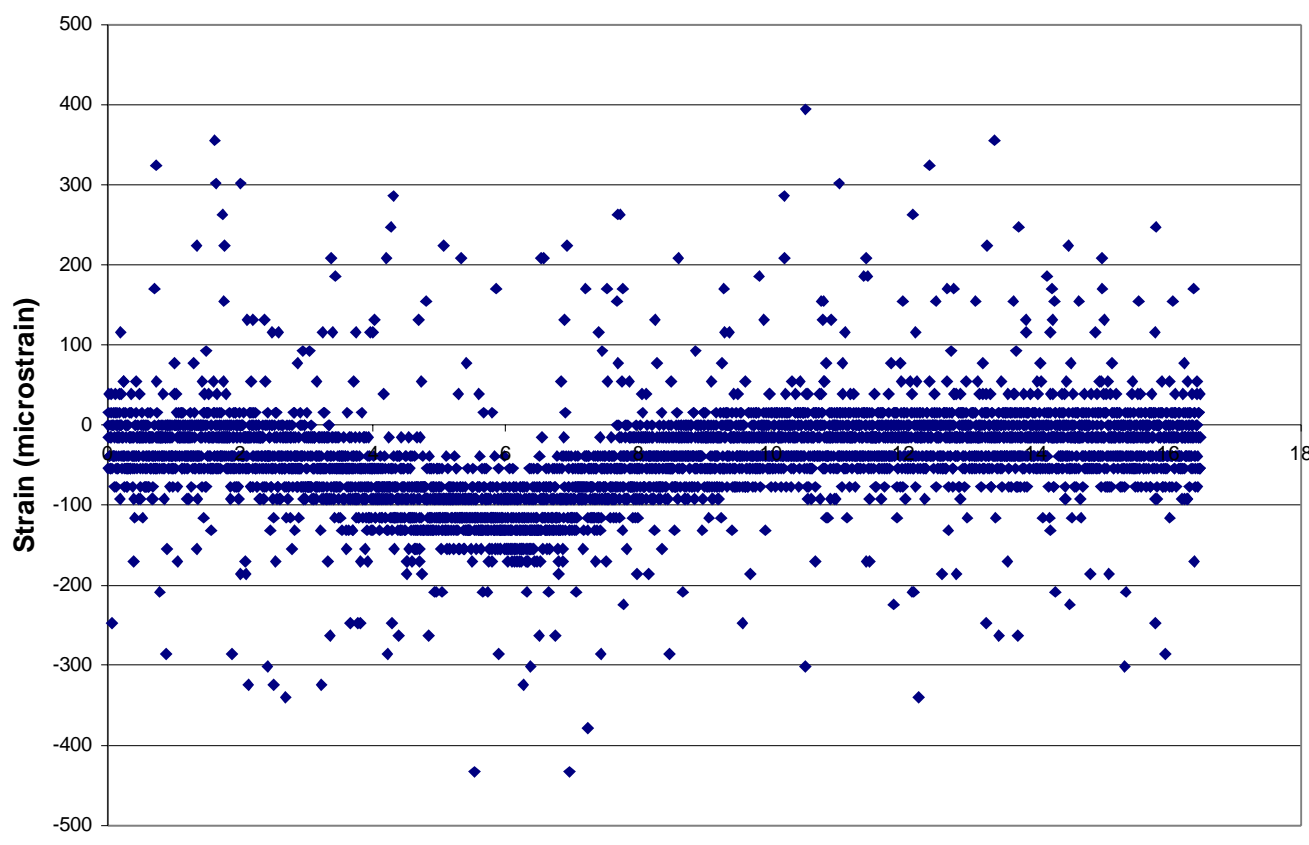

Time (seconds)

(c)

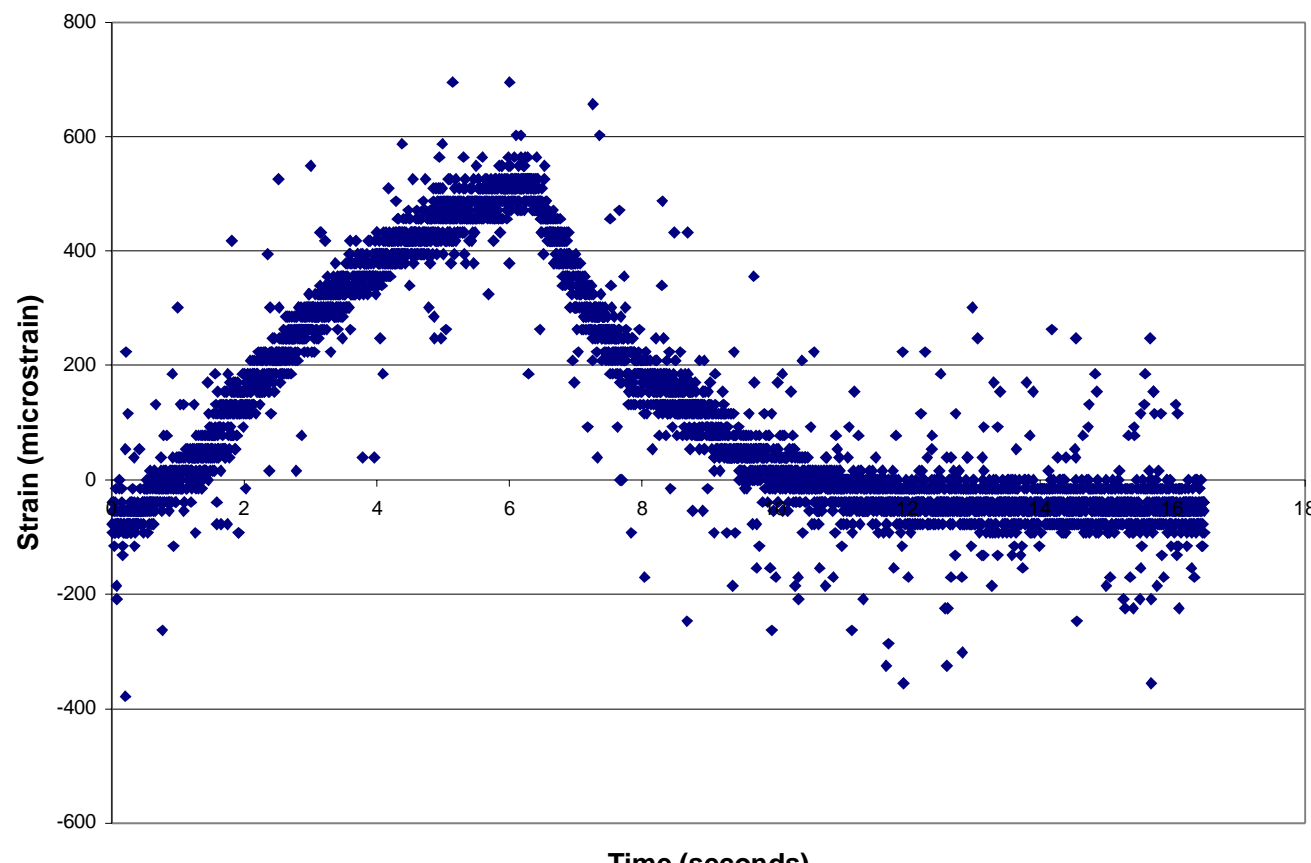

Time (seconds)

(d)

Figure 3.13. Strain Data For Side Transverse Loading (c) Gage C \& (d) Gage D. 


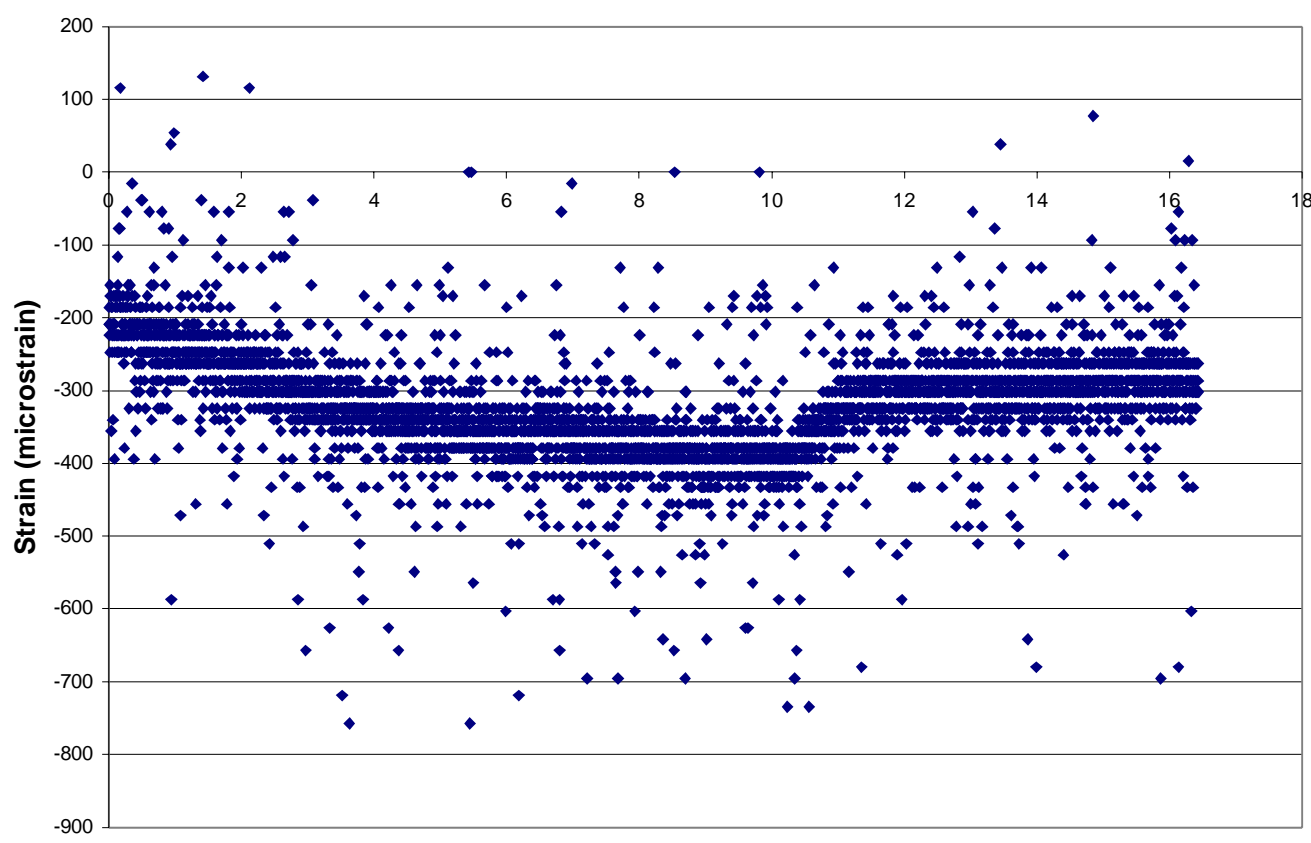

Time (seconds)

(a)

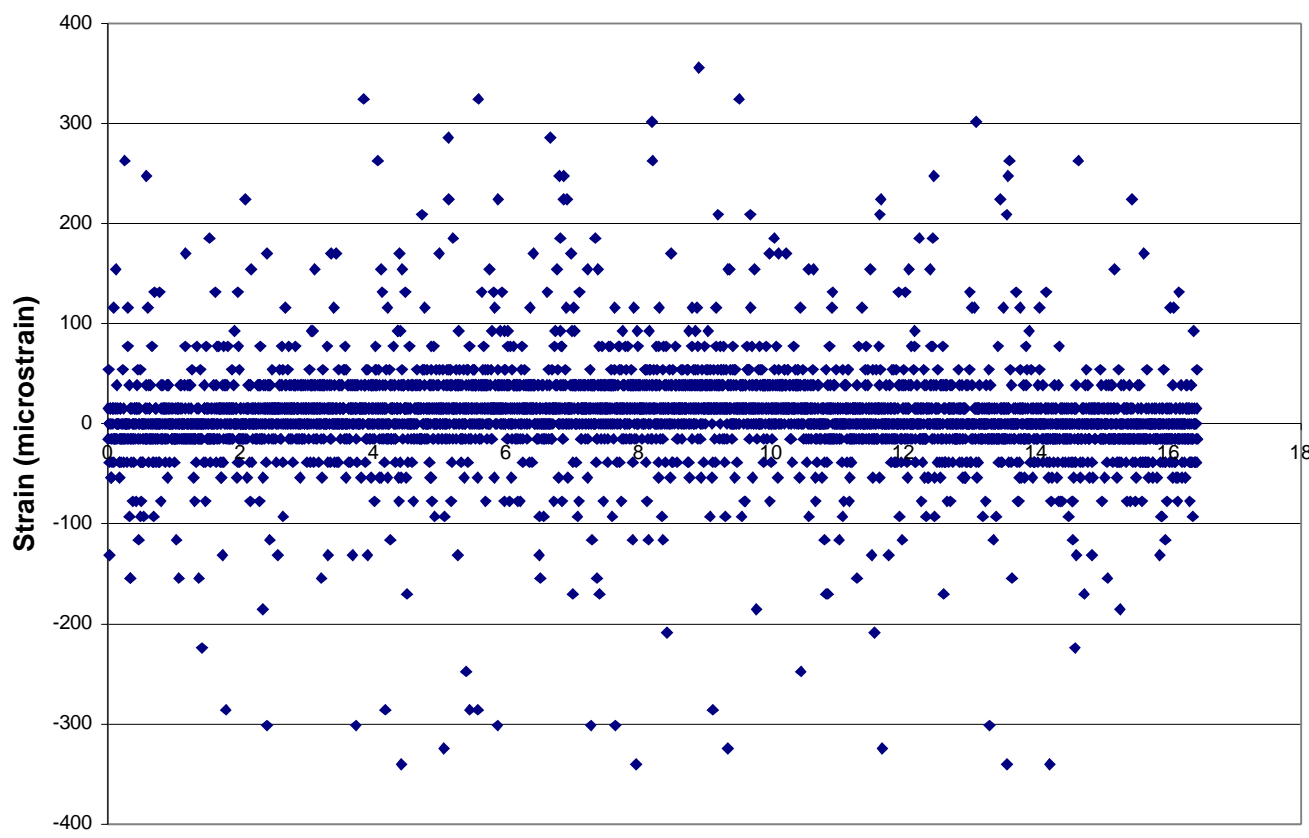

Time (seconds)

(b)

Figure 3.14. Strain Data For Second Longitudinal Loading (a) Gage A \& (b) Gage B. 


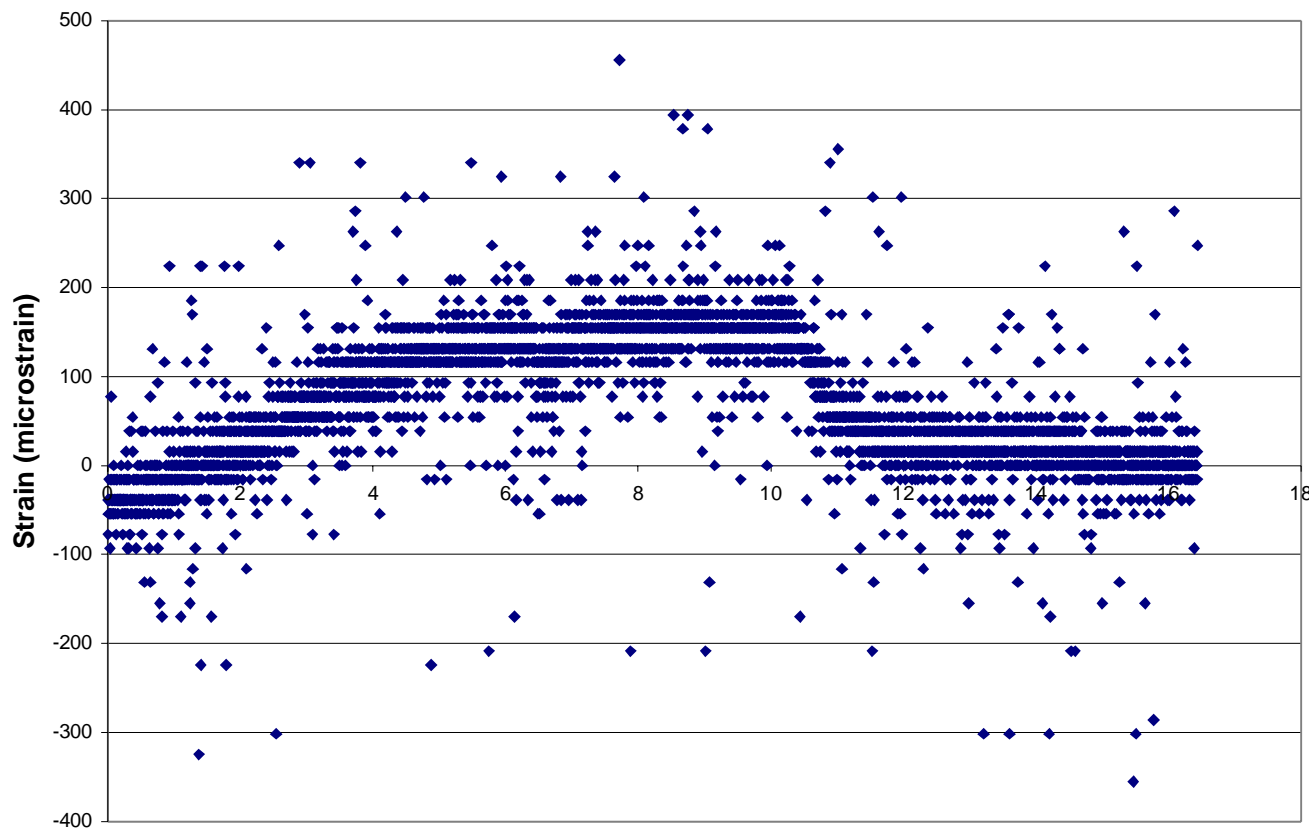

Time (seconds)

(c)

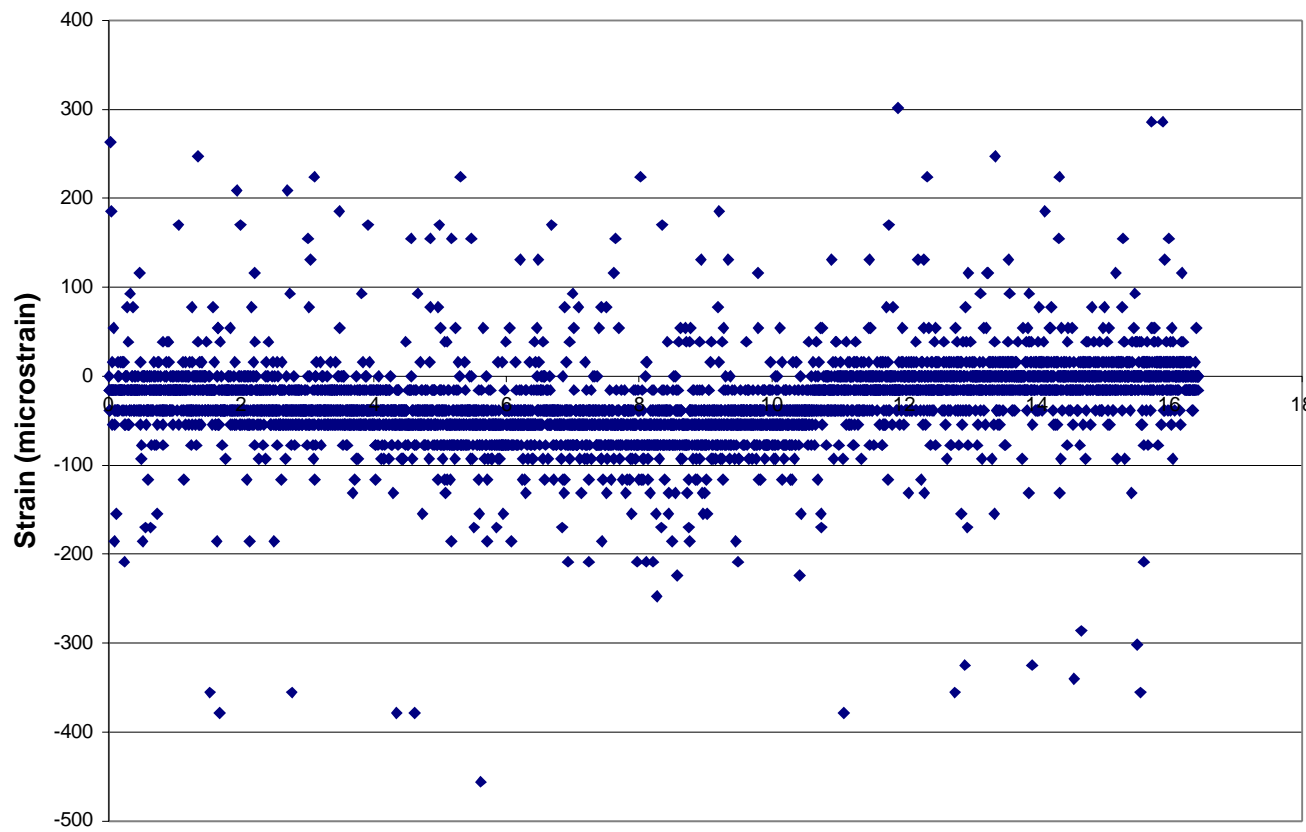

Time (seconds)

(d)

Figure 3.14. Strain Data For Second Longitudinal Loading (c) Gage C \& (d) Gage D. 
Due to the uncertainty of knowing when or at what load the ROPS would absorb or exceed the energy requirements, the two channels on the actuator would have to be constantly monitored. The MicroProfiler helped access program segments, and the load was ramped at a rate not exceeding the $5 \mathrm{~mm} / \mathrm{sec}$ requirement of the SAE J2194 ROPS Standard. The data acquisition program continuously sampled the two channels while the actuators followed their programmed course of action. The program used subroutines developed for the board in order to perform a single A/D conversion on each channel and then converts the analog value to the corresponding voltage value that was later scaled to it appropriate displacement or load number. The arrays were constantly being filled out and rewritten over, but the program kept track of the total sum before it was written over and used the total sum number to be added to the next array.

At the same time as the channels were sampled, a section of the program used the multiple application trapezoidal rule to check the area under the force vs. displacement curve by fitting a set number of trapezoids under the curve. There was some small error encountered due to the trapezoid fit. When the energy criteria was met, a signal was sent to the MicroProfiler to initiate a hold signal, which maintained the loading on the ROPS. In addition, provisions were made in the program to open data files to which force vs. displacement and energy vs. displacement were stored. Force-Deflection charts for the three energy based loadings can be seen in Figures 3.15, 3.16, and 3.17. 
AutoROPS Prototype A

static testing-first longitudinal load

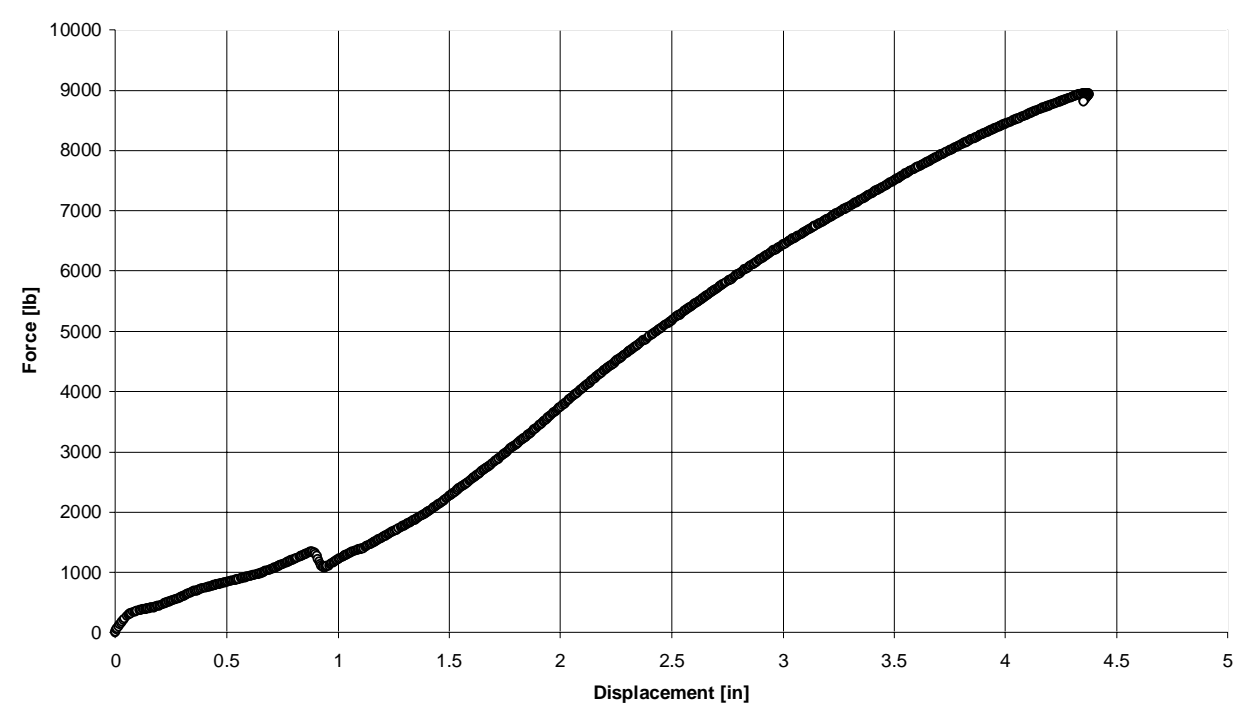

Figure 3.15. Force-Deflection Data for First Longitudinal Loading.

AutoROPS Prototype A static testing - transverse load

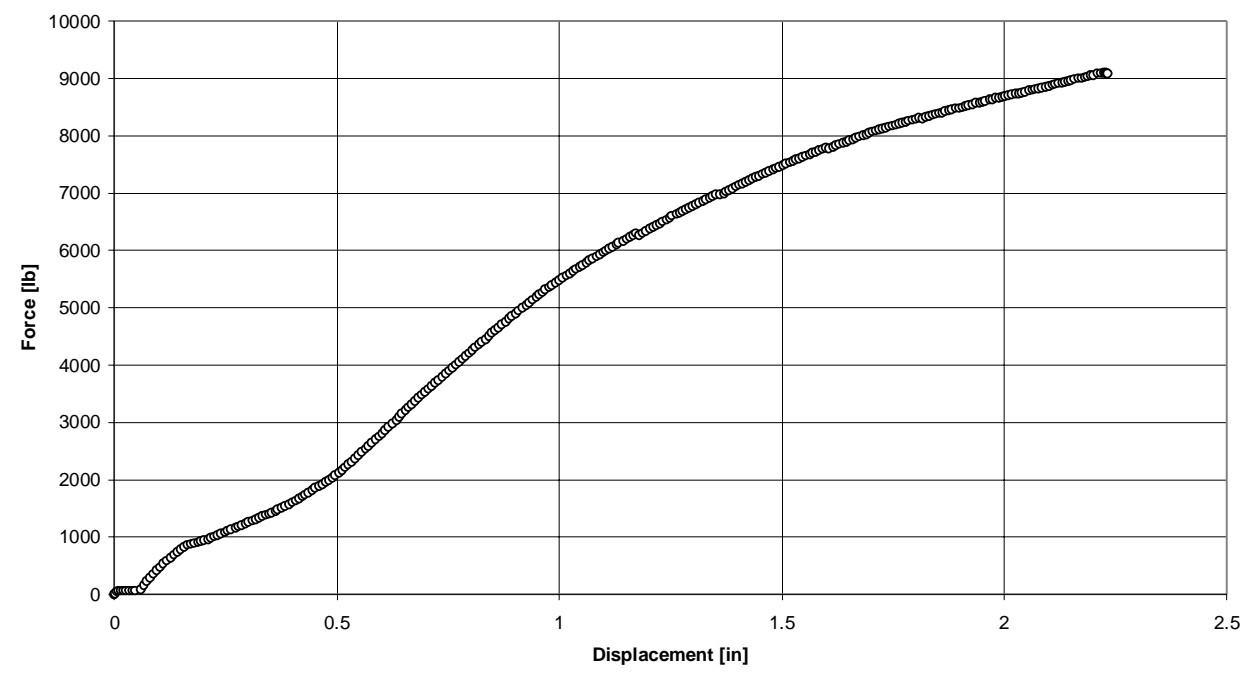

Figure 3.16. Force-Deflection Data for Transverse Loading. 


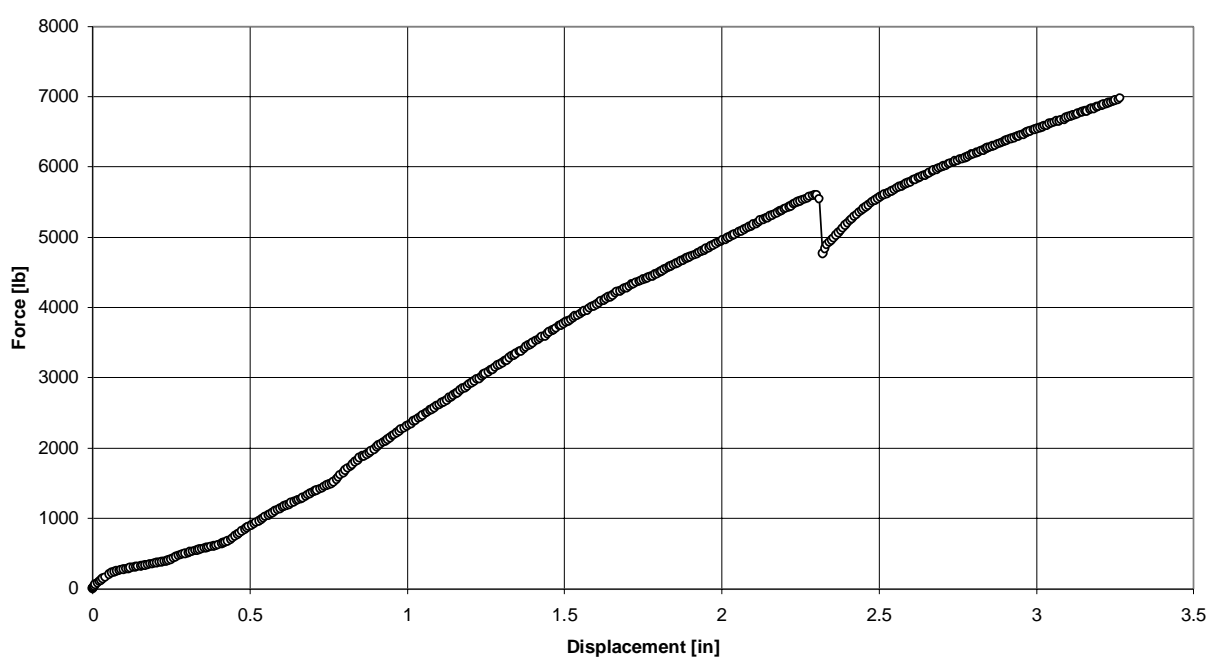

Figure 3.17. Force-Deflection Data for Second Longitudinal Loading. 


\section{Chapter 4}

\section{SOLID AND FINITE ELEMENT MODEL DESCRIPTIONS}

\subsubsection{Mechanical CAD Software}

The first step in creating a complex FEM is to select the proper software that will allow the engineer to solid model, mesh, achieve, and analyze accurate results with the greatest ease. For all of these reasons, the I-DEAS ${ }^{\mathrm{TM}}$ (Integrated Design Engineering Analysis Software) Master Series 7m1 developed by SDRC (Structural Dynamics Research Corporation) was selected for analysis of the original dispersible ROPS as well as the design and analysis of the optimized dispersible ROPS. This software package has user-friendly capabilities to solid model, mesh, apply multiple load sets incorporating time and restraint sets, and perform the finite element analysis of most any given part. The following descriptions of solid modeling generation below was performed in the Simulation Application and Master Modeler Task.

\subsubsection{Modeling the Two Post Deployable ROPS}

The two FE models previously discussed were essentially generated the same way. The original deployable ROPS is the exact one statically loaded by WVU/NIOSH's testing facility in accordance with the SAE J2194 Standard. The optimized ROPS is a prototype lighter in weight as opposed to the original and is designed in accordance with the SAE J2194 Standard. 
I-DEAS ${ }^{\mathrm{TM}}$ offers a Part Catalog, which makes creating a solid part very easy. The Part Catalog offers such parts as blocks, cylinders, tubes, spheres, and planes. Once the part needed has been decided the user only need to input the desired dimensions. The majority of each of the dispersible ROPS can be broken into four parts: lower tube, cap for lower tube, upper tube, and horizontal crossbar. All of these parts were essentially tubes.

The other two key parts of each dispersible ROPS were the latching pins which were modeled as fixed to the lower tubes and the piston for the upper tube that was modeled as threaded to the upper tubes. The latching pins were modeled by creating an octagonal wireframe and then extruding it to the desired length. The piston for the upper tube was modeled by creating a two-dimensional cross-sectional wireframe of the piston and then revolving it about the center axis of the cross-sectional wireframe.

Once all parts were constructed, each part is moved to its desired location. Due to the complexity of these types of models, the ROPS was broken down into two categories, the top part of the ROPS and the bottom part of the ROPS. This allowed easier mapped meshing of the two categories, and the two categories can be appended to one another to create a complete ROPS (this will be explained later in the chapter).

The top part of the ROPS consisted of the two upper tubes and pistons and the horizontal tube connecting the upper tubes. The lower part of the ROPS consisted of each of the lower tubes, latching pins, and the caps for each lower tube. The individual parts were then joined by executing the joining command in the Master Modeler Task multiple times until each category of the ROPS was completely joined. Schematics of 
the original ROPS as well as the optimized ROPS can be seen in Figures $4.1 \& 4.2$, and the dimensions are listed in Tables $4.1 \& 4.2$, respectively.

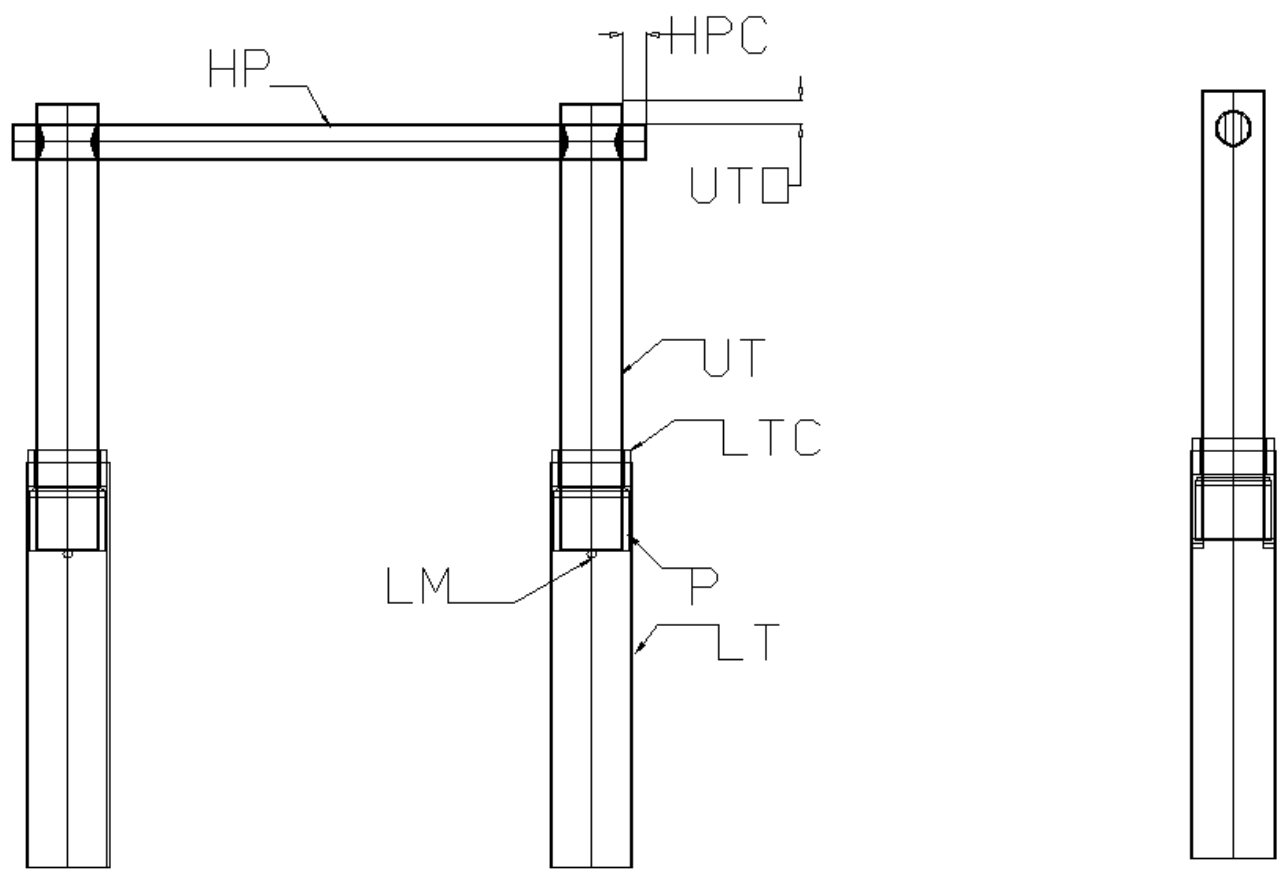

Figure 4.1 Front and Side Views of Original ROPS

Table 4.1. Identity and Geometry of Original ROPS

\begin{tabular}{|c|c|c|}
\hline Symbol & Identity & $\begin{array}{c}\text { Dimension(s) } \\
\text { [inches] }\end{array}$ \\
\hline HP & Horizontal Tube/Pipe & $\begin{array}{c}\text { Inner Radius }=1.3 \\
\text { Outer Radius }=1.5 \\
\text { Total Length }=53.25\end{array}$ \\
\hline HPC & Horizontal Tube/Pipe Clearance & Clearance $=2$ \\
\hline UTO & Upper Tube Overhang & Overhang $=1.625$ \\
\hline UT & Upper Tube & $\begin{array}{c}\text { Inner Radius }=2.375 \\
\text { Outer Radius }=2.625\end{array}$ \\
& & Total Length $=37.5$ \\
\hline LTC & Lower Tube Cap & Inner Radius $=2.75$ \\
& & Outer Radius $=3.25$ \\
& & Total Height $=3$ \\
\hline P & Piston & $\begin{array}{c}\text { Inner Radius }=2.375 \\
\text { Outer Radius }=2.625\end{array}$ \\
& & Inside Height $=5.25$ \\
& & Outside Height $=4.75$ \\
\hline LM & Radius $=0.375$ \\
& Latching Mechanism (Pins) & Length $=1.25$ \\
\hline LT & Lower Tube & Inner Radius $=3.25$ \\
& & Outer Radius $=3.50$ \\
& & Total Length $=34$ \\
\hline
\end{tabular}



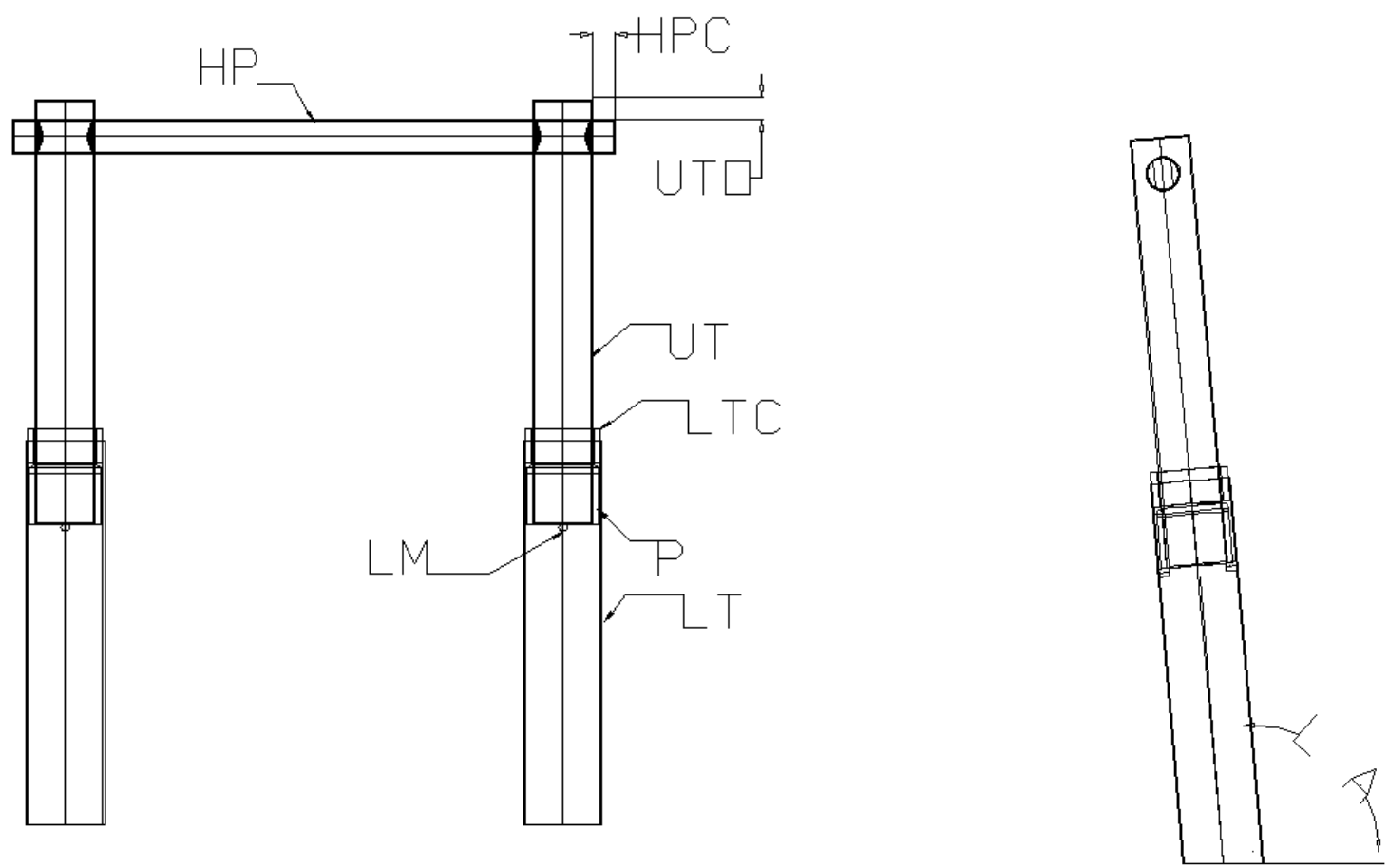

Figure 4.2. Front and Side Views of Optimized ROPS

Table 4.2. Identity and Geometry of Optimized ROPS

\begin{tabular}{|c|c|c|}
\hline Symbol & Identity & $\begin{array}{c}\text { Dimension(s) } \\
\text { [inches] }\end{array}$ \\
\hline HP & Horizontal Tube/Pipe & $\begin{array}{c}\text { Inner Radius }=1.344 \\
\text { Outer Radius }=1.5 \\
\text { Total Length }=53.25\end{array}$ \\
\hline HPC & Horizontal Tube/Pipe Clearance & Clearance $=2$ \\
\hline UTO & Upper Tube Overhang & Overhang = 1.625 \\
\hline UT & Upper Tube & $\begin{array}{c}\text { Inner Radius }=2.469 \\
\text { Outer Radius }=2.625 \\
\text { Total Length }=37.5\end{array}$ \\
\hline LTC & Lower Tube Cap & $\begin{array}{c}\text { Inner Radius }=2.75 \\
\text { Outer Radius }=3.344 \\
\text { Total Height }=3\end{array}$ \\
\hline$P$ & Piston & $\begin{array}{c}\text { Inner Radius }=2.625 \\
\text { Outer Radius }=3.125 \\
\text { Inside Height }=5.25 \\
\text { Outside Height }=4.75\end{array}$ \\
\hline LM & Latching Mechanism (Pins) & $\begin{array}{l}\text { Radius }=0.375 \\
\text { Length }=1.156\end{array}$ \\
\hline LT & Lower Tube & $\begin{array}{c}\text { Inner Radius }=3.344 \\
\text { Outer Radius }=3.5 \\
\text { Short Length }=35 \\
\text { Long Length }=35.6124\end{array}$ \\
\hline LA & Layback Angle & 95 Degrees \\
\hline
\end{tabular}




\subsubsection{Generation of The Operator Clearance Zone Model}

The Operator Clearance Zone was modeled in direct accordance with the SAE J2194 Standard. The Standard gives mandatory dimensions as well as those which are dependent upon the particular type of tractor. The key dimensions and their reference to the Operator Clearance Zone can be seen in Figure 4.3 and further elaborated by Table 4.3 .

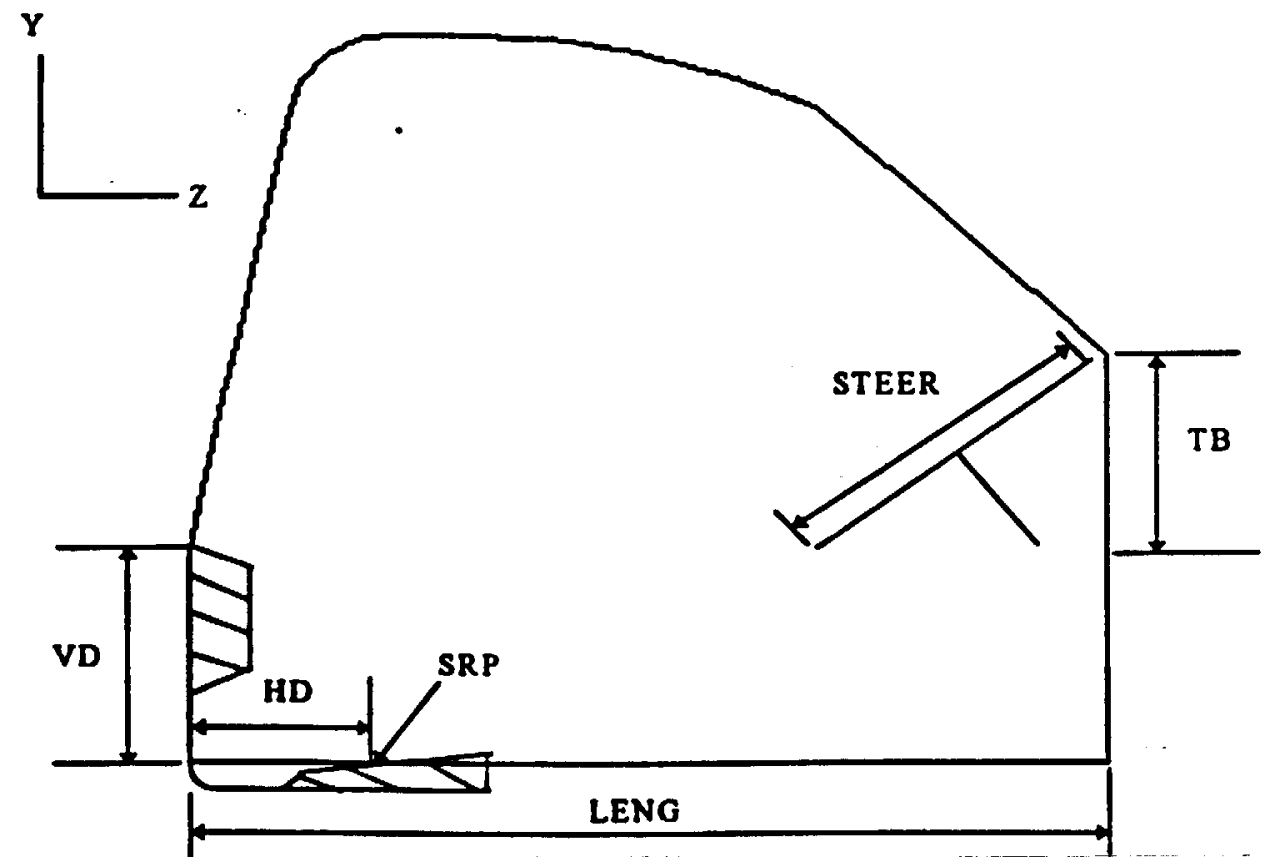

Figure 4.3. Operator Clearance Zone (Side View)

Table 4.3. Identity and Geometry of Operator Clearance Zone.

\begin{tabular}{|c|c|}
\hline Dimension & $\begin{array}{c}\text { Value } \\
\text { (inches) }\end{array}$ \\
\hline Diameter of Steering Wheel (STEER) & 18 \\
\hline Horizontal Distance of SRP to Rearmost of Backrest (HD) & 5 \\
\hline Vertical Distance of SRP to Rearmost of Backrest (VD) & 10.25 \\
\hline Vertical Distance of Steering Wheel Top to Bottom (TB) & 8 \\
\hline * Horizontal Distance of Plane E1F1F2E2 (LENG) & 38.95 \\
\hline Extruded Distance of Zone (OPDEPTH) & 21.15 \\
\hline X-Axis Distance (Center of Mount-SRP) & 19 \\
\hline Y-Axis Distance (Center of Mount-SRP) & 17.375 \\
\hline Z-Axis Distance (Center of Mount-SRP) & 8 \\
\hline
\end{tabular}

*Denotes the Plane E1F1F2E2 in Figure 2.4. 
The solid model of the Operator Clearance Zone started as a wireframe. Once a completely enclosed wireframe was constructed, the section was extruded and placed in the proper location with respect to the Optimized ROPS. This solid model of the Occupant Clearance Zone was only used with the Optimized ROPS and not with the Original ROPS. This was because there was no Operator Clearance Zone used in the Experimental Testing of the Original ROPS.

\subsubsection{Finite Element Model Introduction}

In recent years, Finite Element Analysis has become a "norm" in everyday engineering analysis and design. There are two categories for most finite element analysis approaches, formulation of the discrete model and solution of the discrete model. The formulation of the discrete model consists of several requirements such as defining the element properties, assembling the element stiffness matrices, applying the loads, and defining the correct boundary conditions. The solution of the discrete model is made up of the calculation of strains, deflections, stresses, and computation of reactions.

The approach I-DEAS ${ }^{\mathrm{TM}}$ follows to solve a FEM is not exactly the same as the aforementioned, but the approach is quite similar. The I-DEAS ${ }^{\mathrm{TM}}$ approach to solving any model can be broken into 3 parts: Pre-Processing, Solution, and Post-Processing. The Pre-Processing stage is where the solid modeling occurs, as well as generating the mesh of the solid model, and last, the loads and boundary conditions are applied. The Solution stage solves all equilibrium equations and output selected in the Pre-Processing stage. The Post-Processing stage displays all results selected in the Pre-Processing stage. 


\subsubsection{Nonlinear Statics Solution}

Like most structural models in engineering, there is some degree of nonlinear behavior in both of the ROPS developed in this research. In order to account for this, I$\mathrm{DEAS}^{\mathrm{TM}}$ offers a Nonlinear Statics Solver that examines geometric or material nonlinear behavior or a combination of both. Due to the high strain levels and displacements under static loading, the Nonlinear Statics Solution became the apparent choice. In addition, the Nonlinear Statics Solution allows loadings to be applied over time, which can not be done as easily with other methods.

The fundamentals of finite element methods are based upon the Principle of Virtual Work (PVW). The PVW is a tool for establishing equilibrium and the basis for analytical mechanics and is used by I-DEAS ${ }^{\mathrm{TM}}$. The PVW states a deformable body is in equilibrium when and if the total virtual work of the real external forces and moments are equal to the virtual work of the real internal stresses when subjected to any virtual displacements. In equation form, the PVW is represented as follows:

$$
\delta W=\delta W_{e}+\delta U=0
$$

or as:

$$
\delta U=\delta W_{e}
$$

The above equation can be simplified further as

$$
U=W_{e}
$$


where: $\quad U$ is the strain energy of the elements

and $W_{e}$ is the work done by external forces acting on the elements.

Equation 4.3 can be rewritten if integrated over the volume of the model as

$$
\int_{\text {Volume }}\{\varepsilon\}^{T}\{\sigma\} d V=\left\{d_{i}\right\}^{T}\left\{F_{i}\right\}+\int_{\text {Sufface }}\{d\}^{T}\left\{f_{S}\right\} d S+\int_{\text {Volume }}\{d\}^{T}\left\{f_{B}\right\} d V
$$

The left side of the equation 4.4 is the internal strain energy due to the virtual displacement integrated over the volume. The right side of equation 4.4 is the external virtual work which is point loads, surface loads, and body forces.

In order to obtain the finite element equilibrium equations, the model must first be separated into a set of finite elements and discrete nodal points. The displacements are calculated directly at the nodes. In order to obtain forces and displacements at any place in the body or on the surface of the body from a set of nodal values, the interpolation matrix $[\mathrm{N}]$ is needed. $[\mathrm{N}]$ is also called the shape or displacement function matrix, and it is made up of a set of continuous element interpolation functions. The compatibility matrix $[\mathrm{B}]$ is the derivative of the interpolation function matrix and is important in forming the finite element equilibrium equation. This explanation yields:

$$
\sum_{\text {Element Volume }} \int[B]^{T}\{\sigma\} d V_{e}=\left\{F_{i}\right\}+\sum_{\text {Element Sufface }} \int_{[}[N]^{T}\left\{f_{\text {Sufface }}\right\} d S_{e}+\sum_{\text {Element Volume }} \int[N]^{T}\left\{f_{\text {Body }}\right\} d V_{e}
$$


where the integrals are individually evaluated over each element and summed to formed a set of global equations.

Residual forces are next used by I-DEAS ${ }^{\mathrm{TM}}$ to solve nonlinear models. I-DEAS ${ }^{\mathrm{TM}}$ uses residual forces to measure how much the solution current state has deviated from the initial equilibrium state. The residual force:

$$
\{R\}=\left\{F_{i}\right\}+\sum_{\text {Element }} \int_{\text {Surface }}[N]^{T}\left\{f_{\text {Surface }}\right\} d S_{e}+\sum_{\text {Element }} \int_{\text {Volume }}[N]^{T}\left\{f_{\text {Body }}\right\} d V_{e}-\sum_{\text {Element }} \int_{\text {Volume }}[B]^{T}\{N\} d V_{e}
$$

The entire nonlinear analysis in I-DEAS ${ }^{\mathrm{TM}}$ can be either an iterative procedure or use the sparse matrix solver (the default solver in $\mathrm{I}-\mathrm{DEAS} \mathrm{S}^{\mathrm{TM}}$ ). In the iterative procedure, the tolerances for convergence of a solution and number of iterations for each time step can be specified by the user. In the sparse matrix solver, the tolerances and number of iterations for each time step are defaulted. The user's choice is dependent upon accuracy and solving time. For the case of both ROPS, the sparse matrix solver was used.

For both ROPS, the equilibrium equations were solved at various time steps. The time steps were defined in the load history, and I-DEAS ${ }^{\mathrm{TM}}$ does not proceed past a time step to the next unless the convergence criteria is met in the set number of iterations. Also if the solution is diverging, the solution process will be terminated.

\section{$\underline{\text { 4.2.3 Yield Criteria }}$}

The stresses for plastic deformation are calculated in I-DEAS ${ }^{\mathrm{TM}}$ by using the Von Mises Plastic Yield Function (Equation 4.7).

$$
\sigma_{y}=\sqrt{\frac{1}{2}\left[\left(\sigma_{1}-\sigma_{2}\right)^{2}+\left(\sigma_{2}-\sigma_{3}\right)^{2}+\left(\sigma_{3}-\sigma_{1}\right)^{2}\right.}
$$


The yield function is a surface in a six-dimensional stress space and makes a distinction between the elastic and inelastic zones. The elastic zones are the points that lie on the inside of the yield surface while the inelastic zones are made up of the points that lie on outside of the stress surface (see Figure 4.4).

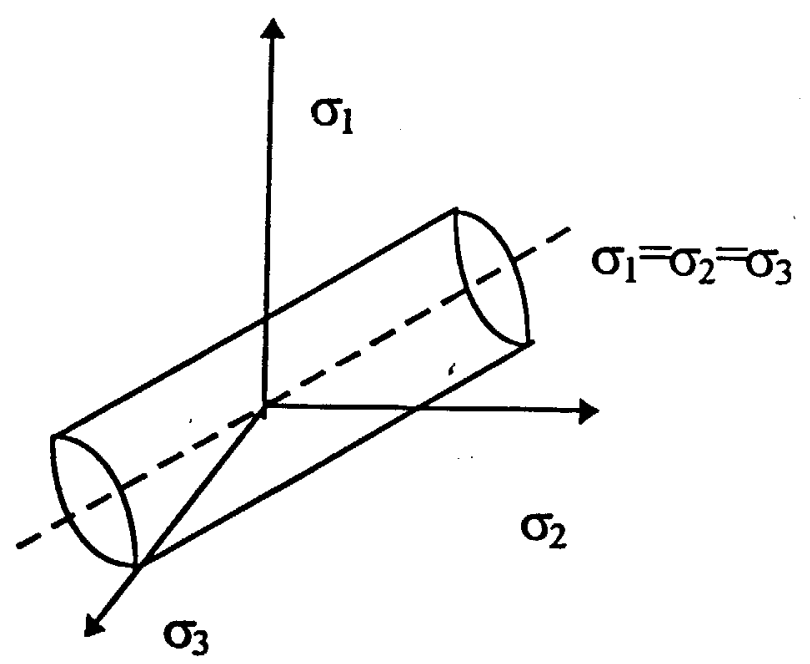

Figure 4.4. Von Mises Yield Surface

The Von Mises Plastic Yield Function is one of the two choices the user has for material nonlinearity in the physical properties table. In I-DEAS ${ }^{\mathrm{TM}}$, the default setting for plasticity is the no plasticity option. The user must always change it so that plasticity is taken into account when dealing with a nonlinear material.

\subsubsection{Hardening Rules}

The hardening rules are very important to the solution of a FEM in I-DEAS ${ }^{\mathrm{TM}}$, because they determine how a model will behave after yielding. Isotropic hardening, the type of hardening used in both ROPS models, assumes the yield surface expands uniformly due to plastic straining. The isotropic hardening is achieved by utilizing a piece-wise linear stress-strain curve. 


\subsubsection{Uniaxial Stress-Strain Data}

In addition to yield criteria and hardening rules, the engineering stress-strain data of the material being used is very important in allowing the model to behave in the same manner as an experimental test. It should be noted the greater the number of data points used on the stress-strain curve, the more closely the model will follow the actual deformation of an experimental test. The points that are entered should dictate the stressstrain curve for both the elastic and plastic areas of the curve. The first points to be entered should be for the yield strain and stress respectively. The rest of the points should represent the plastic area of the curve up to where the slope of the curve is at or near zero. All data points are entered into a table that produces a plot that the user can examine.

\section{$\underline{\text { 4.2.6 Boundary Conditions }}$}

The boundary condition sets for both ROPS models are made up of restraint and load sets. All restraint and loads sets are made up individually and then combined and put in a boundary condition set. The restraint sets were made up by fixing nodes at the base of each lower post of the ROPS. The restraint type used is classified as a "clamp", and does not allow rotation or movement in any direction. This creates a "fixed-end" condition in each post, which is the desired restraint of the base of a ROPS on a tractor axle.

The load sets were made up by applying a single load over a certain number of nodes with respect to time. Time and magnitude of the load were taken into account by creating a time variable curve that allows the user to plot time and load magnitude throughout all different types of loading. This was especially important in allowing loads 
to be applied to a maximum value and then backed off over time back to zero in accordance with the SAE J2194 Standard. This process was repeated until all loads had been applied with respect to time. Once all load sets were created, they were then combined to create a single load set with respect to time. Tables 4.4 and 4.5 show the loading configurations for each ROPS while Figures 4.5 and 4.6 illustrate methods of restraint and application of load sets.

Table 4.4. Simulated Load Sets for Original ROPS.

\begin{tabular}{|c|c|}
\hline Load Type & Load Set \# \\
\hline First Longitudinal & 1 \\
\hline Side Transverse & 2 \\
\hline Second Longitudinal & 3 \\
\hline
\end{tabular}

Note: Load Set 4 is the combination of Load Sets 1, 2, \& 3.

Table 4.5. Simulated Load Sets for Optimized ROPS

\begin{tabular}{|c|c|}
\hline Load Type & Load Set \# \\
\hline First Longitudinal & 1 \\
\hline Side Transverse & 2 \\
\hline Vertical Crush & 3 \\
\hline Second Longitudinal & 4 \\
\hline
\end{tabular}

Note: Load Set 5 is the combination of Load Sets 1, 2, 3, \& 4. 


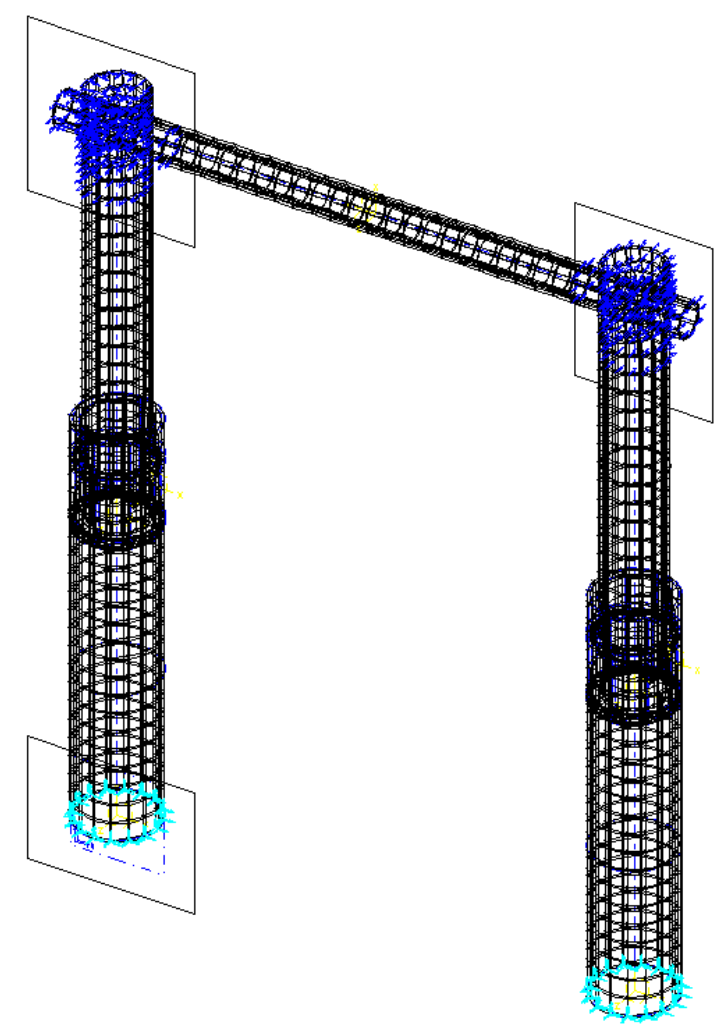

(a)

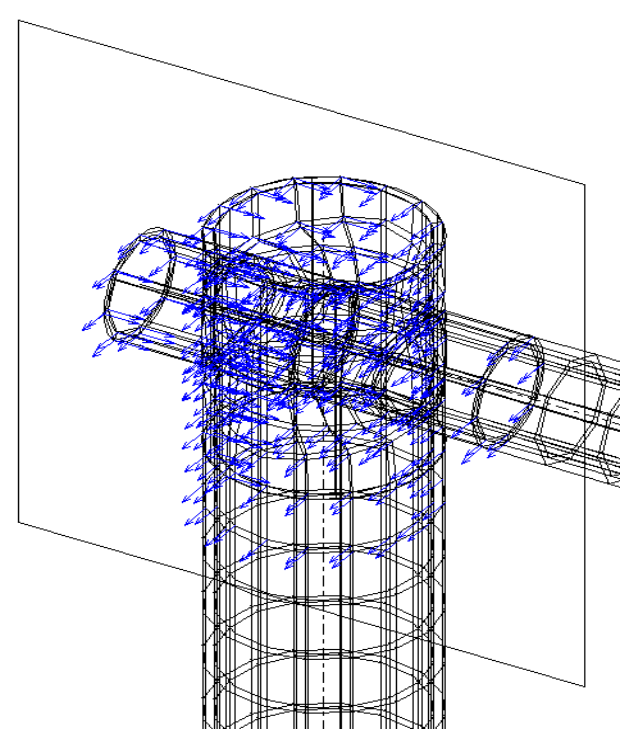

(c)

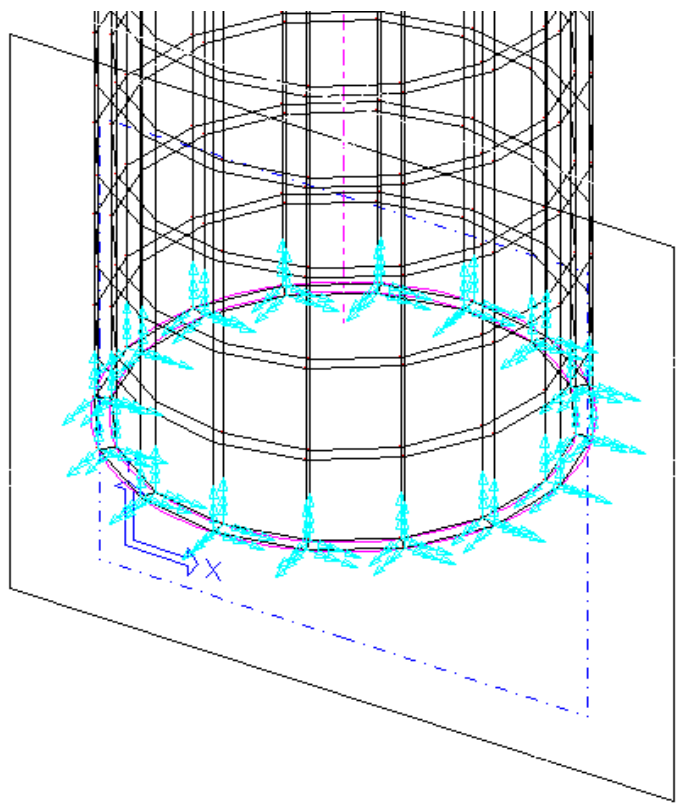

(b)

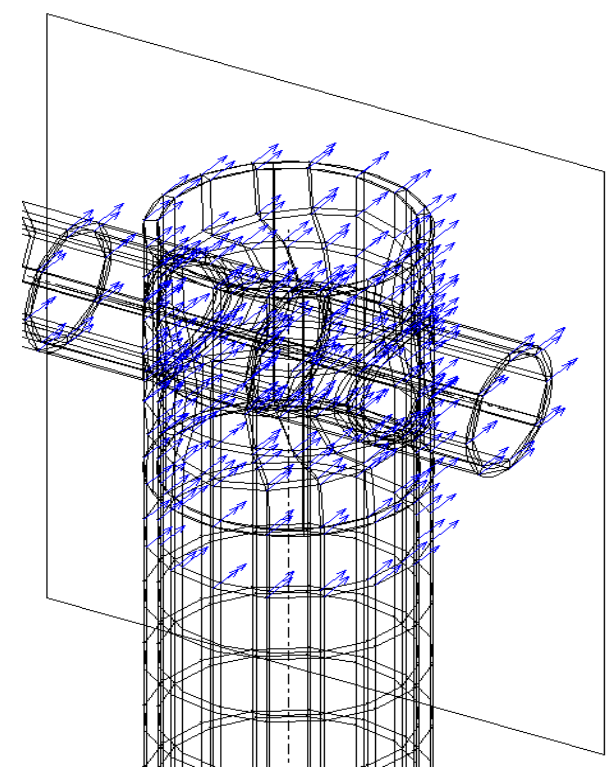

(d)

Figure 4.5. Load and Restraint Conditions for Original ROPS. (a) shows the complete load and restraint sets. (b) shows the fixed restraints at the base of the lower post. (c) shows the first longitudinal and side transverse loading configuration. (d) shows the second longitudinal loading configuration. 


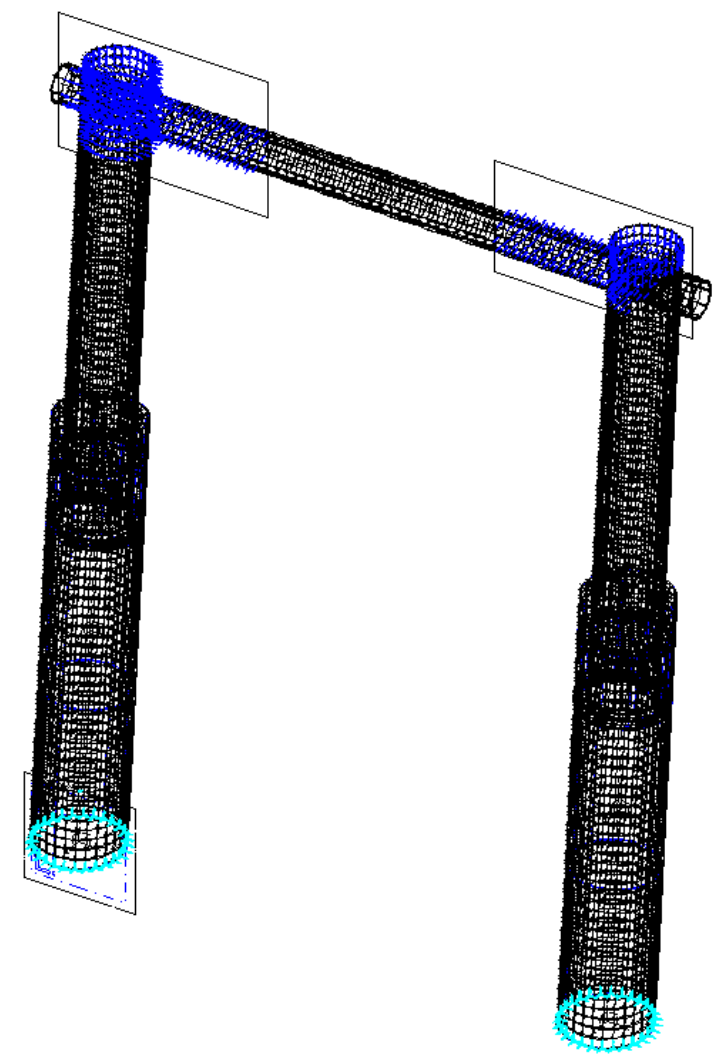

(a)

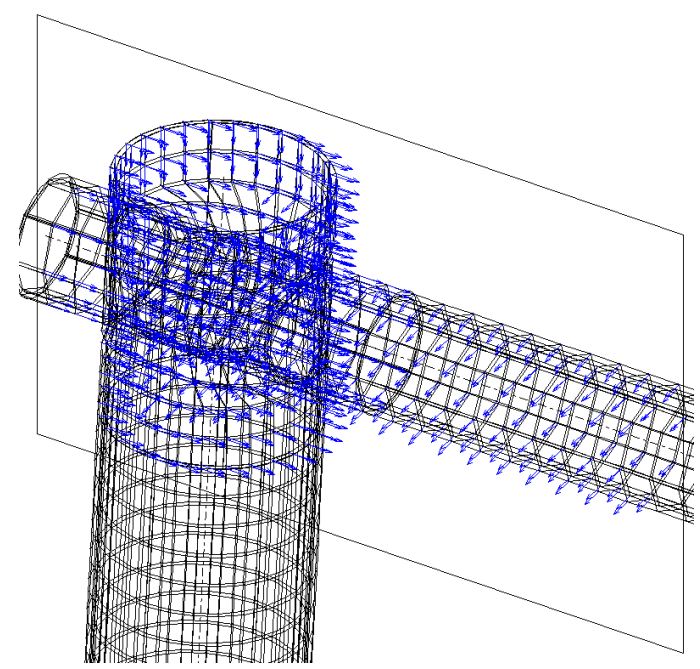

(c)

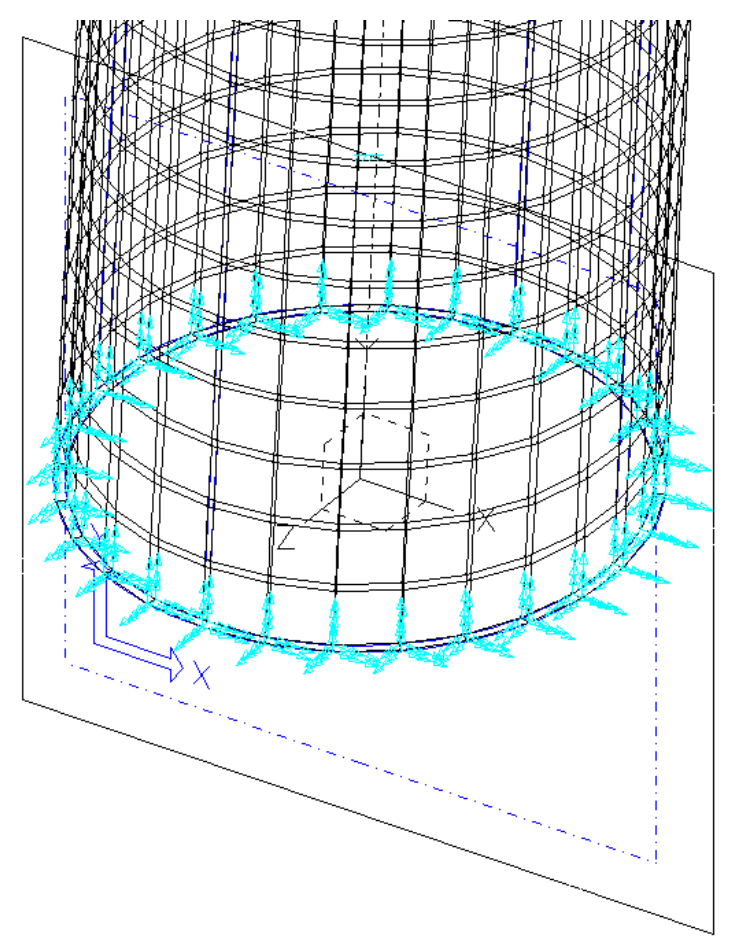

(b)

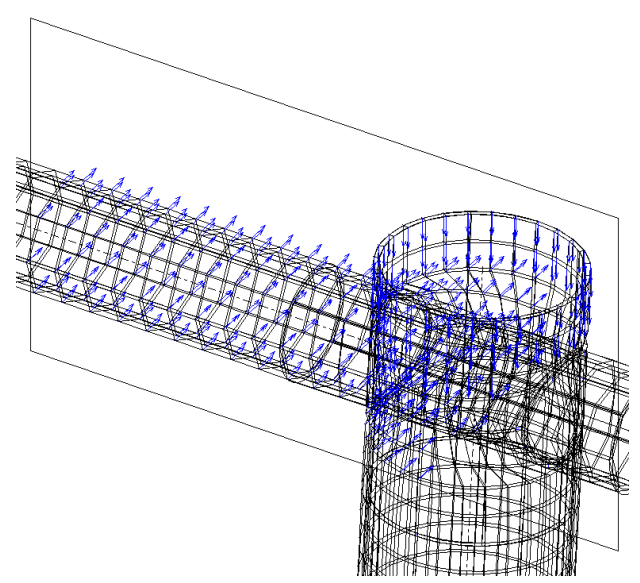

(d)

Figure 4.6. Load and Restraint Conditions for Optimized ROPS. (a) shows the complete load and restraint sets. (b) shows the fixed restraints at the base of the lower post. (c) shows the first longitudinal and side transverse loading configuration as well as the vertical crush loading. (d) shows the second longitudinal loading configuration as well as the vertical crush loading. 


\subsubsection{Finite Element Meshes}

The finite element mesh is a crucial part of any FEM. There are certain characteristics that define an acceptable mesh. Some of these characteristics are the element type, relative distortion of the elements, and aspect ratio of the elements. The type of elements used in all models this research pertains to were solid 3-dimensional elements. These types of elements have 8 nodes and 6 faces and resembles to a certain degree a cube.

The relative distortion of each element is a ratio that measures how much the shape of the element is distorted from having 4 orthogonal corners on each of the 6 faces on an ideal element. The higher the value of the distortion ratio ( 1 being the max), the more accurate the results. The benchmark for acceptability in the models for this research was a 0.7 . The overwhelming majority of elements in both models were found acceptable. The very small relative number of elements that did not satisfy the distortion criteria were in places of low stress.

The aspect ratio, which is the ratio of the largest sizes of a 3D element to the smallest size, must not be too large. This ratio is also important not to be too small due to causing an increased and often too large number of elements when using limited computer capabilities. It is important to find the limit where the accuracy of the results is within reason and acceptance. The aspect ratio for both FEM in the design and research performed was approximately $6 \times 6 \times 1$. Chapter 5 will explain how this number was deemed to be acceptable.

Some other important parameters of any finite element mesh are the Material and Physical Properties Tables. While a model is solving, both of these tables are cross- 
referenced to dictate how the model will behave. It was necessary to input the material data for all of the materials used in both models. Material data includes the elastic modulus, poisson's ratio, shear modulus as well as the uniaxial stress-strain data. The Physical Properties Table dictates how the uniaxial stress-strain data is used in formulating a solution for the model. The Physical Properties Table defines such criteria as the yield function and the hardening rule to be used among other criteria depending upon the type of elements being used. The uniaxial stress-strain plots for both materials used can be see in Figures 4.7 and 4.8 .

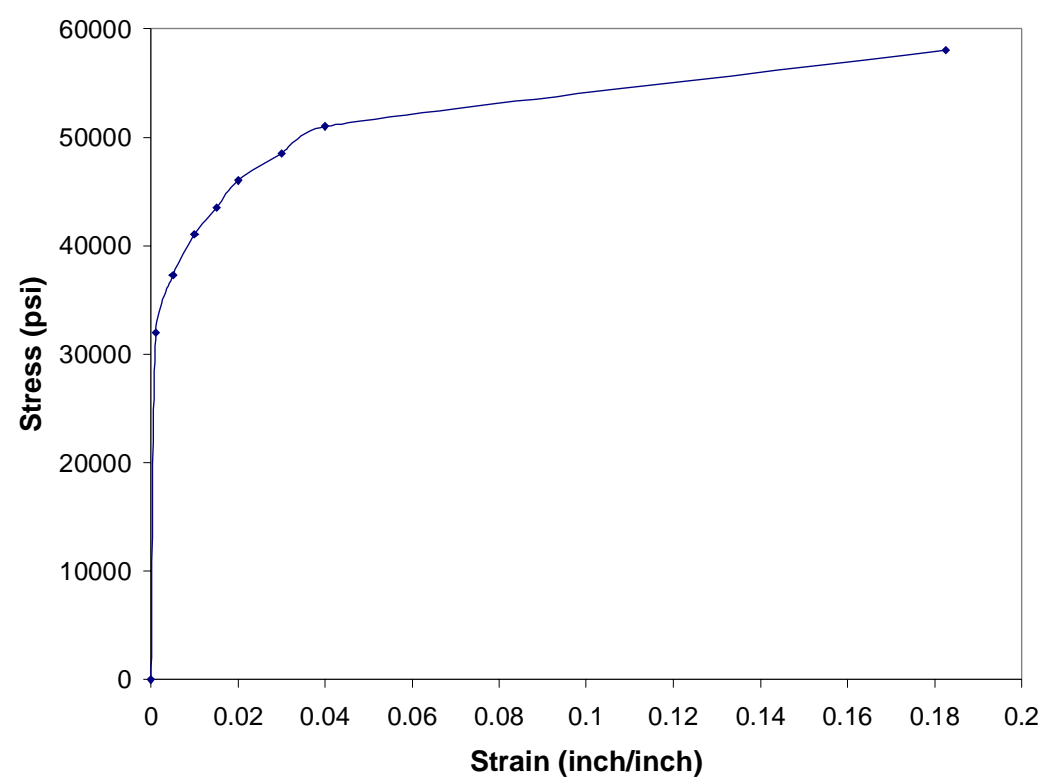

Figure 4.7. HR 1018 Steel Stress-Strain Plot. 


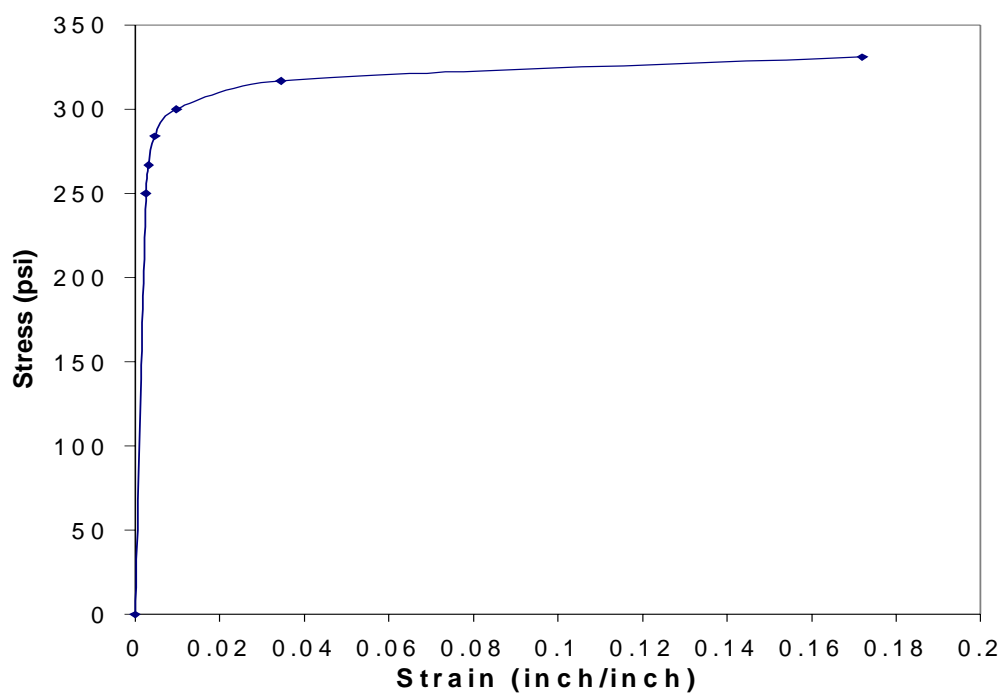

Figure 4.8. Filler Material Stress Strain Plot

It should be noted the 'Filler Material' was used to fill in the gap of air between the outside edge of the piston and inside the wall of the lower tube as well as the outside edge of the upper post near the cap and inside the wall of the cap. It is a generic material that is made up only to allow the interaction of upper and lower tubes in this area to occur freely.

\subsubsection{Solution Set and Control}

The solution control controls whether the solution is a linear or nonlinear solution. The solution control is also responsible for determining how and when the model is loaded. To accomplish a nonlinear solution, the "Loading and Solution Control" icon must first be accessed and set to the user's desires.

The "Loading and Solution Control" icon allows the user to determine whether the solution will be a material nonlinear solution or geometric nonlinear solution or both. This icon also gives the user the choice of saving the restart data. This allows the user to 
restart the model in the event it "crashes" before the solution was completed due to an error once the error was corrected. Restart data was not saved due to it greatly increasing the run time for a solution. Other important features of this icon allow the user to determine whether the stress stiffening feature will be used in the solution as well as whether plasticity or creep will be considered. For the models in this research, stress stiffening was not used and plasticity was considered as opposed to creep.

Other features of this icon are the solution time points. This determines at what times of the loading the user would desire results and the particular types of results (Stress, Strain, Strain Energy, Deflections, etc.) the user desires as output data. The last important feature of this icon allows the user to choose the type of nonlinear solving method and the tolerance for convergence as well as the number of iterations for each solution point. For the models in this research, the solving method was based on energy, the tolerance for convergence was 0.005 , and the number of iterations for each solution point was 20 .

The second icon to be accessed for a nonlinear solution is the "Options" icon. This icon allows the user to select the type of control for loading and starting the solver as well as the whether the type of solver used is a sparse matrix or iterative. For the models in this research, the general "Load Control" was used along with "Restart (Initial Run)" since restart data was not saved. The "Sparse Matrix" solver was used due to its faster run time for a solution.

The "Options" icon is also where a 'hypermatrix file' is created. This file will save all results selected by the user up to the point where the model "crashes" in the event 
that occurs. This file does not allow the user to restart the model at the point it "crashes" but does provide some aid in helping to get a complete solution.

The third and final icon to be accessed for a nonlinear solution is the "Boundary Conditions" icon. This allows the user to select the desired boundary condition set and ensure the boundary condition set selected is made up of proper load, contact, temperature, kinematic degree of freedom, and restraint sets. 


\section{Chapter 5}

\section{COMPARISON OF I-DEAS ${ }^{\mathrm{TM}}$ TO EXPERIMENTAL RESULTS CONCERNING ORIGINAL PROTOTYPE DEPLOYABLE ROPS}

\section{$\underline{5.1 \text { Introduction }}$}

In order to use I-DEAS ${ }^{\mathrm{TM}}$ to optimize the original prototype deployable ROPS, it must first be proven the original ROPS can be successfully modeled so as to give accurate results when compared to the experimental results. This will be shown by comparing strains obtained through experimental testing (See Figures 3.12, 3.13, and 3.14) and those found in a FEM.

\subsection{FEM Mesh of Original ROPS}

The first step taken to optimize the original prototype deployable ROPS was to construct a FEM of the original ROPS. The goal was to use the least number of elements possible in the FEM and still be able to give analytical strain and deflection results that could be matched against the already collected experimental data.

The initial model constructed was made up of elements that had an aspect ratio of 2 $\mathrm{X} 2 \mathrm{X} 1$. The drawback of using this aspect ratio was the amount of CPU time required for the model to solve. Given the large number of elements (over 13,000) and nodes (over 29,000), the model took over 4 days of CPU time to solve so as to get strain and deflection data for the 3 loadings placed on the original ROPS. In addition to the long 
solving time periods, the speed of operations in I-DEAS ${ }^{\mathrm{TM}}$ of the user when dealing with such a large model was at times almost at a standstill.

It was then decided that the aspect ratio had to be increased to decrease solving time and increase the speed at which the user could work with the model. This was also done because when the time for optimizing came about, it was known more elements and nodes would be used compared to the original ROPS with the same aspect ratio. This was due to a decreased wall thickness going from 0.25 inch for the original ROPS to a thickness that would ultimately be smaller in the optimized ROPS.

This model of the original ROPS with a $2 \times 2 \times 1$ aspect ratio gave strains that matched the experimental data very well, but the deflections were not as accurate. The deflections in every type of loading were smaller in the FEM than in the experimental results. It was then realized the rotation of the entire supports that had occurred during experimental testing while small in value would definitely account for the difference (This will be explained in Section 5.4).

The aspect ratio of the elements was then changed to $4 \times 4 \times 1$. The strain and deflection data matched the data from the experimental tests as before. There were minute differences on lower strain values but the model's results on high strain values were very comparable. This model still took approximately 1.5 days to solve and the computer speed to work with the model was not much faster than before.

For these reasons it was decided to try an aspect ratio of $6 \times 6 \times 1$. This lead to a massive reduction of the number of elements and nodes in the model. There were a total of 2,320 elements for this model (see Figure 5.1). This model also had an increased solving time to approximately 7 hours and allowed the speed at which the user could 
construct and work on the model to improve dramatically. The results of the model for some of the lower strain values were slightly different than those models with smaller aspect ratios but the higher strain values were still accurate. The accuracy of this model was deemed to be acceptable (This will be explained further in Section 5.3). It should also be noted that FEM of ROPS with higher aspect ratio have yielded accurate results when compared to experimental test data.

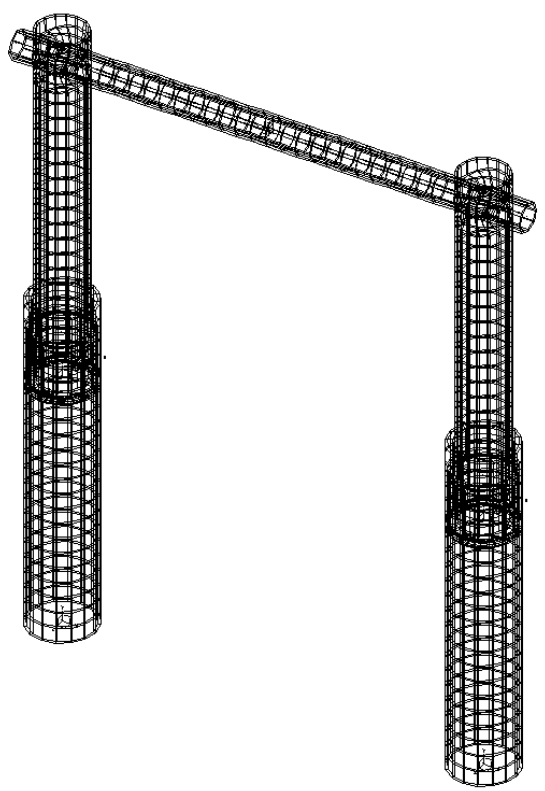

(a)

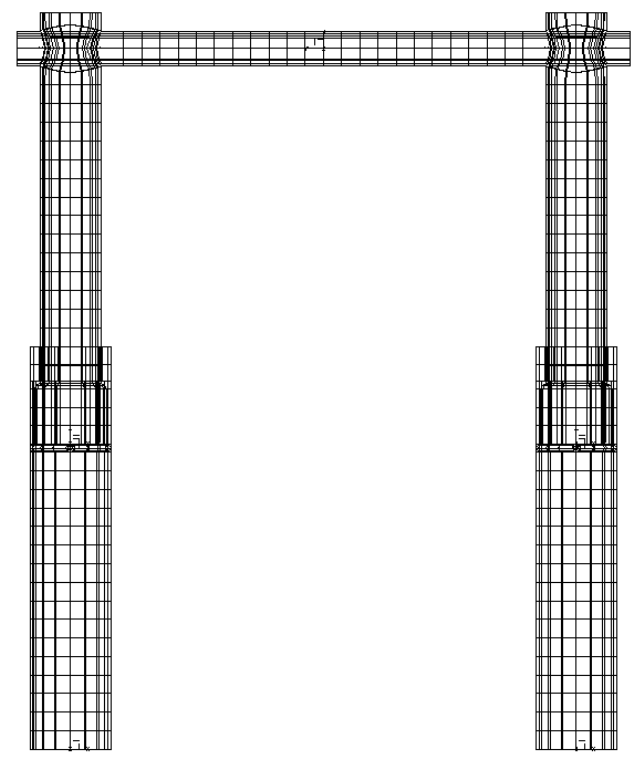

(b)

Figure 5.1. Mesh of Original Deployable ROPS in (a) Isometric View (b) an X-Y View. 


\subsection{Comparison of Experimental and Analytical Strains for Original ROPS}

The experimental strain results (See Figures 3.12, $3.13 \& 3.14$ ) were the result of data collection for 4 strain gages positioned in a ring approximately 2 inches above the base plate of the ROPS (See Figures 3.10 and 3.11). The four gage locations were on the planes of maximum tension and compression and on the neutral axis. Table 5.1 shows a comparison of the maximum experimental strains and the strains obtained from the IDEAS $^{\mathrm{TM}}$ model of the original ROPS.

Table 5.1 Experimental and Analytical Strain Comparison for Original Deployable ROPS.

\begin{tabular}{|c|c|c|c|}
\hline $\begin{array}{c}\text { Load } \\
\text { Description }\end{array}$ & $\begin{array}{l}\text { Strain } \\
\text { Gage }\end{array}$ & $\begin{array}{c}\text { Maximum Experimental } \\
\text { Strain } \\
\text { (micro-strain) }\end{array}$ & $\begin{array}{c}\text { Maximum Analytical } \\
\text { Strain } \\
\text { (micro-strain) }\end{array}$ \\
\hline \multirow{4}{*}{$\begin{array}{c}\text { First } \\
\text { Longitudinal }\end{array}$} & LR1 - A & 1,600 & 1,620 \\
\hline & LR1 - B & -300 & -287 \\
\hline & LR1 - C & $-1,550$ & $-1,620$ \\
\hline & LR1 - D & 250 & 287 \\
\hline \multirow{4}{*}{$\begin{array}{c}\text { Side } \\
\text { Transverse }\end{array}$} & LR1 - A & 150 & 270 \\
\hline & LR1 - B & -450 & -485 \\
\hline & LR1 1 C & -150 & -270 \\
\hline & LR1 - D & 500 & 485 \\
\hline \multirow{4}{*}{$\begin{array}{c}\text { Second } \\
\text { Longitudinal }\end{array}$} & LR1 - A & -400 & -370 \\
\hline & LR1 - B & 80 & 150 \\
\hline & LR1 - C & 200 & 370 \\
\hline & LR1 - D & -80 & -150 \\
\hline
\end{tabular}


As can be seen in Table 5.1, the results from the I-DEAS ${ }^{\mathrm{TM}}$ model are very comparable to that of the experimental results. This is especially true for the higher strains (strains on the planes of maximum tension and compression sides of the ROPS for a particular loading). The deviation between the I-DEAS ${ }^{\mathrm{TM}}$ model and the experimental results for the higher strains was no greater than $7.78 \%$. The small differences in the higher strains and larger differences in the smaller stains (strains on the neutral axis) can be explained primarily by the fact the entire tractor and ROPS had to be repositioned and moved for each type of loading. As much effort as was given not to disturb the gages, it is likely the gages could have been affected to some degree each time the tractor had to be repositioned.

\subsection{Comparison of Experimental and Analytical Deflections for Original ROPS}

The deflections from the model in I-DEAS ${ }^{\mathrm{TM}}$ did not match the experimental results as closely as the strains (see Table 5.2). This can be attributed to the small rotation of the support blocks (See Figure 3.8) that occurred while the loads were being applied. The goal was to eliminate all rotation of the ROPS at the base of each lower post. This did not work as well as would have liked. There did occur some small rotation on every load.

Table 5.2. Experimental and Analytical Deflection Comparison for Original Deployable ROPS.

\begin{tabular}{|c|c|c|}
\hline $\begin{array}{c}\text { Load } \\
\text { Description }\end{array}$ & $\begin{array}{c}\text { Maximum Experimental Deflection } \\
\text { (inch) }\end{array}$ & $\begin{array}{c}\text { Maximum Analytical Deflection } \\
\text { (inch) }\end{array}$ \\
\hline $\begin{array}{c}\text { First } \\
\text { Longitudinal }\end{array}$ & 4.35 & 1.11 \\
\hline $\begin{array}{c}\text { Side } \\
\text { Transverse }\end{array}$ & 2.25 & 0.39 \\
\hline $\begin{array}{c}\text { Second } \\
\text { Longitudinal }\end{array}$ & 3.24 & 0.58 \\
\hline
\end{tabular}


The rotation that occurred for the first longitudinal load and the second longitudinal was directly proportional to the magnitude of each load. For instance, the maximum load in the first longitudinal loading was 8,951 lbs., and the maximum load in the second longitudinal loading was 6,973 lbs. Comparing the experimental and analytical deflections for these two loadings, the difference in maximum deflections was 3.24 inch for the first longitudinal loading and 2.66 inch for the second longitudinal loading.

Each load was applied approximately 60.95 inch above the base plates on the ROPS. Using basic geometry of a right triangle, it can be determined the amount of rotation in the experimental first longitudinal loading was approximately 3.047 degrees (i.e. $\theta$ First Longitudinal Load $=\sin ^{-1}(3.24 / 60.95)=3.047$ degrees $)$. It can be also be determined the amount of rotation in the experimental second longitudinal loading was approximately 2.501 degrees (i.e. $\theta$ Second Longitudinal Load $=\sin ^{-1}(2.66 / 60.95)=2.501$ degrees). The ratio of the amount of rotation to the applied load for the first longitudinal load is $3.404 *(10)^{-4}$ degrees of rotation / lb. (i.e. 3.047 degrees of rotation / $\left.8951 \mathrm{lbs} .=3.404 *(10)^{-4}\right)$. The ratio of the amount of rotation to the applied load for the second longitudinal load is $3.487 *(10)^{-4}$ degrees of rotation / lb. (i.e. 2.501 degrees of rotation / $6973 \mathrm{lbs} .=3.487 *$ $\left.(10)^{-4}\right)$.

Using the above method, the 1.86 inch difference in deflection between the experimental test and analytical model that occurred in the side transverse loading can also be explained. The load was again applied at 60.95 inch above the base plate of the ROPS. Knowing this, it can be concluded the amount of rotation for the side transverse loading was approximately 1.749 degrees (i.e. $\theta$ Side Transverse Load $=\sin ^{-1}(1.86 / 60.95)=$ 1.749 degrees). The ratio of the amount of rotation to the applied load for the side 
transverse load is $1.923 *(10)^{-4}$ degrees of rotation / lb. (i.e. 1.749 degrees of rotation / 9094 lbs. $\left.=1.923 *(10)^{-4}\right)$.

The ratio of the amount of rotation to the applied load for the side transverse load is lower than the other ratios for the other types of loading. This ratio is about $55 \%$ compared to the ratios for the other types of loading. This is reasonable because this type of loading is in a different direction than the other loadings, and it has the advantage of using both support blocks to prevent rotation where the other loadings do not.

\section{$\underline{5.5 \text { Summary }}$}

This chapter has shown an accurate comparison between experimental strain and defection results and those obtained by using I-DEAS ${ }^{\mathrm{TM}}$. Any differences between experimental and I-DEAS ${ }^{\mathrm{TM}}$ have been accounted for and explained. In addition, the aspect ratio can further be shown to be acceptable by noting other FE research has been conducted on ROPS using a higher aspect ratio and lower tolerance for nonlinear convergence when using the same material and uniaxial stress-strain data (Brewer, 1996). 


\section{Chapter 6}

\section{THE OPTIMIZED DEPLOYABLE ROPS FEM}

\section{$\underline{6.1 \text { Introduction }}$}

There were two goals to meet in creating an acceptable FEM of the optimized deployable ROPS. The first goal was to make sure the designed ROPS could pass the static part of the SAE J2194 Standard. Second, it was important to show this optimized ROPS was at the limit of safety in passing the SAE J2194 Standard. For this chapter, limit of safety refers to stress levels found in the results of the model. The remainder of this chapter will demonstrate how these 2 goals were met.

\subsection{Selecting Tube Sizes for the Optimized Deployable ROPS}

The first step in selecting the proper tube sizes for the optimized ROPS was to examine the tube sizes used in the original ROPS. The majority of the members of the original ROPS were tubes with a 0.25 inch thickness. Therefore, it was decided the optimized ROPS would have all members use the same thickness.

It was also decided the outer radii of all members of the ROPS would remain the same due to the availability of sizes of tubing (see Tables 6.1 and 6.2 (Marks' Handbook, 1978)). This was done primarily because of the size restraints of the lower tube. It was necessary to keep the lower tube with an inner diameter that allows enough space to house the inner mechanisms of the ROPS so it is still deployable. This condition along with the availability of tube sizes eliminated the possibility of changing the outer radii of the upper posts. In addition, a drastic difference in outer radii between the lower posts 
and upper posts would not be practical, either aesthetically or in the best use of the design.

Table 6.1. Standard Sizes of Tubing

\begin{tabular}{|c|c|}
\hline $\begin{array}{l}\text { Standard Size of Tubing } \\
\text { (G or inch) }\end{array}$ & $\begin{array}{l}\text { Actual Thickness of Tubing } \\
\text { (inch) }\end{array}$ \\
\hline $20 \mathrm{G}$ & 0.035 \\
\hline $18 \mathrm{G}$ & 0.049 \\
\hline $17 \mathrm{G}$ & 0.058 \\
\hline $16 \mathrm{G}$ & 0.065 \\
\hline $14 \mathrm{G}$ & 0.083 \\
\hline $13 \mathrm{G}$ & 0.095 \\
\hline $12 \mathrm{G}$ & 0.109 \\
\hline $11 \mathrm{G}$ & 0.120 \\
\hline $10 \mathrm{G}$ & 0.134 \\
\hline $5 / 32$ & 0.156 \\
\hline $3 / 16$ & 0.188 \\
\hline $7 / 32$ & 0.219 \\
\hline $1 / 4$ & 0.25 \\
\hline
\end{tabular}

Note: G denotes Gage.

Table 6.2. Availability of Tubing by Outer Diameter.

\begin{tabular}{|c|c|}
\hline $\begin{array}{c}\text { Outer Diameter Range } \\
\text { (inch) }\end{array}$ & $\begin{array}{c}\text { Increments in Range } \\
\text { (inch) }\end{array}$ \\
\hline 2.5 to 3.5 & 0.125 \\
\hline 3.5 to 7.5 & 0.25 \\
\hline 7.5 to 10 & 0.5 \\
\hline
\end{tabular}


With the aforementioned type of strategy and referring to Table 6.1, it is apparent there were many different thicknesses to choose from that were less than the 0.25 inch wall thickness used in the original ROPS. The first attempt to optimize the ROPS was conducted using all members having a 7/32 inch wall thickness. The reason for this choice was to measure the magnitude of the stresses against the energy absorption of the ROPS to get an idea of how much more the wall thickness could be reduced.

It was initially believed the wall thickness could be reduced to a smaller thickness and still pass the SAE J2194 Standard, but it was important to have an acceptable optimized ROPS when judged against the Standard. The results of this test confirmed the initial beliefs. The ROPS did meet all energy and force requirements. The maximum stresses in the model were 53,000 psi, which occurred on the Second Longitudinal Loading.

The next step was to construct a model of the ROPS made of tubing with a 3/16 inch wall. This model of the ROPS was also acceptable to the criteria set by the SAE J2194 Standard, and the stress levels were again acceptable. The maximum deflections for the energy requirements and vertical crush load did in no way intrude upon the operator clearance zone. The stress levels, as well as the deflections, were slightly higher with the thickness of this model as opposed to the earlier model with a 5/32 inch thickness. Again, the maximum stress was found at the base of the lower tubes on the second longitudinal loading and was 54,500 psi.

Referring to Table 6.1, the next step was to construct a model of the ROPS made of tubing with a 5/32 inch wall. This model of the ROPS was also acceptable to the criteria set by the SAE J2194 Standard, and the stress levels were again acceptable. The 
maximum deflections for the energy requirements and vertical crush load did in no way intrude upon the operator clearance zone. The stress levels, as well as the deflections, were once again slightly higher with the thickness of this model as opposed to the earlier model with a $3 / 16$ inch thickness. The maximum stress was found at the base of the lower tubes on the side transverse loading and was 57,200 psi.

The next and what would prove to be the final step was to construct a model made of tubing with a $10 \mathrm{G}$ (or 0.134 inch) thickness. This model was found not acceptable due to higher than allowable stresses. For the transverse loading, the maximum stress was $69,100 \mathrm{psi}$ at the bases of lower posts and, at the same time, the energy criteria from the SAE J2194 Standard was not met. It should also be noted, the energy criteria for the first longitudinal loading and second longitudinal loading was met in this model, but the maximum stresses found in the second longitudinal loading were 63,300 psi which was also higher than allowable. In addition, the stresses found for the vertical crush load were $62,000 \mathrm{psi}$ at the base of the lower tubes of the ROPS, which was above the allowable limit.

The analytical Load-Deflection and Energy-Deflection curves for the different wall thicknesses for the three loadings can be seen in Figures 6.1,6.2, and 6.3. 


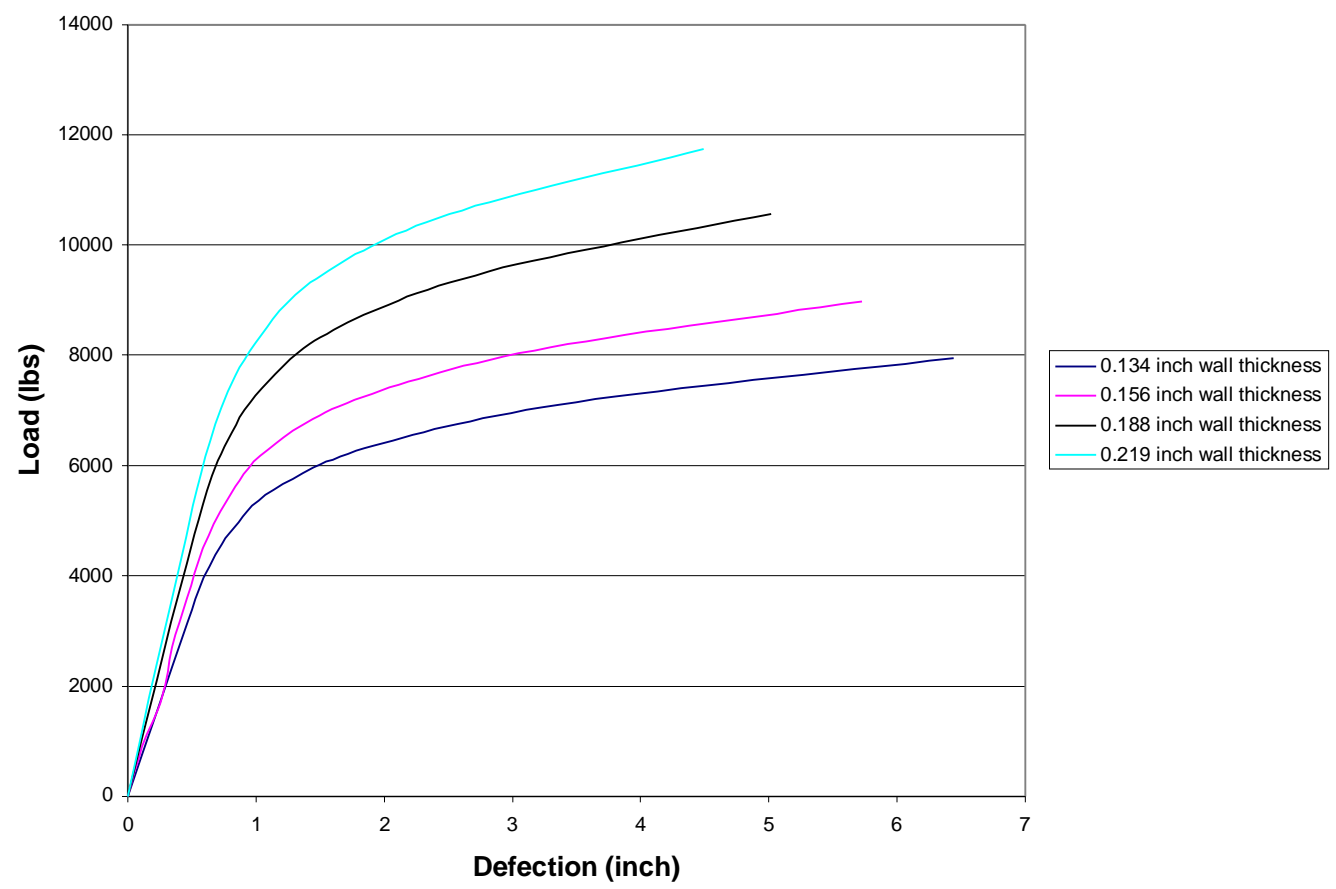

(a)

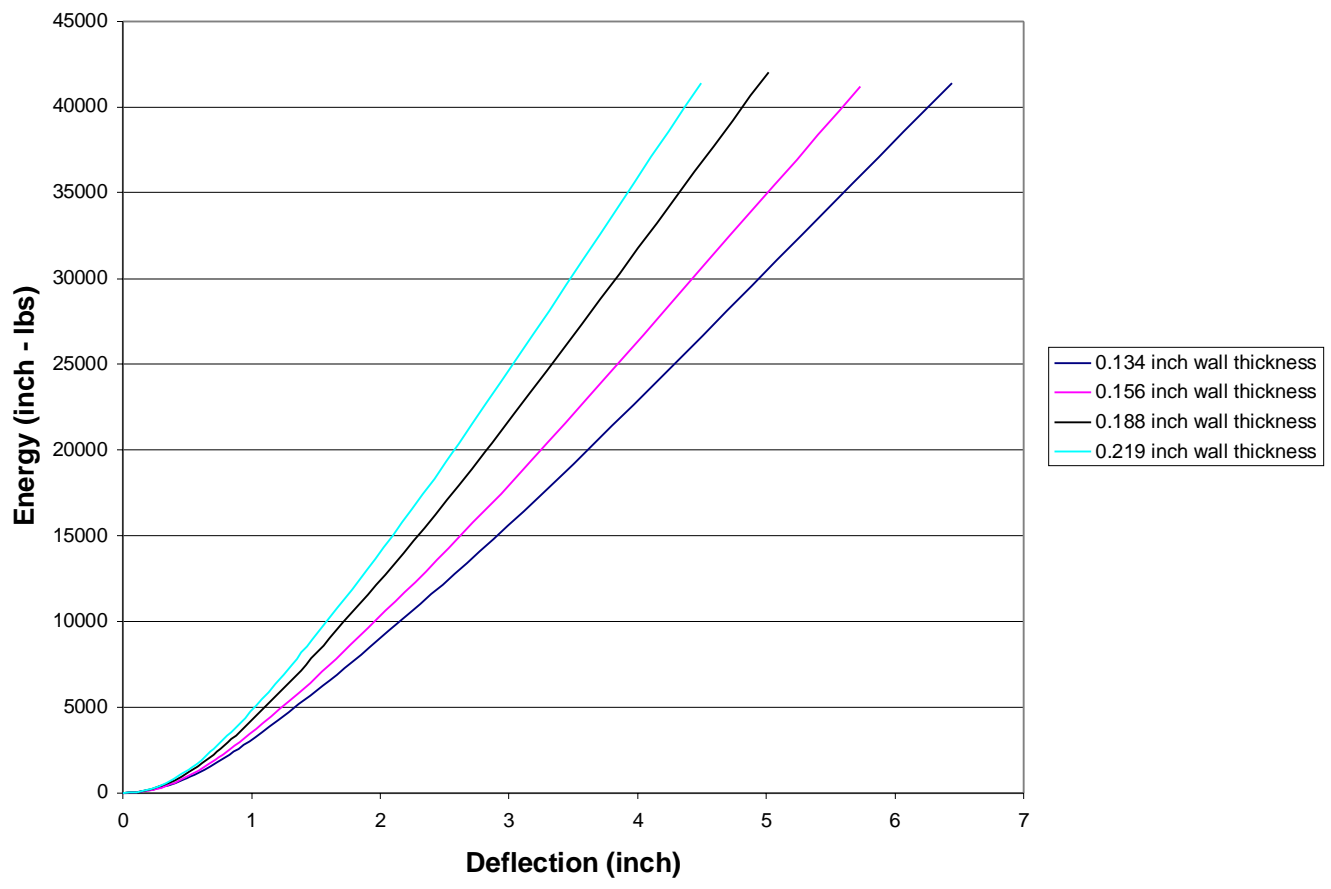

(b)

Figure 6.1. (a) Load - Deflection and (b) Energy - Deflection Curves For the First Longitudinal Loading For Different Wall Thicknesses. 

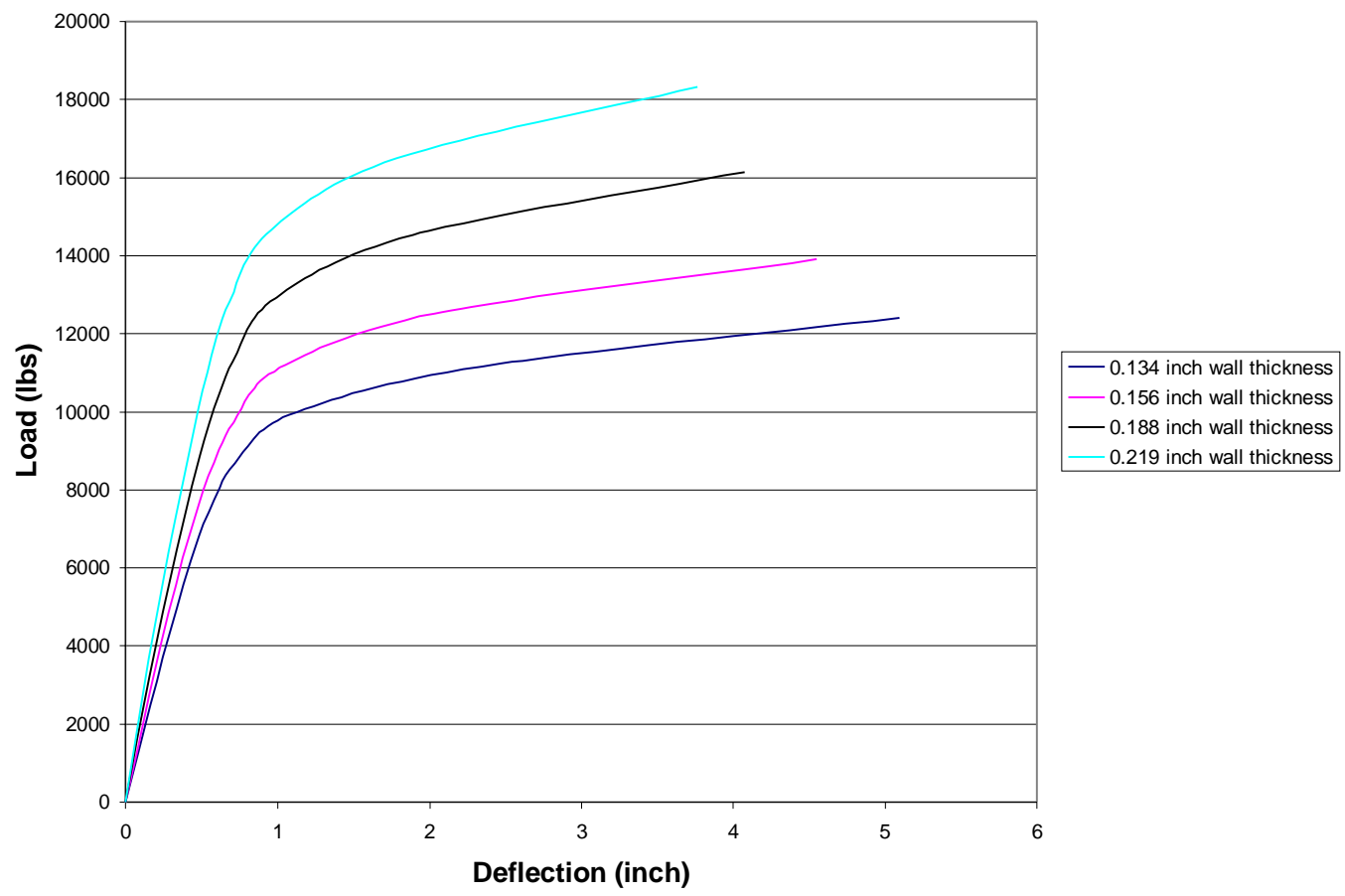

(a)
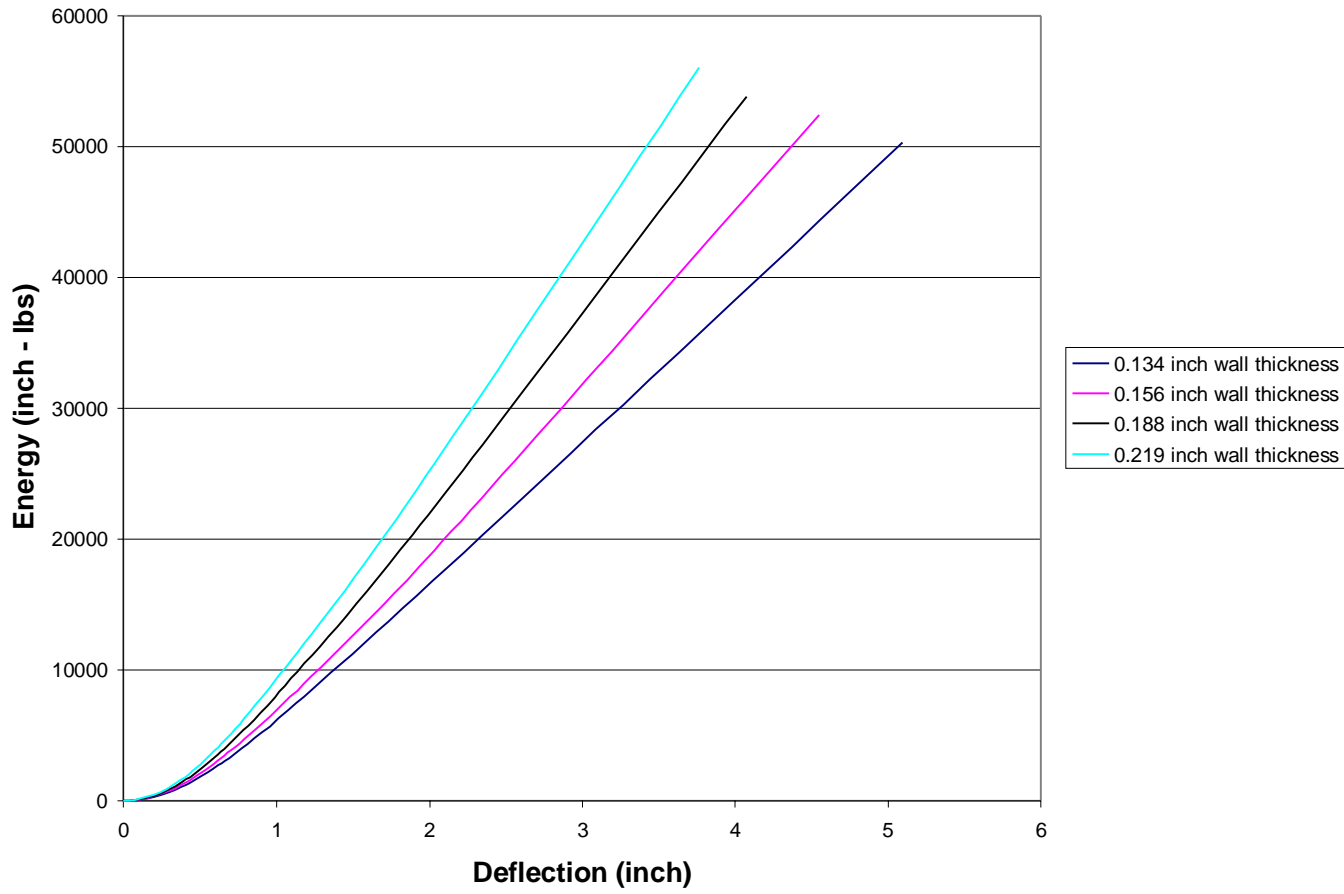

(b)

Figure 6.2. (a) Load - Deflection and (b) Energy - Deflection Curves For The Side Transverse Loading For Different Wall Thicknesses. 

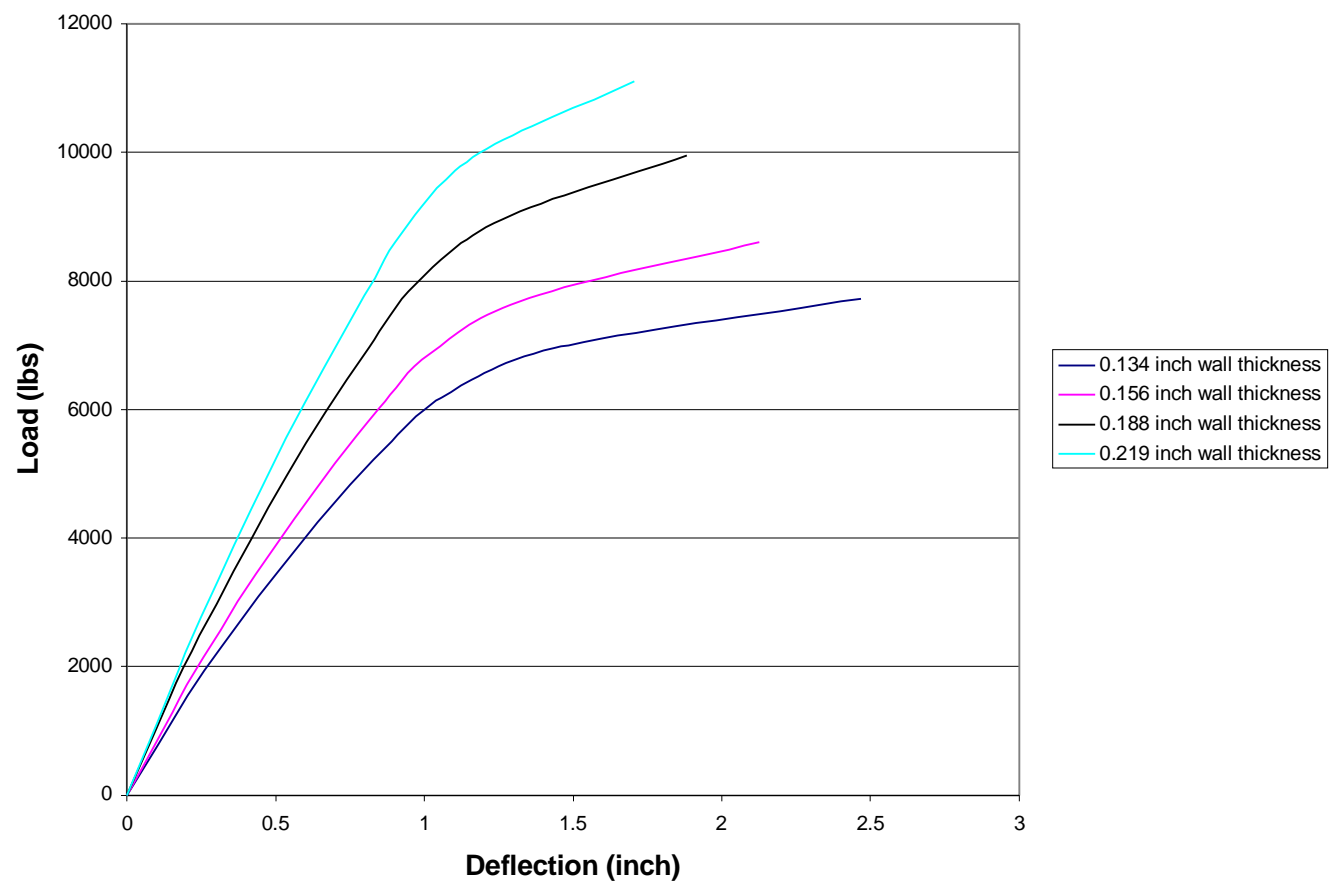

(a)
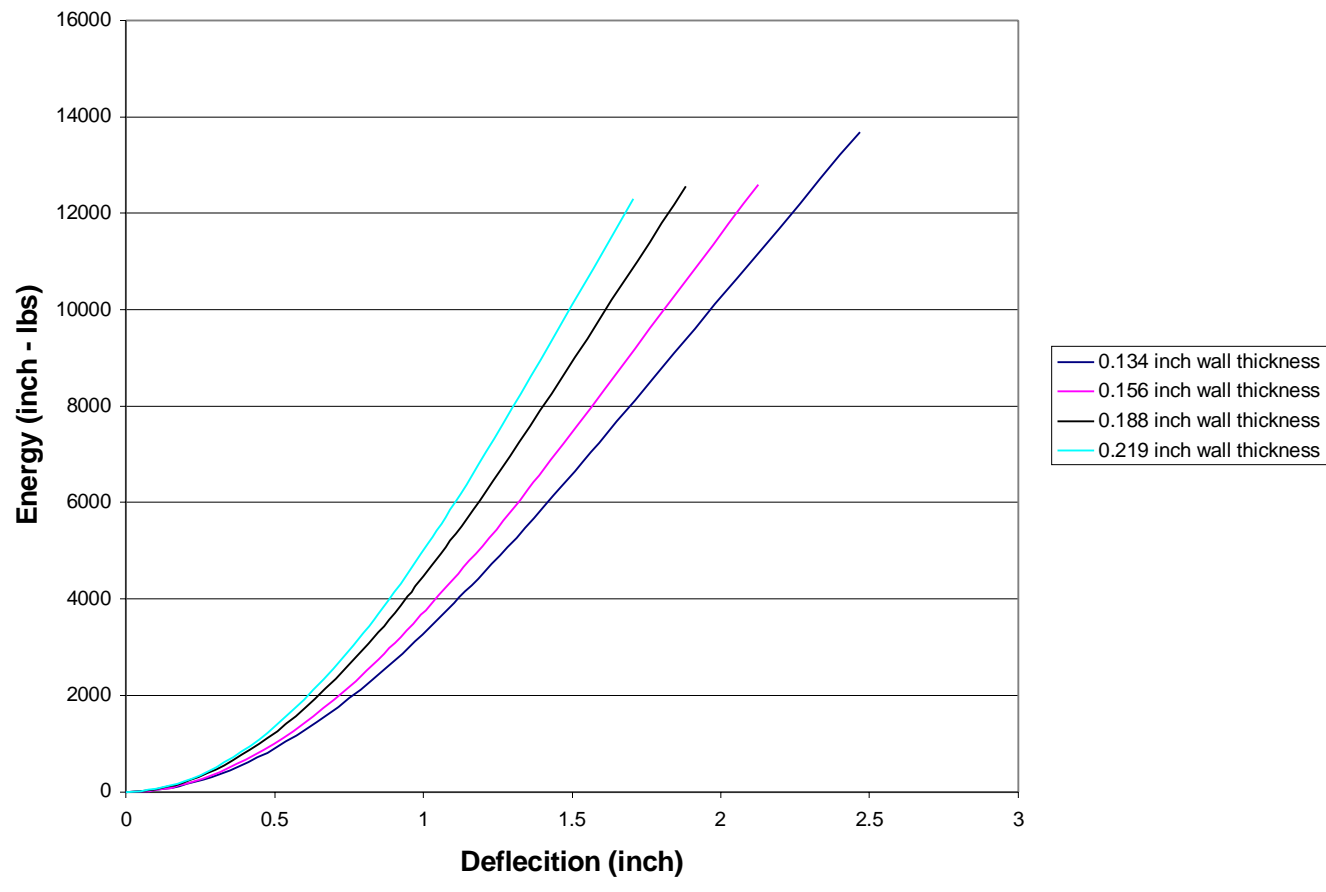

(b)

Figure 6.3. (a) Load - Deflection and (b) Energy - Deflection Curves For The Second Longitudinal Loading For Different Wall Thicknesses. 
Therefore, the conclusion was made to use the model with tubes having 5/32 inch wall thickness as the optimized deployable ROPS (see Figure 4.2 and Table for schematic and dimensions of the optimized deployable ROPS). The choice of this wall thickness for the optimized deployable ROPS resulted in this design requiring only approximately $69 \%$ of the material used in the original deployable ROPS.

This model was made of elements having an aspect ratio at no place in the entire ROPS larger than $5.84 \times 5.84 \times 1$. This aspect ratio is lower than the one used in the model of the original ROPS, therefore the results presented are acceptable. In specific locations such as near the latching mechanism (pins) and in the areas where the upper tubes meet the horizontal cross bar, the aspect ratio was lower. In total, there were 5,776 elements in the mesh. The run time for a solution was approximately $23 \mathrm{CPU}$ hours.

\subsection{Results of FEM of Acceptable Optimized ROPS}

This section will show the energy absorption and/or maximum stress levels of the ROPS for each of the four loading that are required for the SAE J2194 Standard. It will be seen through the load - deflection curves the ROPS does experience plastic deformation for each of the three energy requirement loadings. Energy - deflection curves will also be presented for the three energy requirement loadings. The sequence of loadings and unloadings for the entire model is presented in Figure 6.4. All loads were backed off in 50 percent increments per solution time point once the maximum load was reached. 


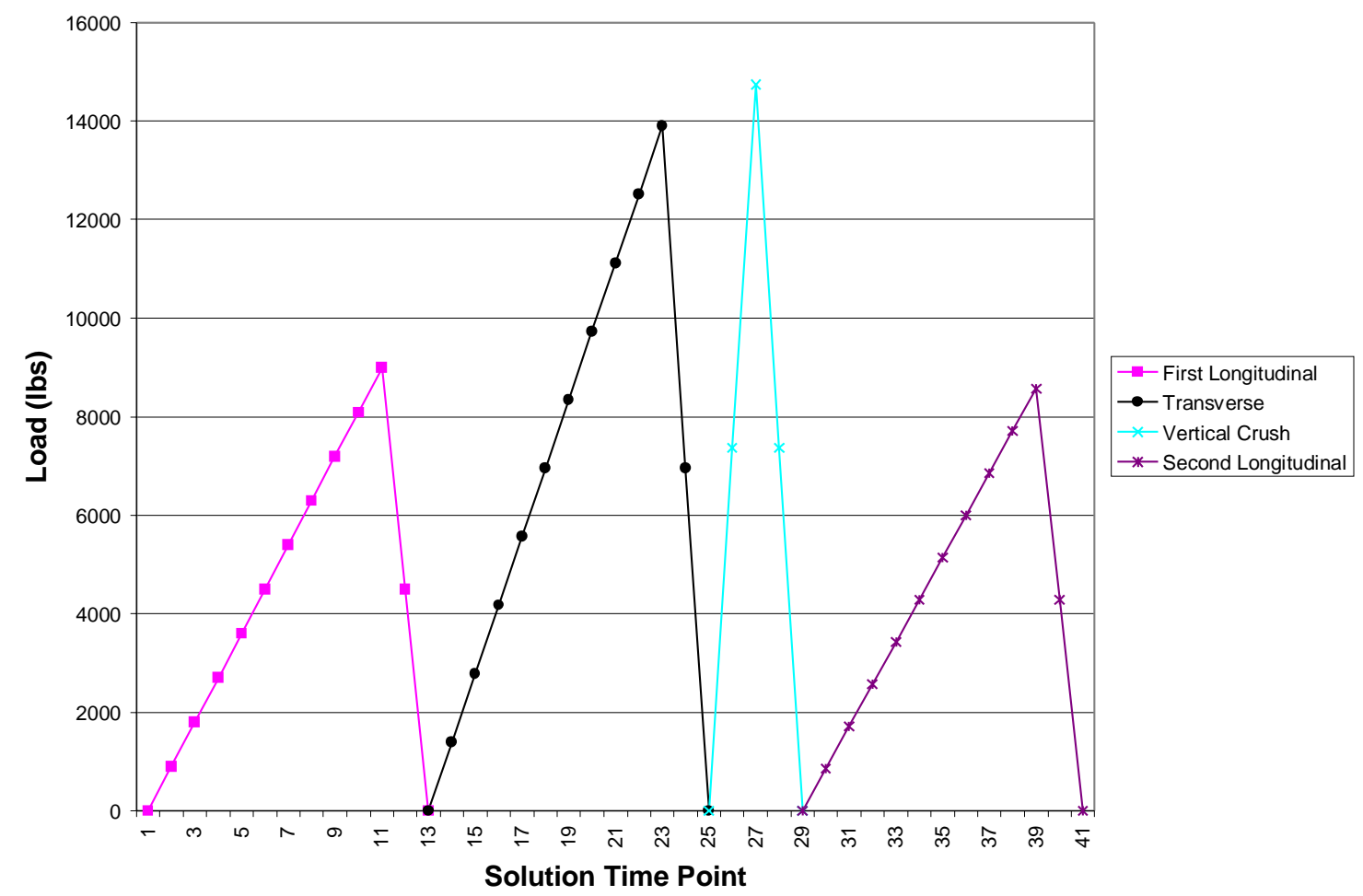

Figure 6.4. Time History of Loading in FEM of Optimized ROPS.

\subsubsection{First Longitudinal Loading Results}

This load was applied in 10 percent increments until a maximum load of 8,985 lbs. was reached. The energy requirement for this loading according to the SAE J2194 Standard is 40,617 inch - lbs, and the energy absorption for the ROPS for this loading was 41,200 inch - lbs. The Load - Deflection and Energy - Deflection plots can be seen in Figures 6.5 (a) and (b). The maximum stress found was at the bottom of the lower post on the side the load was applied and was 52,000 psi. The Optimized ROPS did not intrude on the Operator Clearance Zone during the First Longitudinal Loading. This can be seen in Figures 6.6 (a) and (b). 


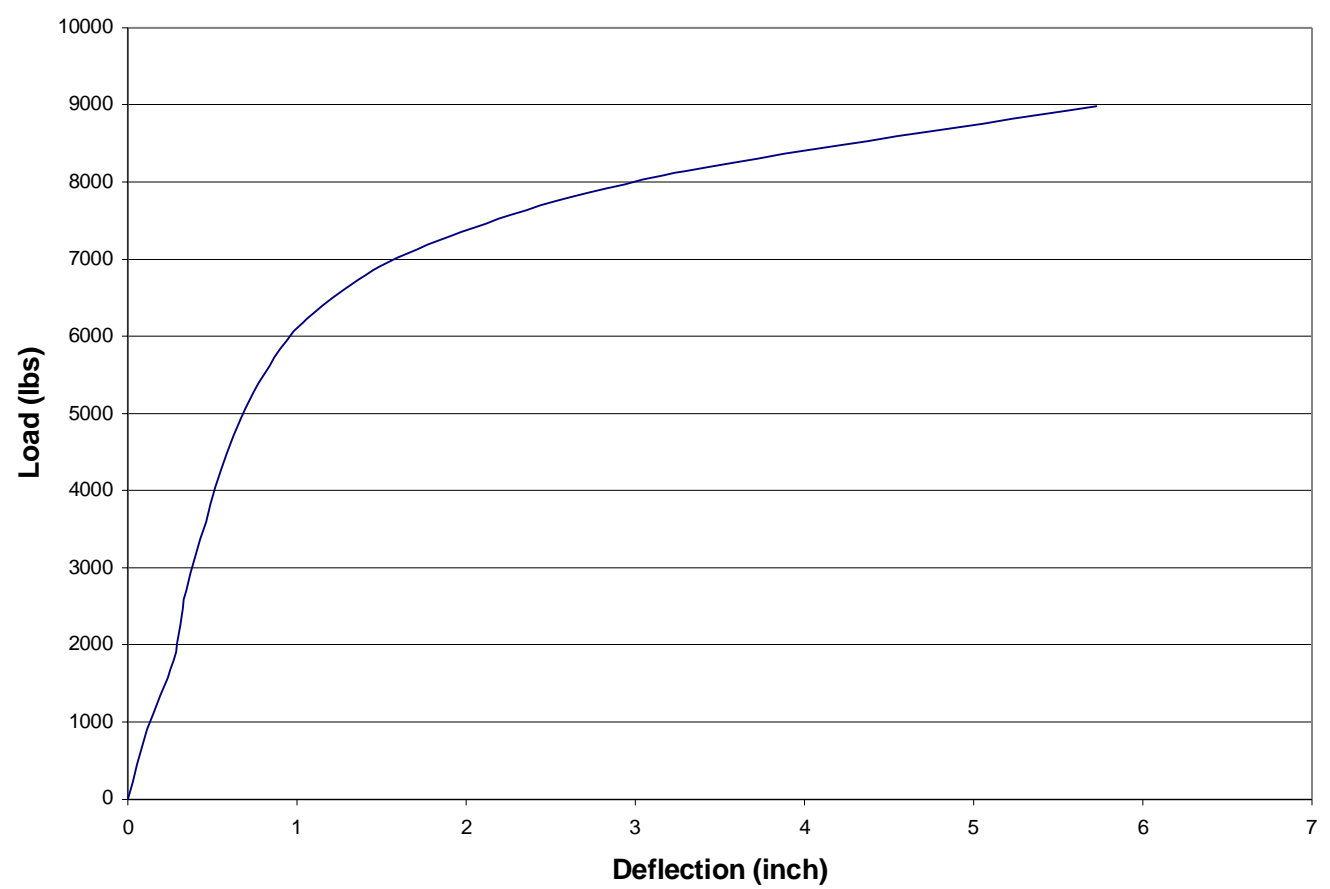

(a)

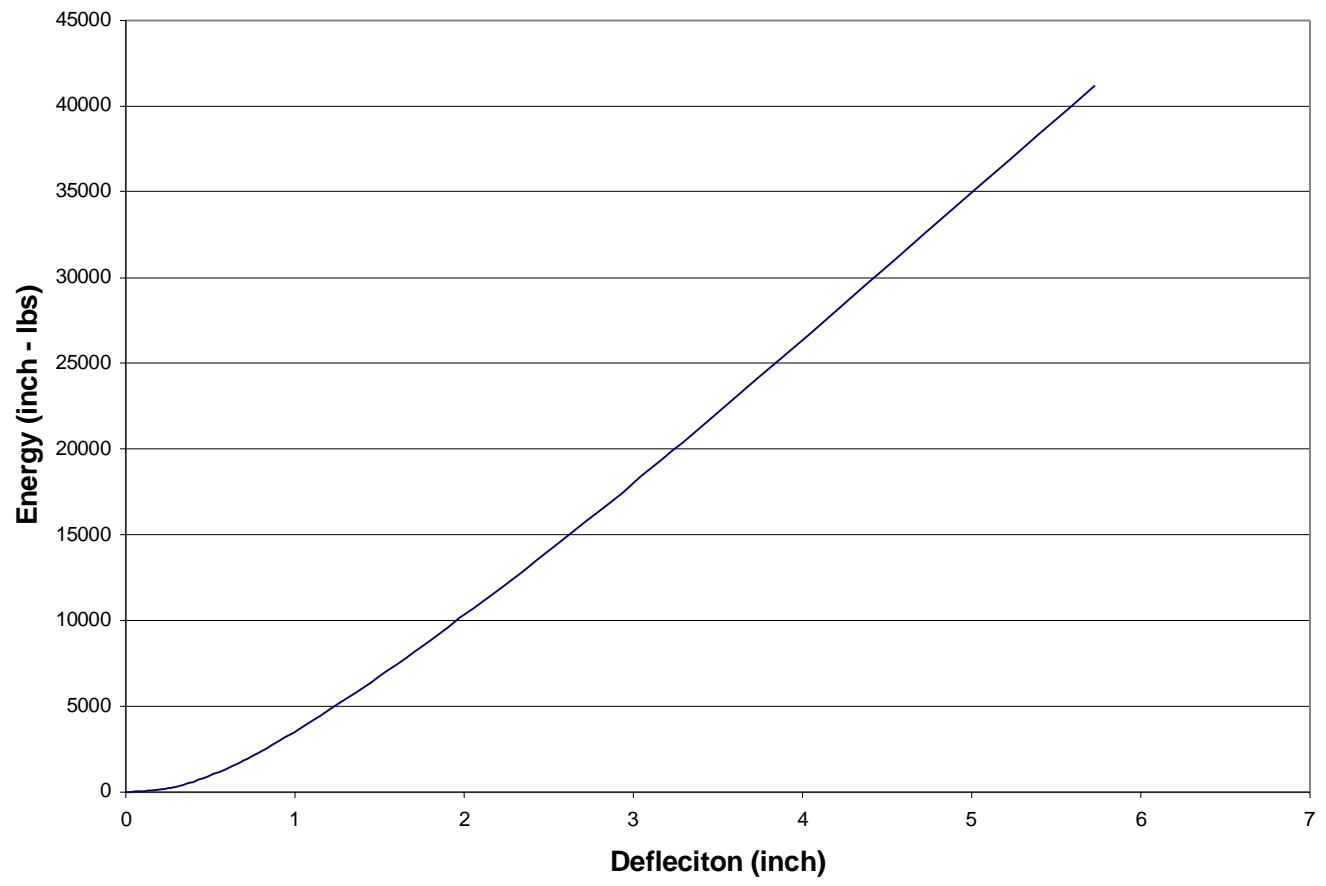

(b)

Figure 6.5. (a) Load - Deflection Curve and (b) Energy - Deflection Curve for the First Longitudinal Loading. 


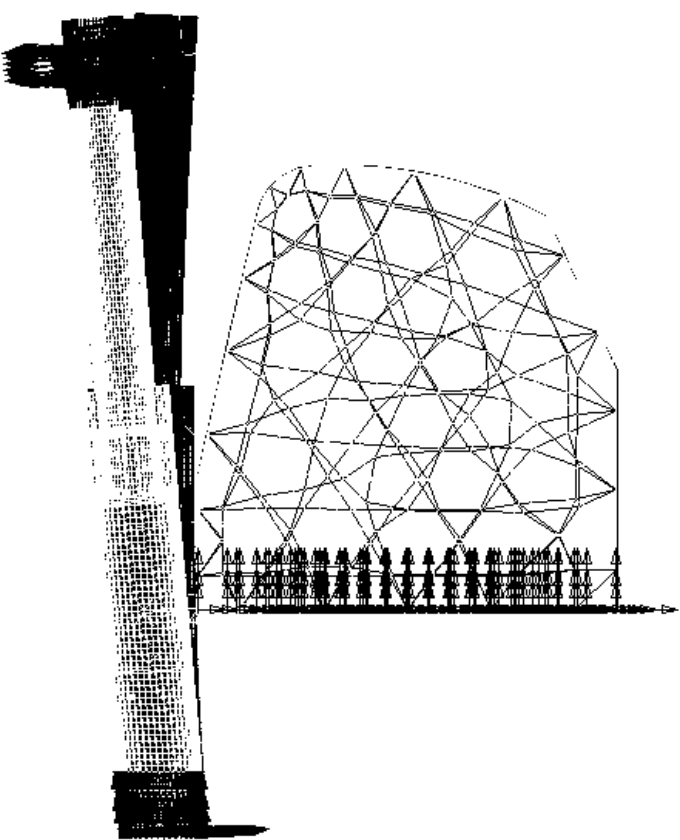

(a)

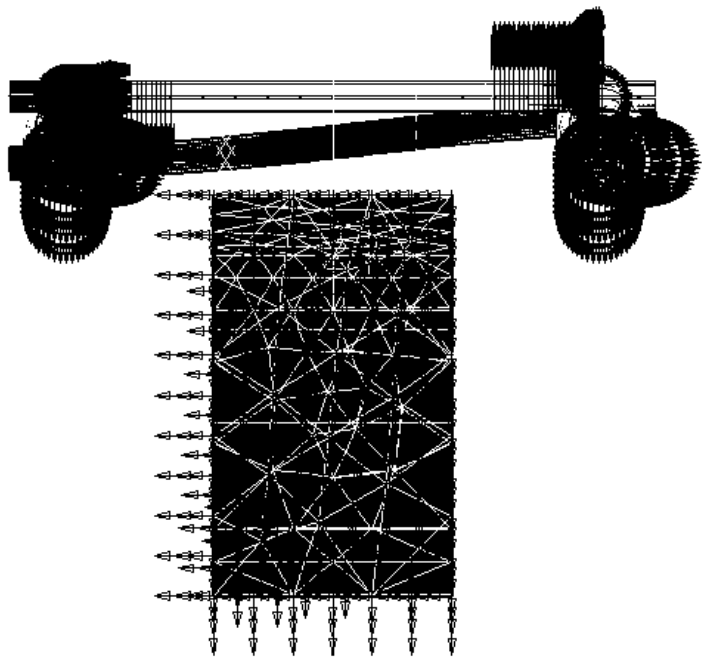

(b)

Figure 6.6. (a) Side View and (b) Top View of the Deformation of the Optimized ROPS with the Operator Clearance Zone during the First Longitudinal Loading.

\subsubsection{Side Transverse Loading Results}

This load was also applied in 10 percent increments until a maximum load of $13,900 \mathrm{lbs}$. was reached. The energy requirement for this loading according to the SAE J2194 Standard is 50,772 inch - lbs, and the energy absorption for the ROPS for this loading was 52,357 inch-lbs. The Load - Deflection and Energy - Deflection plots can be seen in Figures 6.7 (a) and (b). The maximum stress found was at the bottom of the lower post on the side the load was applied and was 57,200 psi. The Optimized ROPS did not intrude upon the Operator Clearance Zone during the Side Transverse Loading. This can be seen in Figures 6.8 (a) and (b). 


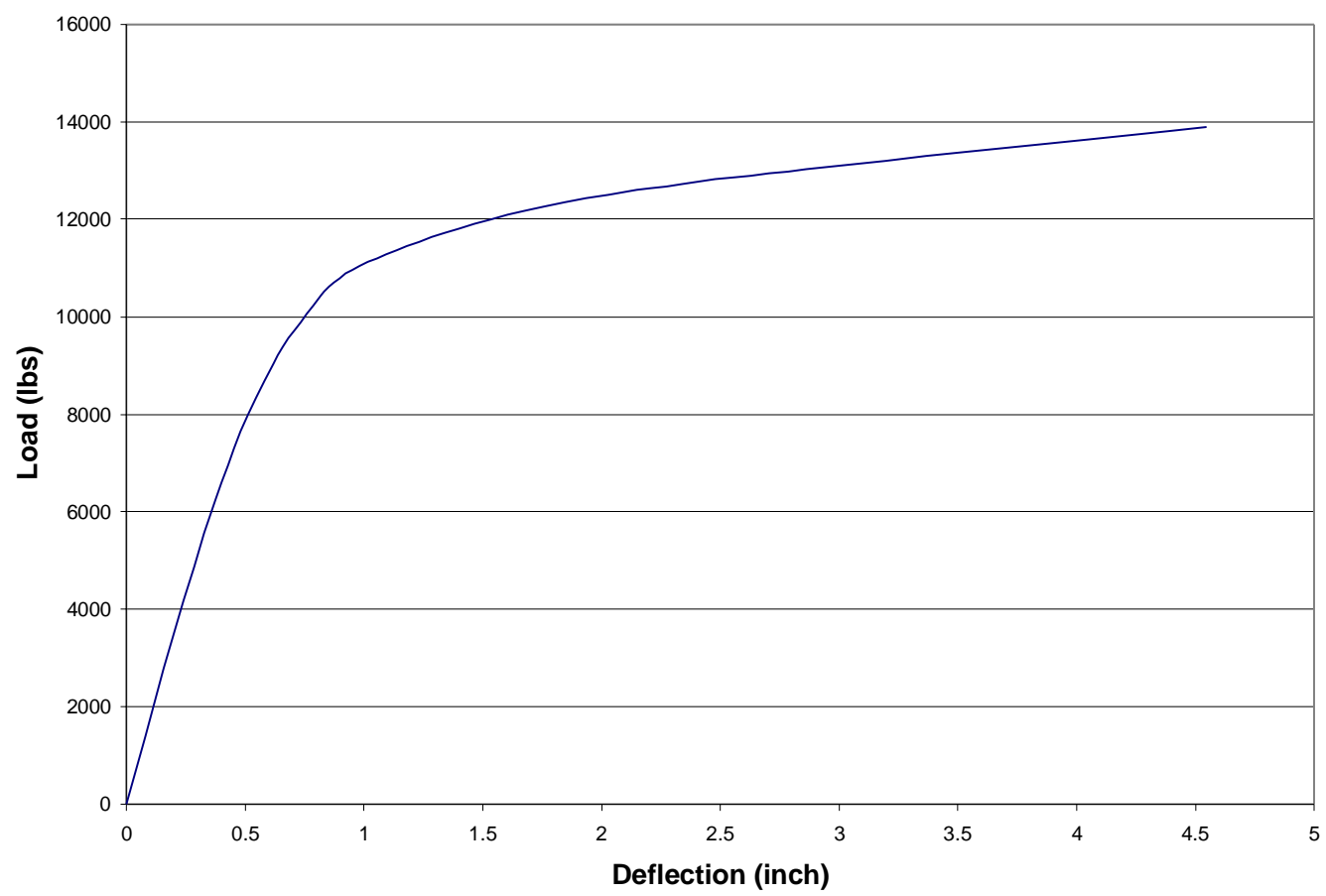

(a)

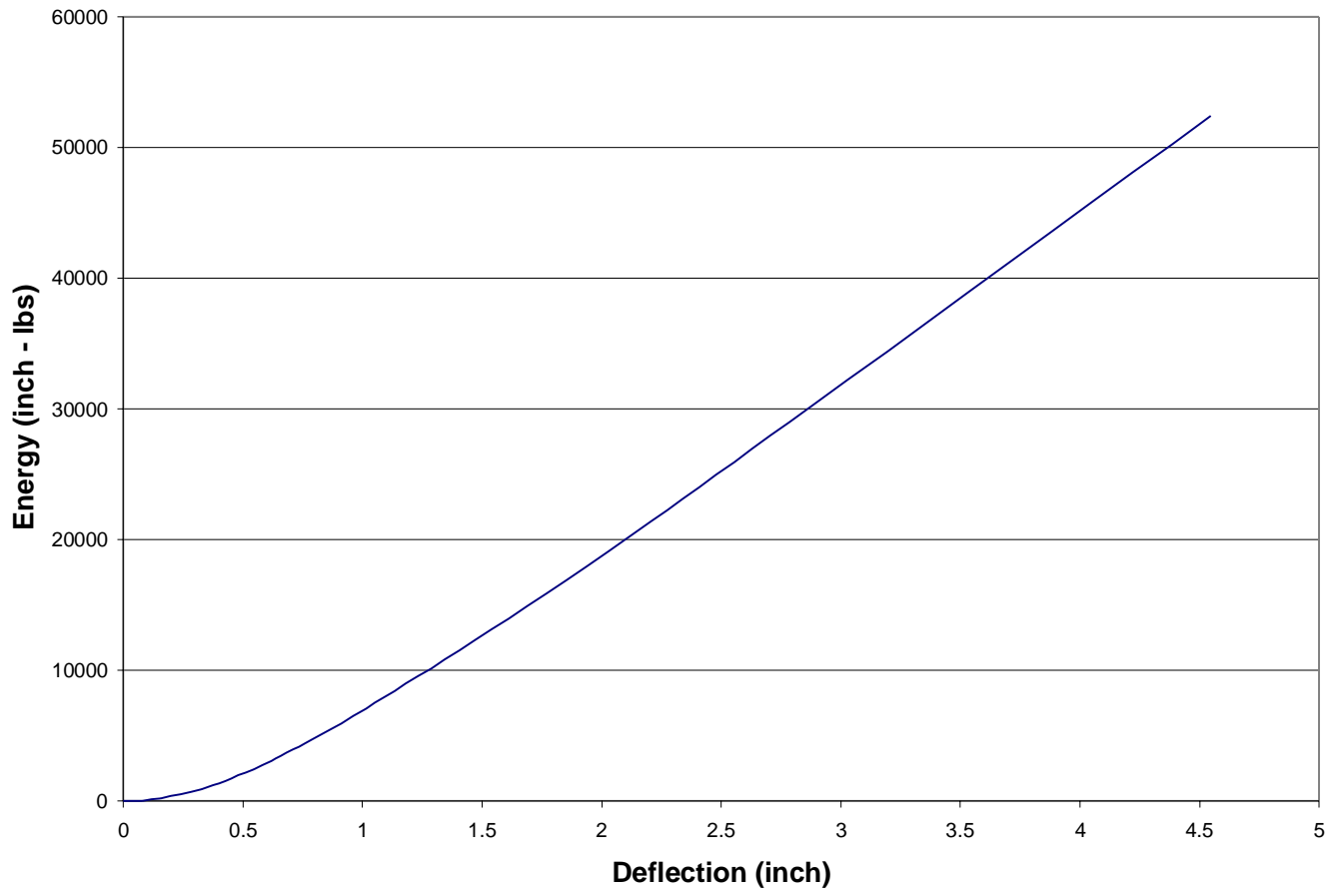

(b)

Figure 6.7. (a) Load - Deflection Curve and (b) Energy - Deflection Curve for the Side Transverse Loading. 


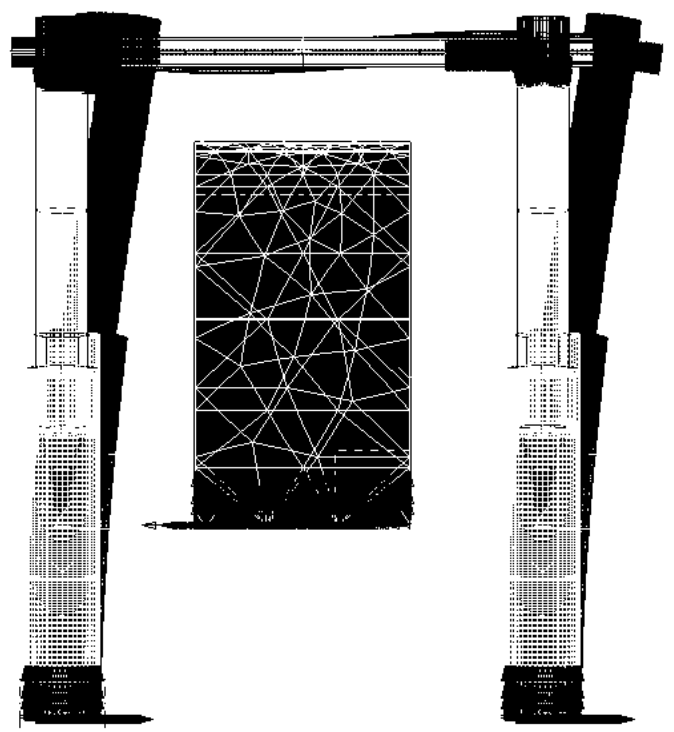

(a)

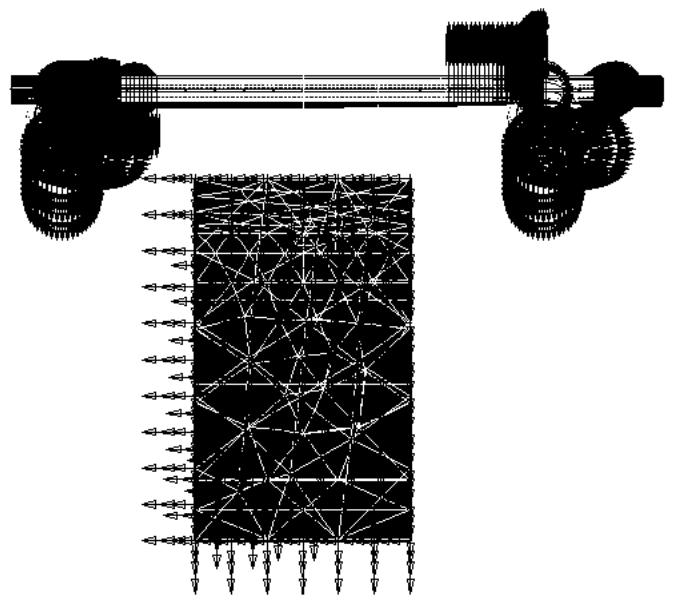

(b)

Figure 6.8. (a) Front View and (b) Top View of the Deformation of the Optimized ROPS with the Operator Clearance Zone during the Side Transverse Loading.

\subsubsection{Vertical Crush Load Results}

This load was applied in 50 percent increments until a maximum load of 14,738 lbs. was reached. The reason for such dramatic load steps was the energy absorption was not a concern. The only concerns had to do with intrusion on the operator clearance zone and maintaining an acceptable stress range. The deflections were small, and no part of the ROPS intruded on the operator clearance zone (see Figures 6.9 (a) and (b)). The maximum stress at the bottoms of the lower posts was 45,100 psi. 


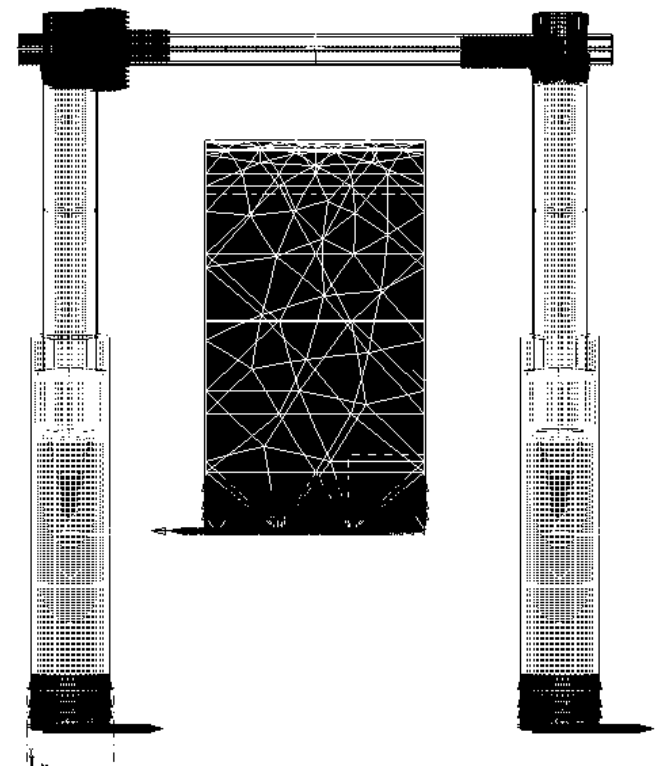

(a)

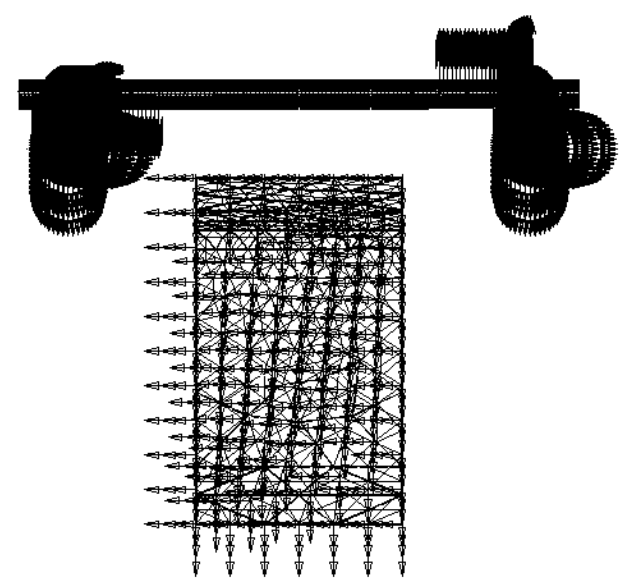

(b)

Figure 6.9. (a) Front View and (b) Top View of the Deformation of the Optimized ROPS with the Operator Clearance Zone during the Vertical Crush Load.

\subsubsection{Second Longitudinal Loading Results}

The energy requirement for this loading according to the SAE J2194 Standard is 10,154 inch - lbs, and the energy absorption for the ROPS for this loading was 12,591 inch-lbs. The Load - Deflection and Energy - Deflection plots can be seen in Figures 6.10 (a) and (b). The maximum stress found was at the bottom of the opposite lower post the load was applied to and was 54,800 psi. The Optimized ROPS did not intrude upon the Operator Clearance Zone during the Second Longitudinal Loading. This can be seen in Figures 6.11 (a) and (b). 


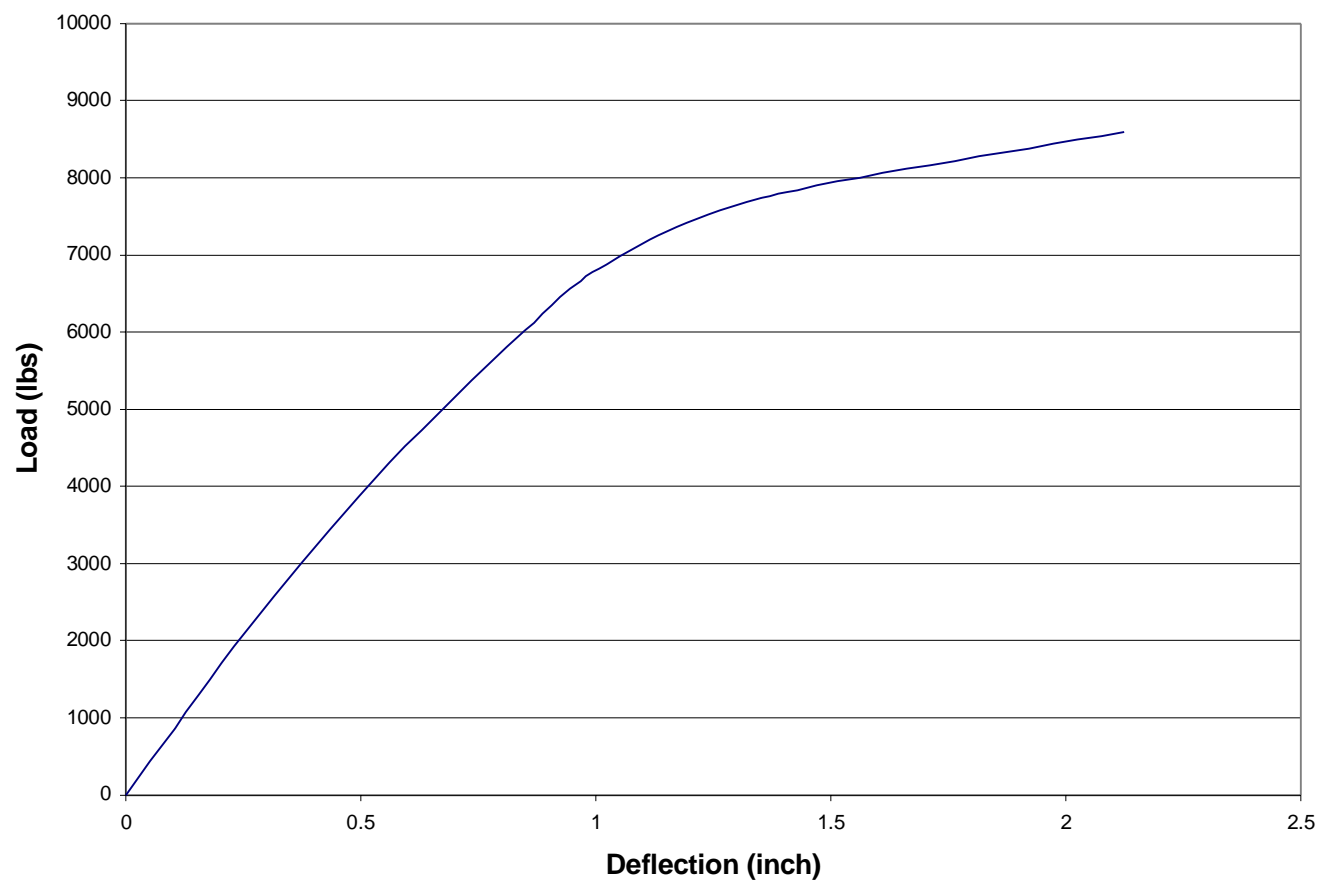

(a)

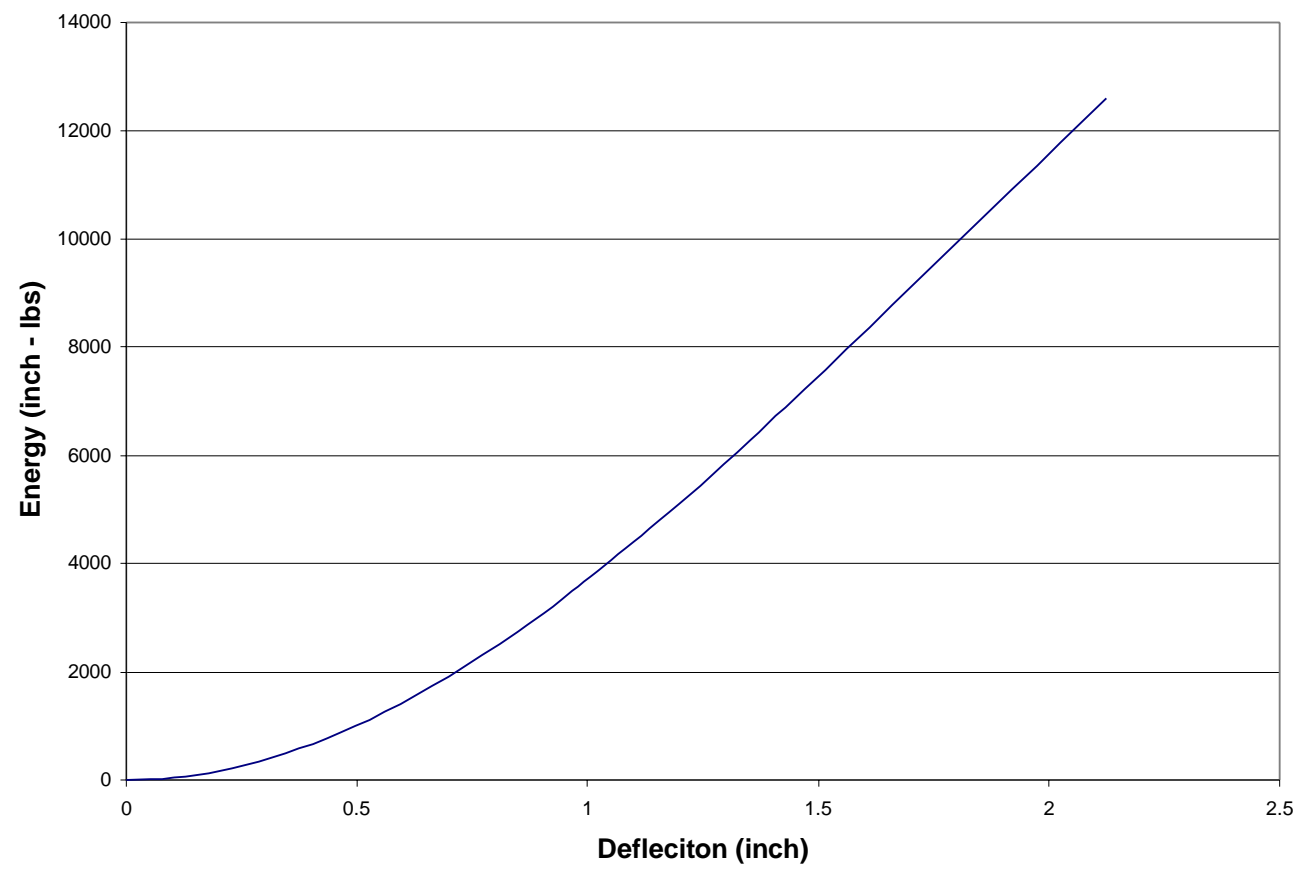

(b)

Figure 6.10. (a) Load - Defection Curve and (b) Energy - Defection Curve for Second Longitudinal Load. 


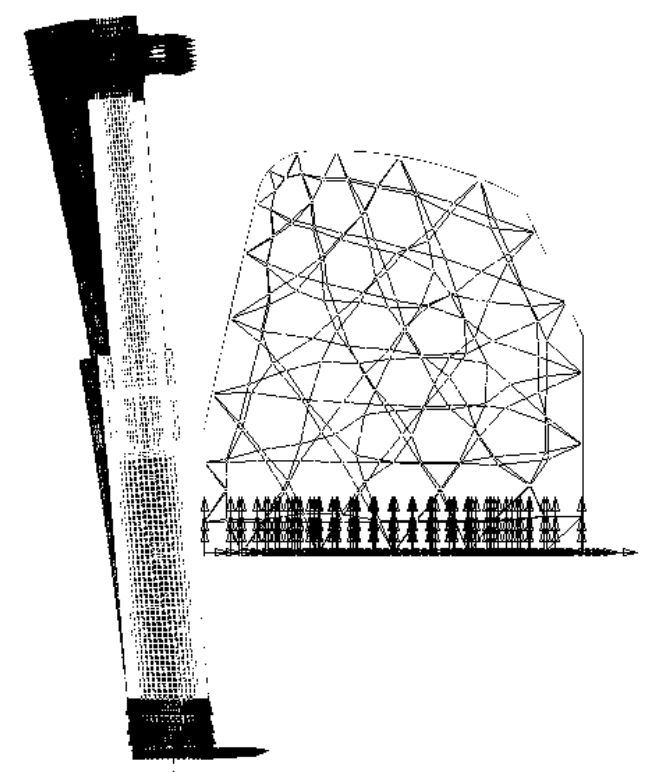

(a)

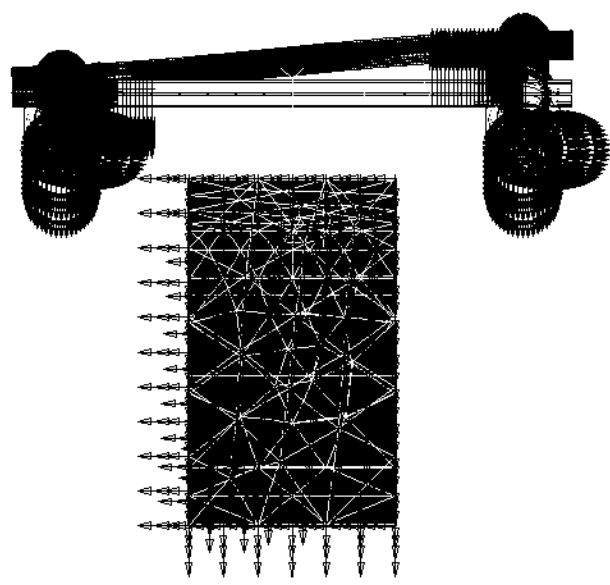

(b)

Figure 6.11. (a) Side View and (b) Top View of the Deformation of the Optimized ROPS with the Operator Clearance Zone during the Second Longitudinal Loading.

\subsubsection{Acceptable Optimized ROPS Conclusions}

This section has demonstrated its intent in showing all energy criteria and load criteria of the SAE J2194 Standard have been met in the FEM of the optimized deployable ROPS as well as maintaining acceptable stress levels throughout its progression. There were higher stress levels in this model than reported. However, the high stress levels were due to distorted geometry of an element in the mesh and occurred in very small areas resembling a stress concentration. These high stresses were no doubt due to the distortion of the element. 


\section{Chapter 7}

\section{CONCLUSIONS AND RECOMMENDATIONS}

\section{$\underline{7.1 \text { Conclusions }}$}

The results of this research show some of the benefits of using finite element analysis. These benefits were primarily related to cost. Finite element analysis gives the ability to depict elastic to plastic behavior in full-scale ROPS testing, which saves cost and time in building and experimentally testing a full-scale ROPS.

This research has been a continuation of earlier research conducted on ROPS conducted in coordination between the West Virginia University Mechanical and Aerospace Engineering Department and the National Institute for Occupational Safety and Health (NIOSH). The first research was focused on using finite element analysis to predict the behavior of a commercial two-post ROPS for a Ford New Holland 4600 Series tractor. The second phase of research dealt with the development of a deployable two-post ROPS. Initially, a single post and the internal mechanisms for deployment were designed using finite element analysis. The single post was then experimentally tested for verification. From the results, a two-post deployable ROPS was built, and the internal mechanisms used for deployment were tested to verify deployment criteria were met.

The third phase of ROPS research has been the focus of this thesis. In this document much has been presented about the development of an optimized two-post deployable ROPS. For the original two-post deployable ROPS, it was demonstrated how analytical results, both strains and deflections from I-DEAS ${ }^{\mathrm{TM}}$ were matched with the 
same types of experimental results for the loadings based upon energy requirements. This document has demonstrated how the models of both the original and optimized ROPS were constructed. It has also been shown how selecting the proper aspect ratio for elements was taken into consideration.

In addition, the methods for solving and nonlinear convergence criteria have been discussed and achieved. It was also shown what steps were taken, as well as the thinking and strategy, to develop a structurally optimized version of the original ROPS. Finally, the energy and force requirements of the optimized ROPS were shown to meet the static requirements of the SAE J2194 ROPS Standard, which was the judgement for acceptance. With these requirements met, the objectives of this document have been met.

\subsection{Recommendations for Future Work}

In order to succeed, one must first fail. As a matter of fact, failures many times prove to be more important learning tools than successes. This section will address some of the failures or problems of this research and how they should be addressed for future work.

First and foremost, the two-post deployable ROPS is a great concept, but the method currently being used for deployment can be improved. Choosing springs to deploy the ROPS forces the use of hydraulics to retract the ROPS for repetitive deployments. The spring and hydraulics mandate the size of the lower tubes used to house these parts to be of a certain size.

This also forces the upper tubes to be of a slightly smaller, but still too large size. The reason for this was both aesthetically, and a drastic change in outer radii between the lower tube and upper tube would not be in the best interest of the design. If such a 
strategy were used, this would cause the upper tubes of the ROPS to undertake most of the bending and absorb most of the bending.

Instead of limiting the design by the use of springs and hydraulics, another possible method for deployment that should be considered is the use of compressed air. This method for deployment would provide the same deployment ability, and at the same time, the release and lowering of the ROPS could be done with out the use of hydraulics. Turning a valve, which would allow the compressed air to be escape, could do the lowering. This strategy would allow the design to use smaller sizes for both the upper and lower tubes.

Another problem found in this research that needs to be addressed is the support blocks that were used to restrain the base of the ROPS to the tractor axle. The goal was to eliminate translation and rotation. While no translation was discovered, there was discovered some rotation despite all attempts to prevent such behavior. This should force a new design of the support blocks before any new ROPS research is conducted, and for new experimental tests, the support blocks should be continuously monitored for rotation during all loadings.

The last recommendation for future ROPS designs is exploring the use of square cross-sections for the tubes as opposed to round ones. Of course, this would only improve the design if a different method of deployment were used. This recommendation would also ease the design of load application fixtures. The use of round tubing increases the difficulty in following the standard. It also increases the possibility of a load fixture slipping during the loading process. This is most true for the first longitudinal loading 
and the second longitudinal loading. It also increases difficulty during the vertical crush test. 


\section{BIBLIOGRAPHY}

Brewer, Clay D., "Solid Modeling Generation and Nonlinear Finite Element Analysis of a Two Post Roll-Over Protective Structure (ROPS) in accordance with SAE J2194 Static Loading Standard", MS Thesis, West Virginia University, Dept. of Mechanical and Aerospace Engineering 1996.

Fritz, Edward A. et. al., "Small Agricultural Tractors ROPS New Operator Protective Zone", SAE Paper 911782, 1991.

Harris, James R. "Finite Element Modeling of Roll-Over Protective Structures for Analysis of Standard ASAE S519”, MS Thesis, West Virginia University, Dept. of Mechanical and Aerospace Engineering 1995.

Howard, Steven H., "A Study of Impact on Elastomeric Materials", MS Thesis, West Virginia University, Dept. of Mechanical and Aerospace Engineering 1998.

I-DEAS $^{\text {TM }}$, Smart View, On - Line Documetation, Release 7m1, 1999.

"I-DEAS TM Master Series 7m1 Student Guide", Structural Dynamics Research Corporation, Milford, Ohio, 1999.

International Standards Organization, "Tractors and Machinery For Agriculture and Forestry-Seat Reference Point-Method of Determination”, ISO 3462 - 1987.

Marks' Handbook for Mechanical Engineers, Ninth Edition, Edited by Avalon, Eugene A., McGraw - Hill Book Company, New York, 1986.

MTS Systems Corporation, Product Information

SAE Standards, "Roll-Over Protective Structures (ROPS) for Wheeled Agricultural Tractors", J2194, December 1987.

Schneider, Rollin D. \& Baker, L. Dale, "Prevention of Injury or Death From Farm Tractors", presented at Winter meeting of the ASAE December 11 - 15, 1973

Staab, J. E., "Development of ROPS Criteria for Construction and Industrial Vehichles', SAE Transactions, pp. 2399-2411, 1971.

"STRESS: A USER'S MANUAL", M. I. T. Press, Massachusetts Institute of Technology, Cambridge, Massachusettes, 1964.

Teaford, William J., "Roll-Over Protective Structures (ROPS) For Wheeled Agricultural Tractors", presented at Winter meeting of the ASAE December 15, 1993. 
Woodward and Swan, "ROPS Field Performance - A Status Report", SAE Paper 800679, 1980.

Yeh, Rudolph E. et. al., "An Analytical Procedure For the Support of ROPS Design", SAE Paper 760690, 1976. 